\title{
الوالدية اليقظة عقلياً وعلاقتها بالحساسية الزائلدة لدي عينة من الوالدين وأبنائهم الموهوبين بالمرحلة الثانوية

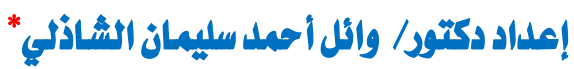

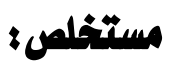

هدفت الدر اسة إلى التعرف على طبيعة العلاقة بين الو الدية اليقظة عقلياً، والحساسية الزائدة لدى عينة من الو الدين و أبنائهم

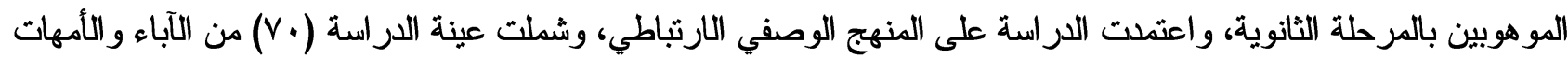

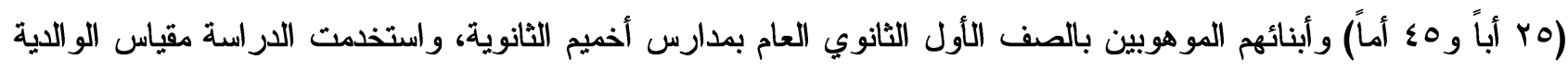

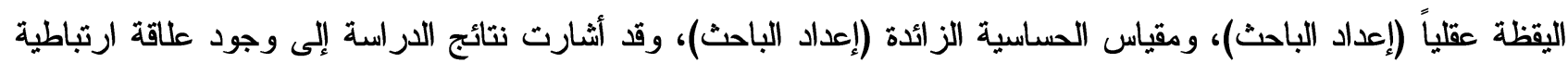

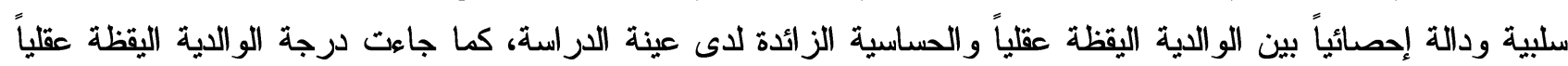
(متوسطة) لدى آباء و أمهات الطلاب الموهوبين، بينما جاءت درجة الحساسية الزائدة (مرتفعة) لدى الأبناء من الطلاب الموهوبين

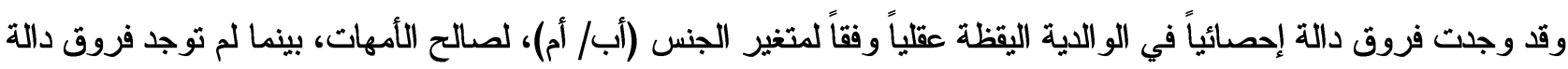

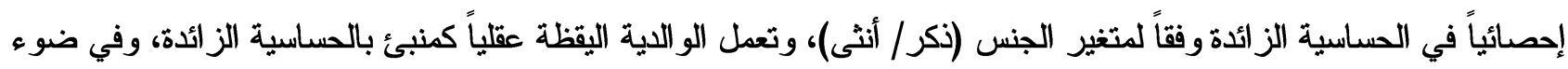
ذللك قدمت الدر اسة مجموعة من التوصيات لتلبية الحاجات النفسية والاجتماعية للمو هوبين من خلال وضع بر امج تعليمية وتربوية لهذه الفئة، وكذلك وضع برامج إرشادية للو الدين لنتمية الو الدية اليقظة عقلياً لديهم مما يحقق للأبناء النمو النفسي و العاطفي السوي. الكلمات المفتاحية: الو الدية اليقظة عقلياً- الحساسية الزائدة- الموهوبون

\section{Abstract:}

The study aimed to identify the nature of the relationship between mindfulness parenting and excessive sensitivity among a sample of (25) fathers and (45) mothers and their gifted sons in the secondary stage. The study relied on the descriptive and correlative approach. Mindfulness parenting scale (Prepared by: Researcher) and excessive sensitivity scale (Prepared by: Researcher) were applied to sample of study. The results of the study indicated that there was a negative and statistically significant correlation between mindfulness parenting and excessive sensitivity in the study sample. Mindfulness parenting was (moderate) in the parents of gifted students, while excessive sensitivity was (high) in gifted students and found statistically significant differences in mindfulness parenting according to sex variable (father / mother), in favor of mothers, while there were no differences a statistically significant in excessive sensitivity according to the sex variable (male/ female), Mindfulness parenting acts as a predictor of excessive sensitivity, in light of this, study presented a set of recommendations to meet the psychological and social needs of the gifted through the development of educational programs for this category, as well as the development of counseling programs for parents to develop their mindfulness parenting, which achieves for sons the psychological and emotional development.

Keywords: Mindfulness parenting- Excessive sensitivity- Gifted 


\section{مقدمة:}

تمثل جهود الموهوبين ونتاجهم الفكري وعطاؤهم العلمي نقلة في حياة البشرية بأسرها وذلك بالتحول إلى حياة أفضل

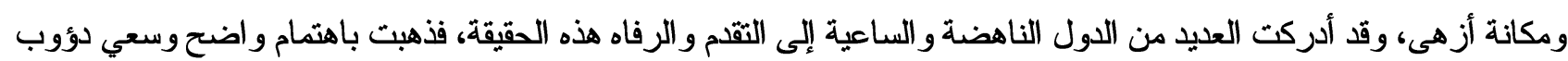

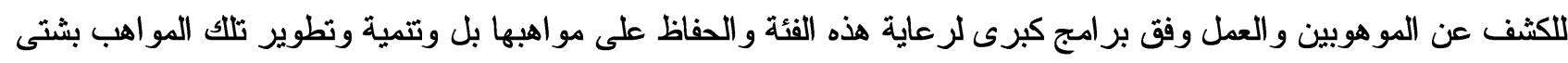

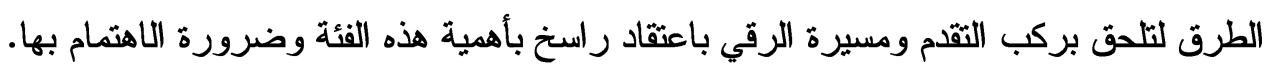
و الموهوبون هم أولئك الأفراد الذين يستطيعون بفضل قدراتهم الكامنة وإمكاناتهم المميزة وأدائهم العالي تحقيق إسهامات لأنفسهم وللمجتمع بشكل مميز، و إحراز الإنجازات الواضحة في مجال من المجالات التالية: القدرة العقلية العامة، استعداد أكاديمي معين، التفكير الإبداعي أو المنتج، القدرة القيادية، الفنون البصرية الأدائية، القدرة النفس حركية" (جيمس، جانيب، إدورد وآرلين، (r) מ ويظهر هؤلاء الطلاب الموهوبون عادة حساسية شديدة لما يدور في محيطهم الأسري و المدرسي والاجتماعي بشكل عام

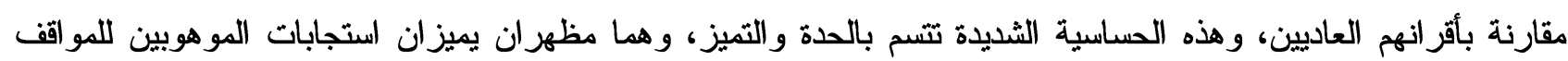

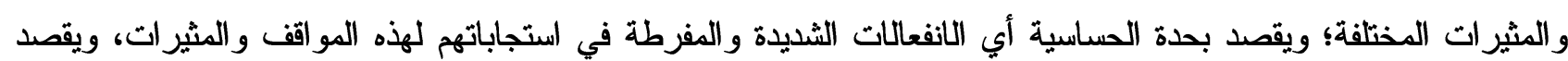
بتميز حساسية الموهوبين أي استجاباتهم لمو اقف قد تبدو عادية لدى غيرهم من الطلاب العاديين؛ لذا تعثبر هذه الحساسية مميزة للمو هوبين وأحد خصائصهم الو اضحة. وتتضح هذه الحساسية الزائدة- التي تمثل المظهر الأكثر وضوحاً في النمو العاطفي للموهوبين- في بعض سلوكياتهم

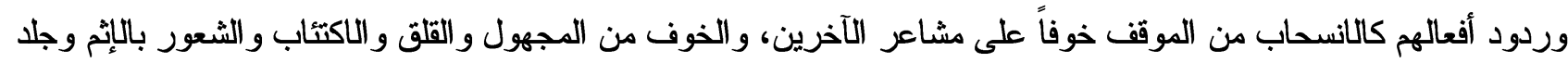

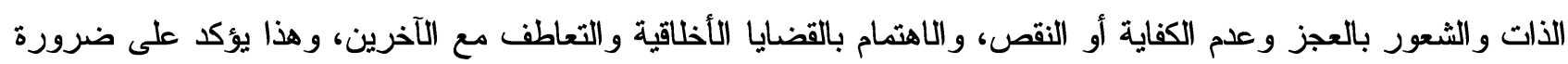

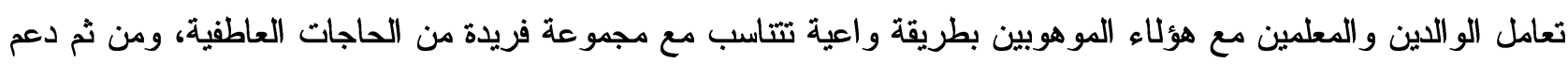

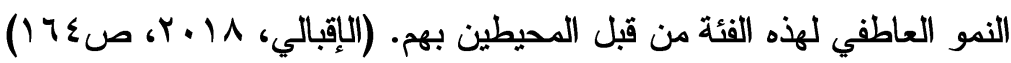
و هذا ينسجم مع اتساع دائرة الاهتمام ونقلها من الموهوب فقط إلى المحيط الذي يعيش فيه- وخاصة أسرته ووالديه-

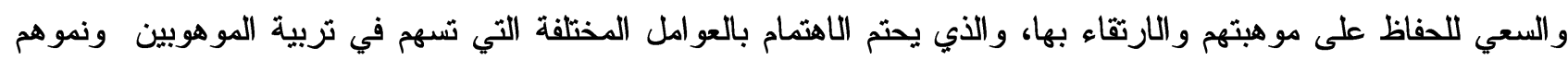
السوي وتتمية قدر اتهم ومو اهبهم، ومن أهم هذه العو امل محيطه الأسري، وو الديه على وجه الخصوص؛ حيث وليث يقع على الو الدين

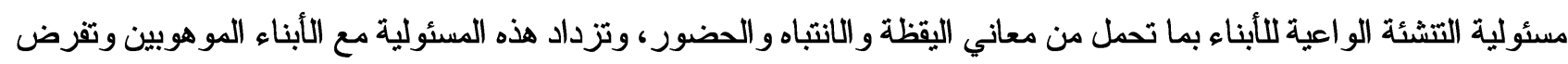

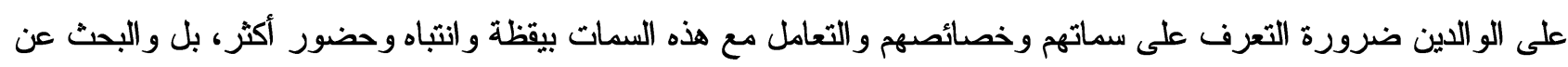

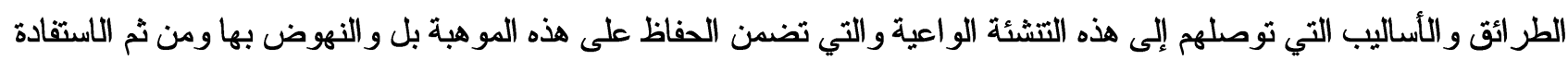

وتتطوي الو الدية اليقظة عقلياً على بعض الأساليب والمهارات التي تأخذ بيد والدي الموهوب للوصول إلى هذه التتشئة

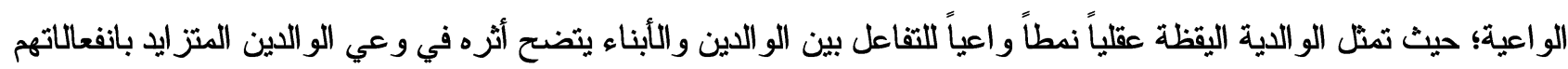
وذو اتهم وكذلك انفعالات وذوات الأبناء، وتنمية مهار ات التظظيم الانفعالي و التحكم في الذات بالقدر الذي يؤدي إلى استجابة الو الدين

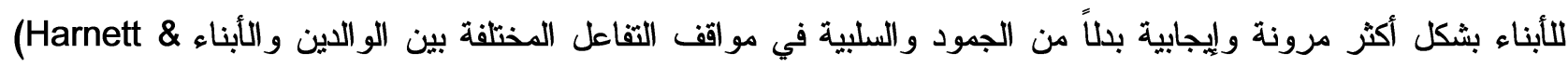

Dawe, 2012, p.196)

ويعتبر هذا النمط الو اعي للتفاعل بين الو الدين و الأبناء من أهم مكونات التو افق النفسي و الاجتماعي و العاطفي للأبناء؛ فبقدر ما يوفر هذا النمط أساليب ومهارات الاهتمام الواعي والاستماع الوافي والتقبل الواقي، كلما كان هناك وعي بالمشكلة واستيفاء 
لجو انبها ووفاية من آثارها السلبية على الأبناء مما يوفر طريقة لبناء الشخصية السوية في ظل النمو العاطفي والانفعالي السوي و البعيد عن التطرف و الحساسية الزائدة و الاستجابات المفرطة.

ومن هنا جاءت فكرة الدراسة الحالية والتي تسعى لتوفير أدلة بحثية أكثر تحديداً لاستقصاء الأثر الناجم عن الوالدية اليقظة

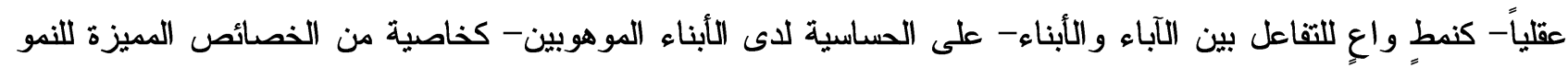
العاطفي للمو هوبين- لدى عينة من الو الدين وأبنائهم المو هوبين بالمرحلة الثانوية.

\section{:}

هناك اهتمام بحثي ملحوظ بالخصائص العاطفية والنمو العاطفي للموهوبين، ولا سيما زيادة الحساسية لدى هذه الفئة،

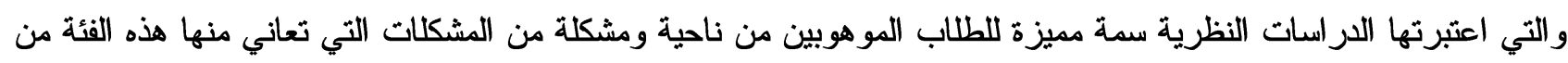

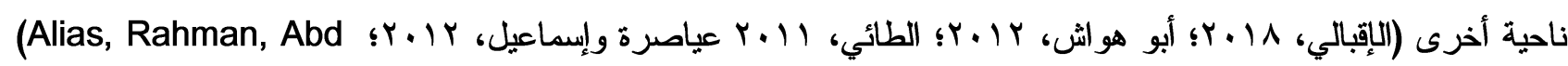
Majid\& Yassin, 2013; Coleman, Cross, Suphh- Yamin,\& Neber 2016; Dodd, 2004; Donnell, 2004; (لاllovecky, 1992; Piechowski\& Chucker 2011; Yakmaci-Guzel\& Akarsu,2006) هذه الظاهرة من خلال مقابلة الطلاب الموهوبين ومعلميهح وأولياء أمورهم والوصول إلى تجربة المعايشة لخصائصهم وسماتهم

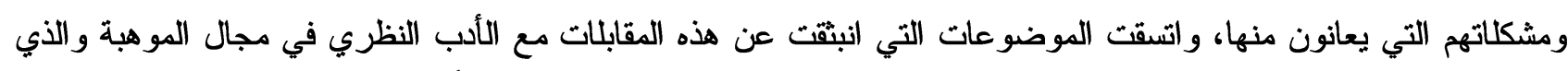
أثار إلى أن زيادة الحساسية من السمات الو اضحة لدى هذه الفئة، و التي قد تسبب لهم كثيراً من المتاعب و والمشكلات. وفي هذا الصدد أشارت مجموعة من الدر اسات إلى بعض هذه المتاعب و المشكات الناتجة عن هذه الحساسية؛ ففي المجال الفكري غالبًا ما تسبب الحساسية الزائدة مشاكل في عملية التعليم و التعلم مثل ارتفاع الفضول و الميل للخيال و الاقتر احات الإبداعية

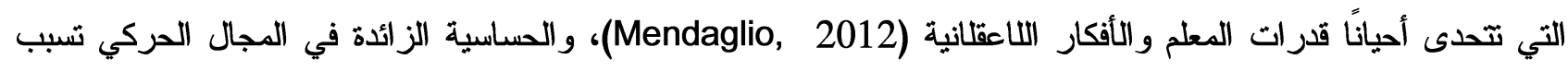
الحركة بشكل متسرع وعفوي في محاولة للتعبير عن طاقة داخلية هائلة، واضطر اب فرط الحركة ونقص الانتباه، وعدم قبول فكرة الخسارة أو الفشل (Amend, 2009; Daniels \& Meckstroth, 2009)، و الحساسية الزائدة في المجال العاطفي تتسبب

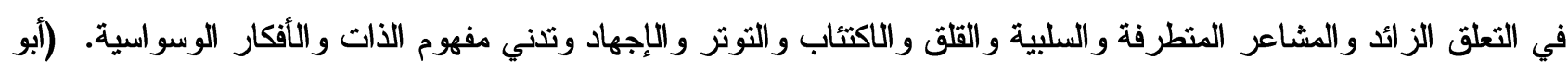

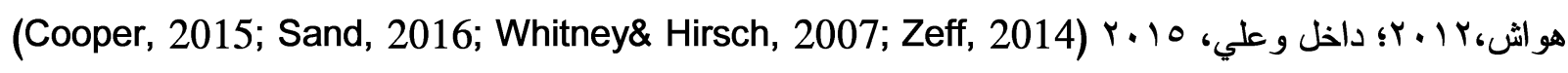
وفي سياق يوضح مشكلة البحث فإن الحساسية الزائدة تمثل مشكلة معقدة ومتعددة الأطراف؛ حيث يمثل الموهوب أحد هذه الأطراف التي تعاني من هذه الحساسية الزائدة فمجرد الإحساس بالاختلاف عن الآخرين يثير في نفوس الطلاب الموهوبين

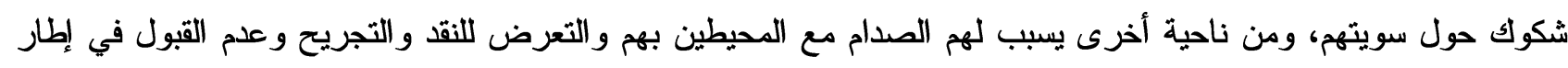
تفسير السلوك الذي يتجاوز حدود المعايير السائدة من حيث النوع والشدة على أنه شاذ وغير عقلاني، ويمثل المجتمع المحيط

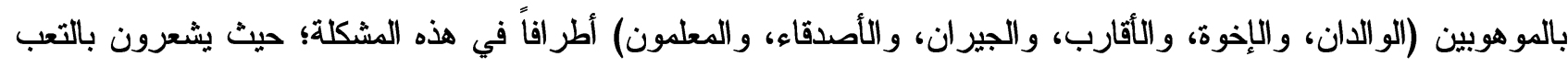

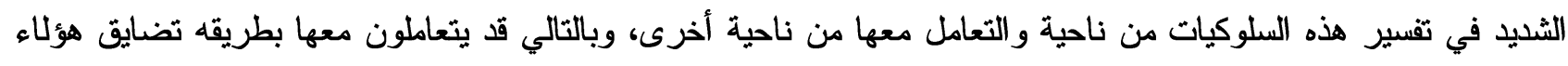
المو هوبين وتز عجهم، وتئثر بشكل سلبي على موهبتهم.

ومن جانب آخر يمكن النظر إلى الحساسية الزائدة لدى الطلاب الموهوبين باعتبارها وسيلة إيجابية لتحفيزهم وزيادة

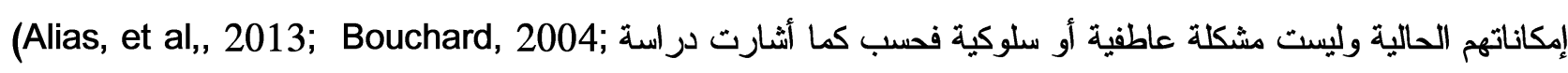

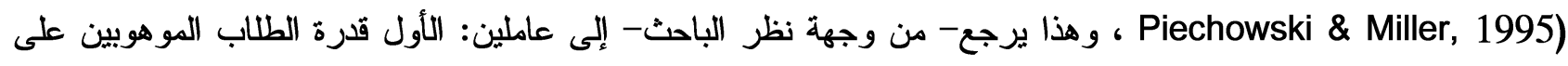
استغلال مظاهر هذه الحساسية الزائدة في تتمية إبداعاتهم وقدر اتهم كاستغلال مظاهر الحساسية الزائدة العقلية في تتمية قدراتهم الأكاديمية والتحصيلية والمعرفية، واستغلال مظاهر الحساسية الزائدة العاطفية في تتمية علاقاتهم الاجتماعية والرفي بالجانب 
الأخلاقي، والثاني قدرة أولياء الأمور و المحيطين بالموهوب على تقبل انفعالاتهم في إطار من الوعي وبدون نقد ولا أحكام ظاهرية منسرعة قد تؤدي إلى انطفاء هذه الموهبة تدريجياً. و هذا التقبل الواعي لانفعالات المو هوبين يمثل أحد مظاهر الوالدية اليقظة عقلياً التي ترتبط إيجابياً بالعديد من المتغيرات

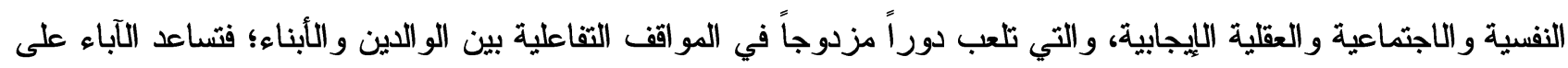
التعامل مع أبنائهم في جو من الدفء و الاهنمام و الوعي والقبول وهذا بدوره ينعكس على الأبناء ويساعدهم للحفاظ على قدر اتهم ومواهبهم في جو من النمو العاطفي والنفسي والاجتماعي السوي.

وفي إطار هذا الدور المزدوج اهتمت بعض الدر اسات الارتباطية التي تتاولت الو الدية اليقظة عقلياً بدراسة تأثير ها على الى الثى مهارات الوالدين المتعلقة بالوعي والانفتاح على خبرات الأبناء وقبولها كما هي بدون أحكام ظاهرية وكفاءة المواجهة الواتوات الدية

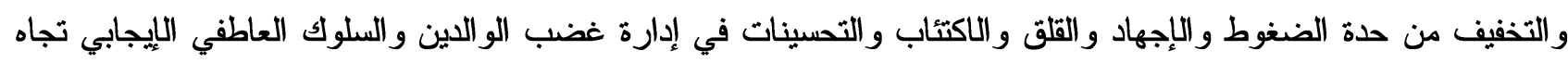

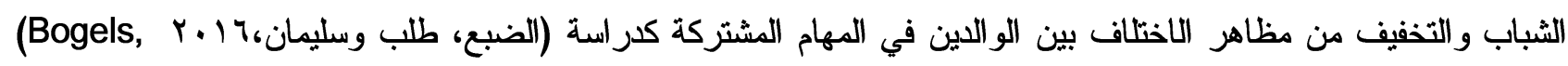
Lehtonen\& Restifo 2010; Coatsworth, Duncan, Greenberg\& Nix, 2010; Corthon, 2018; Dawe\& Hartnett, 2007; Gouveia, Carona, Canavarro\& Moreira, 2016; Rayan\& Ahmad, 2018; Laurent, Duncan, Lightcap\& Khan, 2019) الإيجابية على سلوك الأبناء ومهار اتهم وتفاعلهم مع المحيطين ونموهم العاطفي السوي والمتو افق وصحتهم النفسية والسعادة

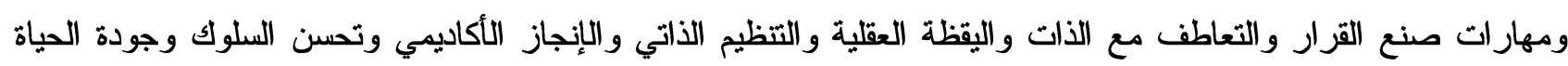
(Bruin et al, 2014; Bogels, Hellemans, van Deursen, Romer\& van der Meulen, 2013; كدر اسة ودئة Coleman, 2015; Dehkordian, Hamid, Beshlideh\& Mehrabizade, 2017; Duncan, Coatsworth\& Greenberg, 2009; Geurtzen, Scholte, Engels, Tak, \& van Zundert, 2015; Medeiros, Gouveia, Canavarro,\& Moreira, 2016; Moreira\& Canavarro, 2018; Moreira, Gouveia,\& Canavarro, 2018; Tak, Van Zundert, Kleinjan, \& Engels, 2015; Waters, 2016; Wong et al., 2019)

\section{أسئلة الدراسة:}

ا. . ما طبيعة العلاقة بين الو الدية اليقظة عقلياً والحساسية الزائدة لدى أفراد عينة الدراسة؟

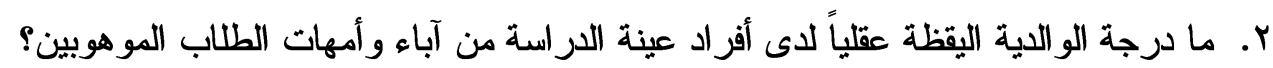

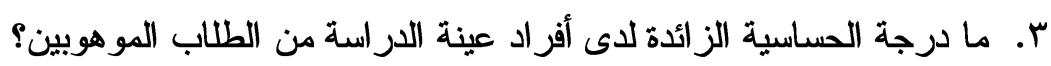

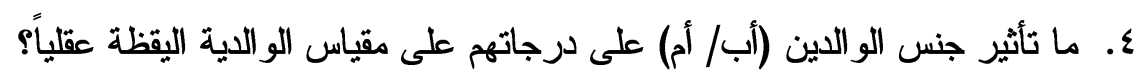

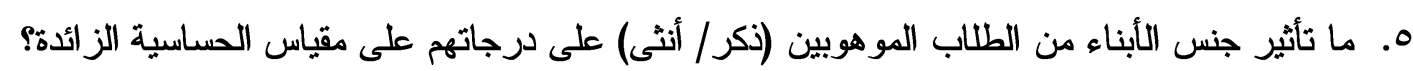

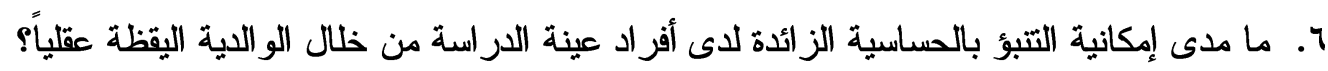

\section{أهداث الدراسة2:}

تهدف الدراسة الحالية للتعرف على:

1. ـ طبيعة العلاقة بين الو الدية اليقظة عقلياً و الحساسية الزائدة لدى أفراد عينة الدراسة.

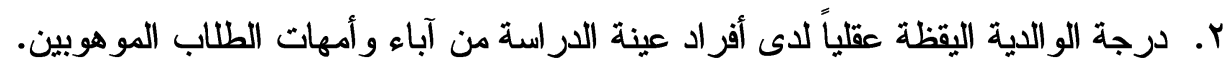

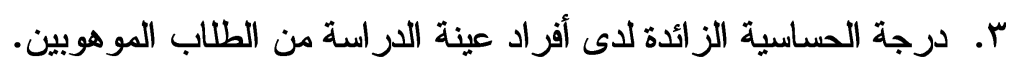

ع. تأثير جنس الوالدين (أب/ أم) على درجاتهم على مقياس الو الدية اليقظة عقلياً.

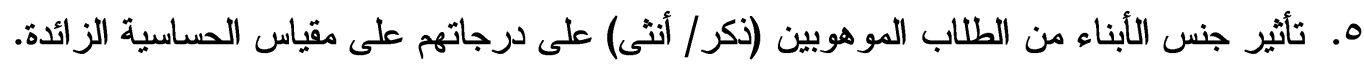


ج. إمكانية التنبؤ بالحساسية الزائدة لدى أفر اد عينة الدراسة من الطلاب الموهوبين من خلال الو الدية اليقظة عقلياً.

\section{أهية الدراسة: \\ أوأاء الأصية النظرية:}

تكتسب الدراسة أهميتها النظرية من خلال إلقاء الضوء على متغيرين مهمين في مجال الصحة النفسية وهما: الحساسية الزائدة و التي تمثل مشكلة من المشكلات التي يعاني منها الطلاب الموهوبون وتتسبب لهم في الكثير من المظاهر السلبية، و الو الدية

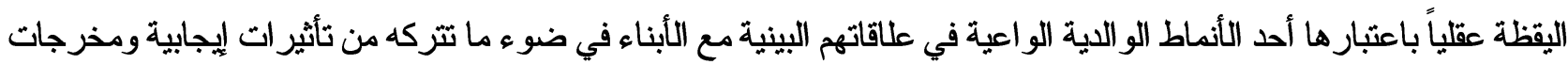
سوية تسهم في نموهم العاطفي وتكوينهم الانفعالي بشكل متو افق.

\section{ثانياً ؛ الأمية التطبيقية:}

تتمثل في استفادة أولياء الأمور و التربويين و المهتمين من نتائج الدراسة الحالية في بناء وتصميم برامج إرشادية تسهر

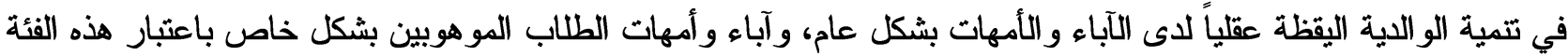
الخاصة من الطلاب تتطلب تدخلاً خاصاً من الرعاية و الاهتمام للاستفادة من إمكاناتها.

\section{مشاحات الدراسة:}

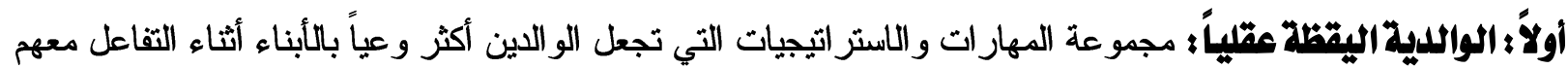
من خلال الاستماع إليهم وقبولهم والوعي الانفعالي والتحكم في الذات، مما يتيح للوالدين الاستجابة بشكل أكثر فعالية لحاجات الأبناء، وتوفير مناخ أسري أكثر توافقاً وسوية، ويعبر عنها إجرائياً بالدرجة التي يحصل عليها والدا الطاب الطلاب الموهوبين على مقياس الو الدية اليقظة عقلياً.

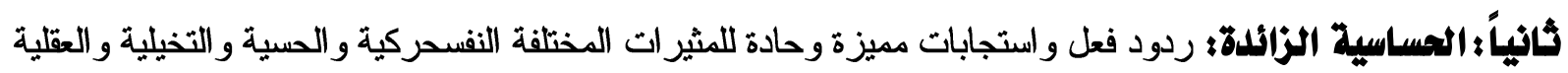

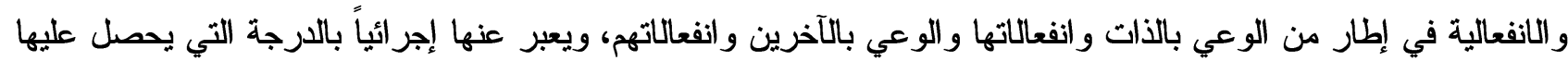
الطلاب المو هوبون على مقياس الحساسية الزائدة.

ثُالثاً الموهوبوذ: هم الأشخاص الذين يمتلكون القدرات المميزة في مجال قدرة واحد على الأقل من مجالات: القدرات العقلية، و التقوق الدراسي، والقدرات النفسحركية، والقيادة، وتميز هذه القدرات يكون بدرجة تجعل الطفل أو الشخص البالغ في

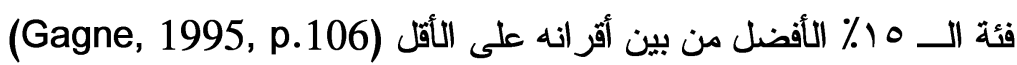

محددات اللدراسة:

تحددث الار اسة الحالية بالمحددات التالية:

ا. المحدد الموضوعي: التعرف على طبيعة العلاقة الارتباطية بين الو الدية اليقظة عقلياً والحساسية الزائدة. r. المحدد البشري: عينة من الطلاب الموهوبين بالصف الأول الثانوي ووالدئهر.

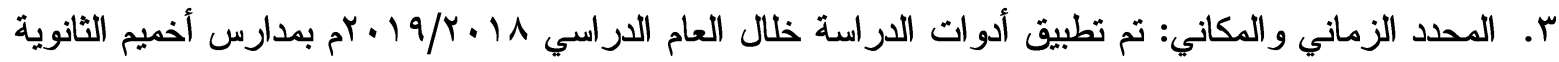
(المطورة- بنات). 
يشار إلى الوالدية اليقظة عقلياً بالوعي الذي يظهر من خلال الاهتمام بالتصرفات عن قصد في الوقت الحاضر أثناء التعامل مع الأبناء، ودون حكم ظاهري، وهذا الوعي يسهم بشكل أو بآخر في تكشف خبرات جديدة لدى الفرد لحظة بلحظة.

(Kabat-Zinn, 2003, p. 145)

كما يمكن النظر إلى الو الدية اليقظة عقلياً على أنها مجموعة سمات ومهار ات وممارسات يمكن تعزيزها من خلال الممارسة و التدخل، ولذا يصف Dumas (2005, p.789 الوالدية اليقظة عقلياً بأنها مهارة استبدال أو إيقاف السلوك وردود الأفعال بوعي من قبل الو الدين عند الحاجة؛ فيمكن استخدام اليقظة العقلية بشكل هادف من قبل الوالدين لتغيير السلوكيات غير التكيفية واختيار المزيد من السلوكيات البديلة التكيفية مع الأبناء، وعندما ينجحون في ذلك يستبدلون كثيراً من العادات القديمة بأخرى أكثر فاعلية ومناسبة. ويؤكد على هذا المعنى Bishop et al. (2004, p. 231 من خلال التدريب العقلي وتتمية الجوانب المعرفية؛ فيصف الوالدية اليقظة عقلياً بأنها شكل من أشكال التّريب العقلي للحد من الضعف المعرفي لردود الأفعال التي تزيد من التوتر و الضيق العاطفي أثناء التعامل مع الأبناء.

بينما ينظر إليها (Baer, Walsh, \& Lykins (2009, p. 155) على أنها مجموعة من المهارات التي تؤدي في النهاية إلى الحضور و الانتباه الواعي أثثاء التفاعل مع الأبناء كالقبول، و الانفتاح، والسماح، وعدم الحكم الظاهري السريع، والاستعداد، واللطف، و الفضول وحب الاستطلاع.

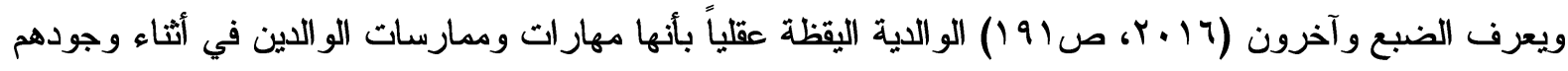

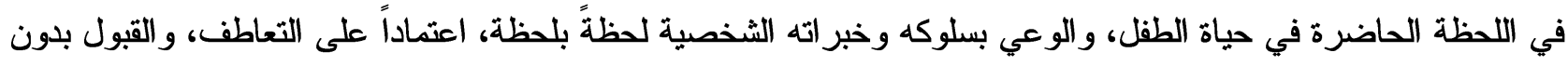

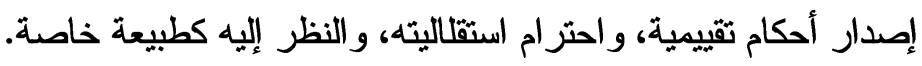

ويعرف الباحث الو الدية اليقظة عقلياً بأنها مجموعة المهارات والاستراتيجيات التي تجعل الو الدين أكثر وعياً بالأبناء أثناء التفاعل معهم من خلال الاستماع إليهم وقبولهم و الوعي الانفعالي و التحكم في الذات، مما يتيح للو الدين الاستجابة بشكل أكثر فعالية لحاجات الأبناء، وتوفير مناخ أسري أكثر تو افقاً وسوية، ويعبر عنها إجرائياً بالدرجة التي يحصل عليها و الدا الطلاب الموهوبين على مقياس الو الدية اليقظة عقلياً.

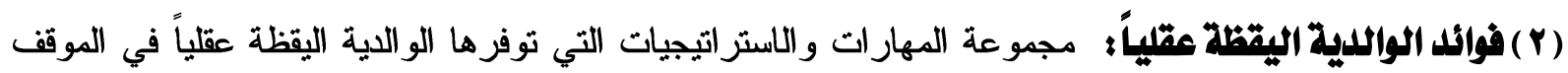
التفاعلي بين الو الدين و الأبناء تخرج لنا العديد من الفو ائد والمزايا في هذا الموقف و التي يمكن توضيحها كما يلي: أ. الإيجابية ثنائية الاتجاه: توفر الو الدية اليقظة عقلياً الإيجابية في المعاملة مع الأبناء ليس من جهة الآباء فحسب بل تتعكس

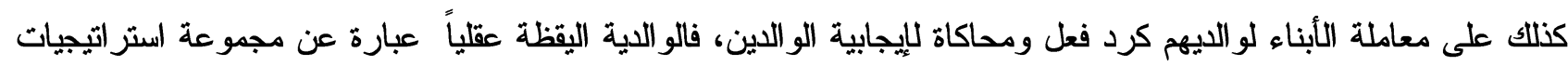

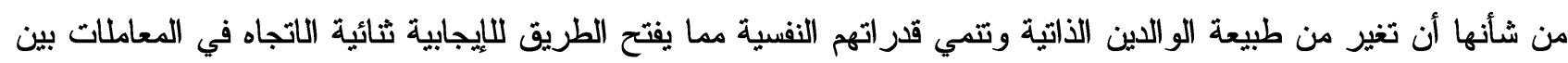

الو الدين و الأبناء. (Singh et al., 2006, p.175)

ب. إدراك وقبول حاجات الأبناء: من خلال الوالدية اليقظة عقلياً يستطيع الآباء والأمهات الاستمرار في إدراك وقبول

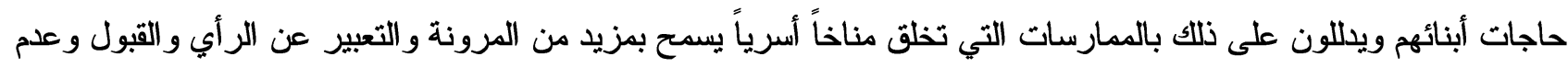

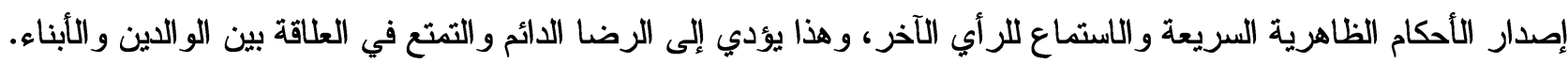

(Duncan et al., 2009, p. 256)

ج. ثتمية القدرات و الآليات التربوية للو الدين: تؤدي الوالدية اليقظة عقلياً إلى الحد من ردود أفعال الوالدين المنطرفة وزيادة الصبر، و المرونة والاستجابة المناسبة، والتو اقق، والانسجام مع أهداف وقيم المجتمع وتحسين الثقة والعاطفية المتبادلة 
وتقليل الإجهاد الوالدي والتنظيم الذاتي، علاوة على ذلك توفر الوالدية اليقظة عقلياً اختيار استراتيجيات التربية الأكثر فعالية

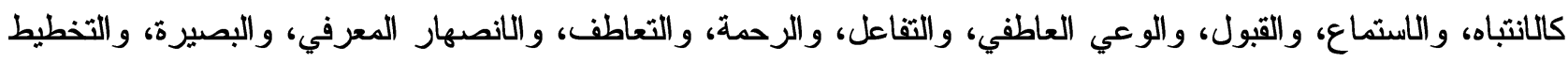
(Coyne \&Wilson, 2004; Dishion, Burraston\& Li, 2003; Dumas, 2005; Duncan et al., 2009; Williams\&

Wahler, 2010)

دـ. التخفيف من حدة الاضطر ابات النفسية وتحسين الصحة النفسية: أشارت نتائج عدد من الدر اسات إلى أن الو الدية اليقظة عقلياً ترتبط سلبياً بالعديد من الاضطر ابات النفسية كالقلق والتوتز و الإجهاد النفسي والاكتئاب؛ فكلما زادت الوالوالدية اليقظة عقلياً قلت حدة هذه الاضطر ابات، وذلك في ضوء ما توفره الو الدية اليقظة عقلياً من مناخ أسري يسوده التفاهم و المودة و الرحمة ولترة

(Baer et al., 2006; Bögels, Hellemans, van Deursen, Romer\& van der Meulen, 2013; Cash \& Whittingham, 2010; Corthorn\& Milicic, 2015; Corthorn, 2018; Duncan\& Bardacke, 2010; PerezBlasco, Viguer\& Rodrigo 2013; ; Vieten\& Astin, 20

\begin{tabular}{|c|c|c|}
\hline الإيجابية ثنائية الاتجاه & \multirow{9}{*}{ الوالدين تفاعلي بين } & الوعى التام \\
\hline إدراك وقبول حاجات & & الانتباه \\
\hline تتمية القدرات والآليات & & الأحكام المتريثة \\
\hline & & التنظيم الذاتى \\
\hline للوالادين والأبناء & & الاستماع \\
\hline توفير القدوة والنموذج & & القبول \\
\hline الرفق و الهدوء & & التعاطف \\
\hline \multirow{2}{*}{ اللاضطرابات النفيسية } & & الانفتاح على الخبرات \\
\hline & & عدم النقد \\
\hline
\end{tabular}

شكل (1) يوضح كيفية عمل الو الدية اليقظة عقلياً

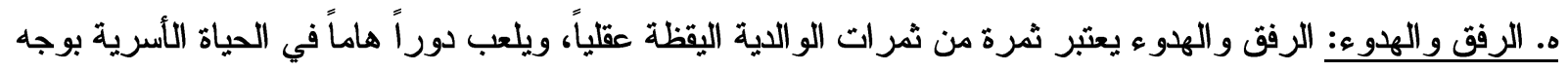

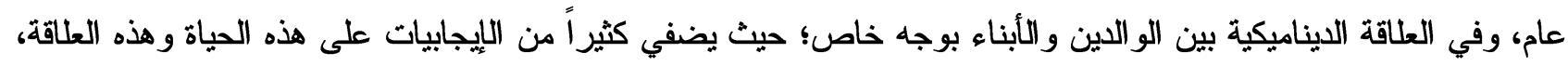
ويزرع القدرة على تحقيق الأهداف التربوية في جو من الاتساق والعلاقات الدافئة والرعاية العاطفية والثقة المتبادلة و الإيجابية

و المرونة والحكمة التربوية المنبيقة عن عدم الإجهاد والتؤدة والروية. (Duncan et al., 2009, p. 261) و ـ توفير القدوة و النموذج: تعمل الو الدية اليقظة عقلياً على صقل الآباء و الأمهات بالعديد من الخصائص و السمات و القرات التي تسهح بشكل كبير في توفير القدوة والنموذج التربوي للأبناء، وهذا يسهل على الآباء والأمهات المهمات التربوية المختلفة وذلك في ظل التربية بالقدوة وهي طريقة تربوية تؤتي ثمارها بوضوح في المواقف التفاعلية بين الوالدين والأبناء عن طريق

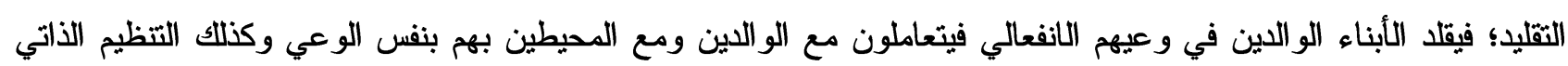
و التحكم في الذات و الانفتاح على الخبرات وقبول فئائ الآخرين و الاستماع إليهم.

(Y) النعاذج والنظريات المفسرة؛ حاولت بعض النظريات و النماذج تفسير الو الدية اليقظة عقلياً ومعرفة الممارسات التي تؤدي

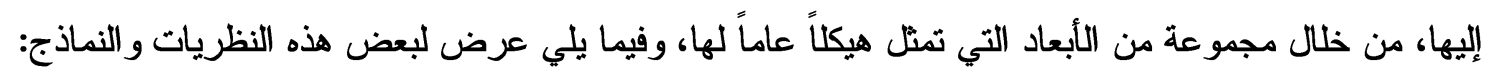


تفترض نظرية (RFT) أنه يمكن الوصول إلى الو الدية اليقظة عقلياً من خلال علاقة الو الدين مع أبنائهم و التي ينبغي أن

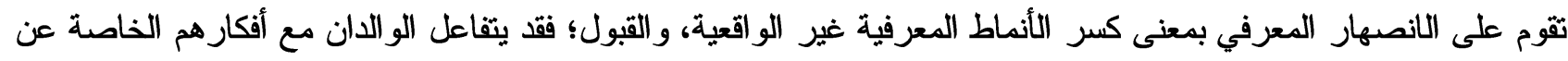
بعض الإخفاقات في تربية الأبناء (على سبيل المثال: أنا غير قادر على التحكم في سلوك طفلي، يحاول ابني أن يغضبني) وفي الحقيقة هذا عكس ما يفكر فيه طفلهم في الوقت الحاضر ؛ مما يؤدي إلى زيادة جهود الو الدين غير الفعالة، وكذلك يمكن تحقيق

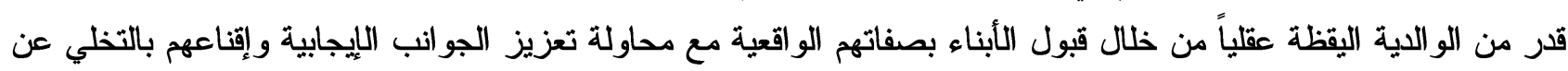
الجوانب السلبية. (Coyne \& Wilson, 2004, p.469) من البنه

\section{ب. بverall model النموذج الشامل:}

افترض هذا النموذج علاقة ثلاثية هرمية متبادلة التاثير، تمثل الو الدية اليقظة عقلياً رأس هذا الهرم حيث تتحكم في ضلعي

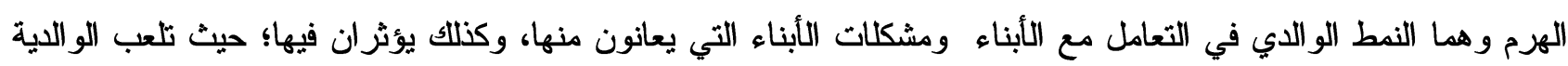
اليقظة عقلياً دوراً كبيراً في تحديد النمط الوالدي الذي ينحصر في نمطين (استبدادي- يضع الثقة في الأبناء) وذلك من خلال

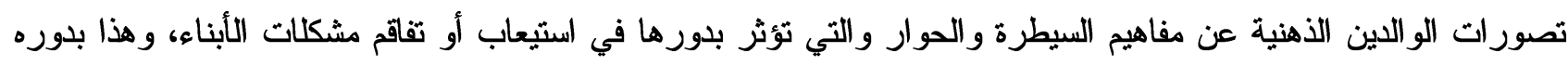
يؤثر بشكل أو بآخر في الوالاية اليقظة عقلياً. (Williams\& Wahler, 2010, p.p.232-233)

The triangular model ج. النموذج الثاثي

قدم Dumas (2005, p.783 نموذجاً للوصول إلى الو الدية اليقظة عقلياً يتمثل في ثلاث طرق لتعزيز اليقظة العقلية لادى الو الدين وهي: تسهيل الاستماع للأبناء ومشكلاتهم وحاجاتهم وقضاياهم حتى يجدوا الآباء بجانبهم متى احتاجو الذلك، و الابتعاد عن النقد غير المفيد وغير المقبول والذي يمثل عقبة للوصول إلى علاقات سوية مع الأبناء، والتخطيط للعمل بدو افع محركة تضمن استمر اره، ويمكن أن تستخدم هذه الطرق الثاثة كنقطة انطلاق لطرق أخرى تعمل على تتمية اليقظة العقلية لاى الو الدين،

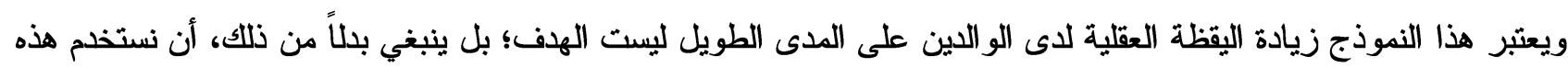
الاستر اتيجيات لنصل إلى الو الدية اليقظة عقلياً على المدى القصير. د. دموذج العلاقات البينشخصية Interpersonal model

وقدم Duncan et.al (2009, p.p.259-260 نموذجاً لتفسير الو الدية اليقظة عقلياً يستند على أربعة أبعاد إذا حققها

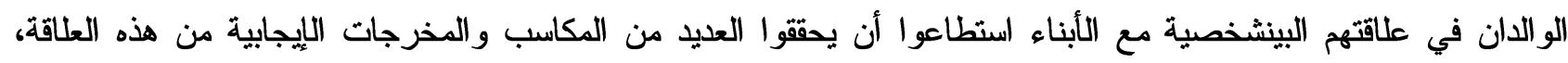
كالتوازن بين أهداف الو الدين وحاجات الأبناء، والتقليل من المشاعر السلبية لاى الأبناء، وفهم وتقدير لخصائص الأبناء، ومن ثم هن علاقة تو افقية يبحث عنها الآباء و الأبناء. وتمثل هذه الأبعاد الأربعة السمات المعبرة بدقة عن المسئولية الو الاية، وتشتمل على: الاستماع بانتباه كامل للأبناء، والوعي بانفعالات الذات و انفعالات الأبناء في ذات الوقت، وتنظيم الذات والتحكم في الانفعالات أثناء العلاقة مع الأبناء، و القبول المتمثل في قبول الذات من ناحية وقبول الأبناء من ناحية أخرى، وكذلك التعاطف مع الذات ومع الأبناء بما يوفر الرحمة والتسامح و العطف. ويتضح مما سبق أن هذه النماذج و النظريات حاولت بناء هيكل عام للو الدية اليقظة عقلياً مع تعدد الأبعاد المكونة لهذا الهيكل؛ ولتهاء

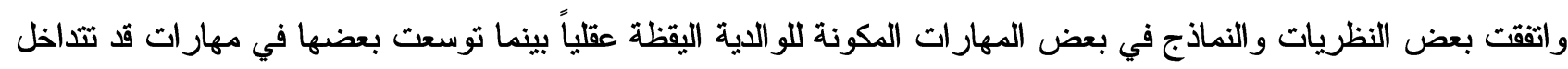
فيما بينها لتكون هذا الهيكل من الوعي الوالدي من وجهة نظرهم، و وذذا يتضح في الجدول الآتي:

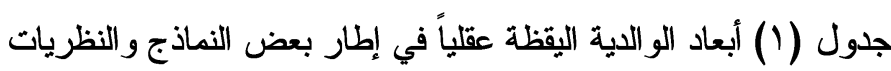




\begin{tabular}{|c|c|c|c|c|c|}
\hline & & & r. حل مشكلات الأبناء & يضع الثقة في الثآيناء الذي & النعوذج الشامل \\
\hline & & rا. التخطيط & r. الابتعاد عن النقد & 1. تُهيل الأستماع & النعوذج الثلاثى \\
\hline الذات ومع التأبناءع & للات واتلبنياء & "r. تتظيم الذات & 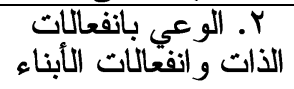 & ا ـ الاستمل باع بانتباه & نبوذج الملالاقية \\
\hline
\end{tabular}

قانياً: الهساسية الزوائلة

(1) مثهوم الحساسية الززائلدة:

ينظر Lovecky (1992, p.21 إلى الحساسية باعتبارها سمة من السمات المرتبطة بالموهبة و المميزة للموهوبين ويصفها بأنها عمق المشاعر وزيادة الانفعالات كنتيجة لاندماج الفرد وشعوره وتعاطفه الشديد مع من حوله من الناس والحيو انات و الطبيعة و الكون المحيط به و اهتمامه بقضاياه المختلفة للا سيما القضايا الأخلاقية.

ويعرفها (1993, p.13 بilverman (19) بأنها وعي موسع، وزيادة القدرة على الاستجابة للمحفزات و المثيرات المختلفة،

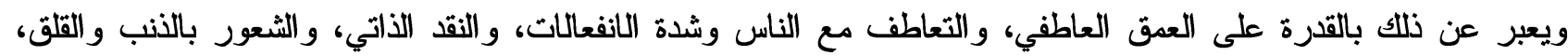
والحماس و النشاط، وسعة الخيال، و النهم في اكتساب المعرفة.

ويشتمل الوعي الموسع على الوعي بالذات والوعي بالآخرين أيضاً، والوعي بالذات يشتمل بدوره على فهم الذات والذي

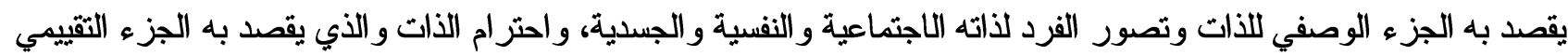
للذات وتقييم الفرد لذاته الاجتماعية والنفسية والجسدية ويستند على النجاح و الفشل في العلاقات مع الآخرين و المو اقف التعليمية و الحياة العملية. ويعرف Dabrowski (1996, p.83 الحساسية الز ائدة على أنها طاقة تحرك الموهبة والإبداع وتظهر في مجموعة من الخصائص أبرزها المشاركة الوجدانية، والتطرف في الحب والكراهية، والتمسك بالقيم والمثل العليا، والوعي بالذات، و الحماس في أداء المهمات و الاستغراق الكلي فيها، ولها خمسة مجالات أساسية هي: النفسية، والحركية، و الحسية، و العقلية، و التخيلية، وتعمل على تقوية النشاط العقلي بشكل خلاق.

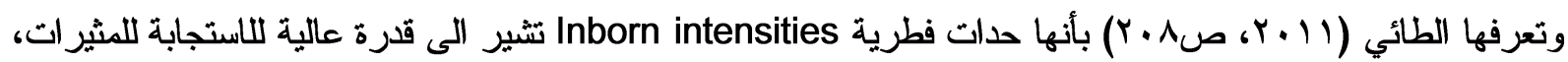

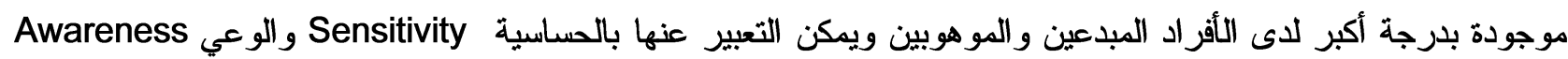

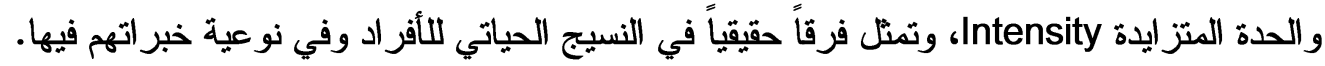
ويعرف الباحث الحساسية الزائدة على أنها ردود فعل واستجابات مميزة وحادة للمثيرات المختلفة النفسحركية والحسية

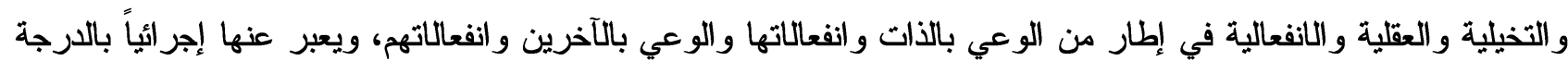
التي يحصل عليها الطلاب الموهوبون على مقياس الحساسية الزائدة.

\section{(r) أسباب العساسية الزائدة عنل الموهوبين؛}

أ. المر اقبة الثديدة و التقكير العميق: يصف Aron (2002, p.7 الأفر اد ذوي الحساسية الشديدة بأنهم أشخاص لايهر ميل إلى المر اقبة بشكل أكثر للبيئة و التفحص و الاستغراق في فهم سلوك المحيطين بهم، والتفكير بعمق في كل شيء قبل الاستجابة له، و هذا يرجع إلى أن أدمغتهم تعالج المعلومات بشكل أكثر شمولاً وعمقاً. ب. الوعي الموسع: ينظر إلى الحساسية على اعتبار أنها الوعي بواحد أو أكثر من الأمور التالية: أفكار ومشاعر الذات و الآخرين، وسلوك الذات وسلوك الآخرين، وهذا الوعي الموسع الذي لا يقتصر على الفرد بل يتعدى للآخرين لديه القدرة على بلى فهم أكبر لهذه السلوكيات والانفعالات، مما يتسبب في زيادة الاستجابة العاطفية لمشاعر الذات والآخرين، وفي هذا الإطار من ولن الاستجابة العاطفية الزائدة تكون ردود الأفعال المختلفة والحادة. (Mendaglio, 1995, p.171) 
ج. تكوين ارتباطات شرطية عالية: الشخص شديد الحساسية يكون ارتباطات شرطية للمو اقف و الأشخاص و الأماكن بدرجة أعلى من بقيه الناس، فمثاً إن كان على سفر وأتعبته هذه التجربة فربما يكره السفر تماماً بل ويتفاداه مستقبلاً، وإن كانت تجربته

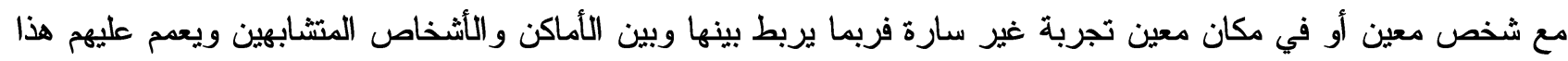
الشعور.

د. النقد الذاتي: التقييم النقدي للذات و الميل إلي إصدار أحكام سلبية قاسية على الذات، ومحاولات جلد الذات المتكررة

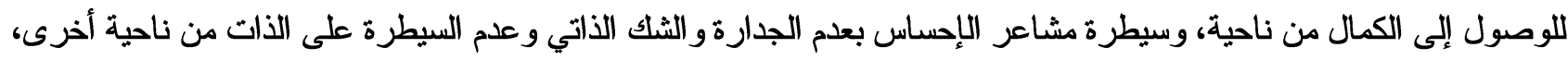

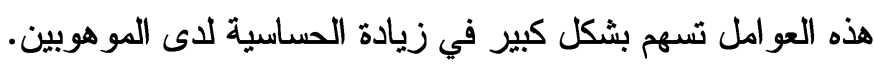

هـ قوة الذاكرة الوجدانية: يمتلك الموهوبون ذاكرة وجدانية قوية تمكنهم من تذكر الانفعالات والمشاعر التي ارتبطت أو نتجث عن التعرض لمواقف انفعالية منذ فترات طويلة، ولا يقتصر هذا التنكر على مجرد التذكر المعرفي بل يتعدى ذلك إلى دونى معايشة هذه الانفعالات و المشاعر كما لو كانو ا يتعرضون لها الآن ولا تزال محفورة في وجدانهم حية، وهذه الذاكرة الوجدانية القوية تتعكس على عو اطفهم و انفعالاتهم في صورة ردود أفعال شديدة ومميزة

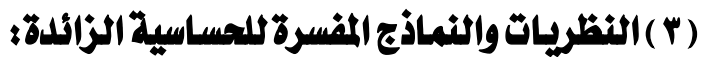

\section{أ. النظرية المعرفية:}

يربط أصحاب هذا الاتجاه بين النمو العاطفي للموهوبين و النمو المعرفي لديه؟؛ فالنمو عملية متكاملة ومتداخلة المظاهر؛ لذا يتأثر النمو العاطفي للموهوبين بالنمو المعرفي والنمو العقلي والذي يتسم بالتعقيد- في ظل عنصر الموهبة- والذي يؤدي

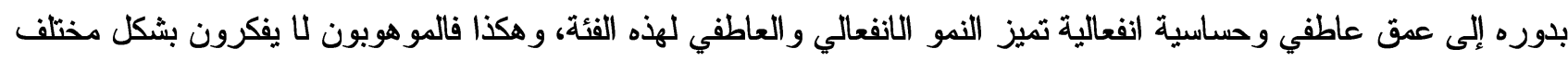

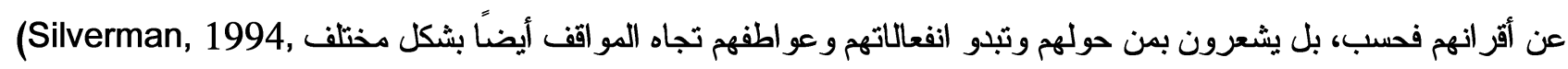

وكذلك ترجع هذه النظرية الحساسية لاى المو هوبين إلى تصور اتهم المعرفية الخاصة بعالمهم عن القضايا و المفاهيم العامة

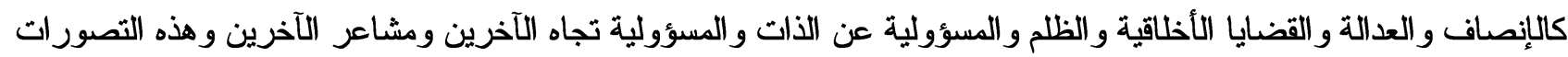
تتسم بالوعي الشديد تجاه هذه القضايا وتجاه مشاعر الآخرين، مما قد يؤدي إلى ردود أفعال تتسم بالحساسية الزائدة.

ب. نموذج الحساسية الز ائدة متعددة الأوجه: Heightened Multifaceted Sensitivity

افترض نموذج (Mendaglio (2003, p.p. 74- 76 أن هناك مظهرين للحساسية الزائدة لدى الموهوبين المظهر الأول موجه للذات و المظهر الثاني موجه للآخرين وكلاهما ينطوي على بعدين معرفيين هما: الوعي و القدرة على التخيل و الاستنتاج،

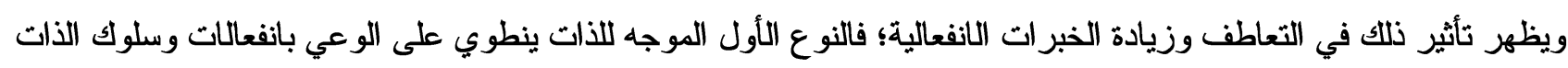
ومحاولة استتناج وتخيل نتائج هذه الانفعالات والسلوكيات، ومن ثم التعاطف مع الذات وزيادة الخبرات العاطفية، و النوع الثاني

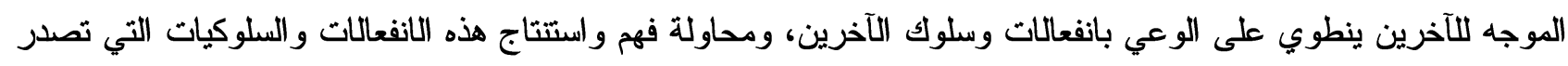

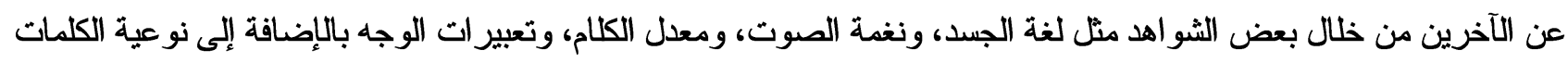

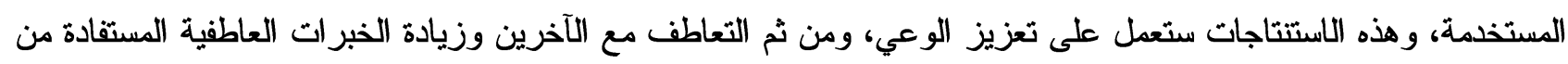
التعامل معهم.

و هذا النموذج المقتر حلحساسية الزائدة متعددة الأوجه (HMS) يحاول أن يعكس ويمثل وجهات النظر المختلفة فيما يتعلق بالحساسية الزائدة من ناحية، ويوسع دائرة الحساسية من الفرد ومشاعره و انفعالاته إلى الآخرين ومشاعر هم و انفعالاتهم من ناحية 
أخرى في محاولة لربط الفرد بالمحيطين به، و الذين يمثلون مصدراً هاماً لانفعالاته من ناحية وصقل تجاربه الانفعالية من ناحية أخرى.

ج. النظرية الفسيولوجية: يؤكد أصحاب هذه النظرية على أن مصدر الحساسية هو الوراثة والطبيعة Heredity and ) ( Nature) المختلفة للمحفزات الاجتماعية والبيئية، ومن ناحية أخرى تعمل هذه الحساسية كتكتيك فطري للبقاء على قيد الحياة من خلال هذا

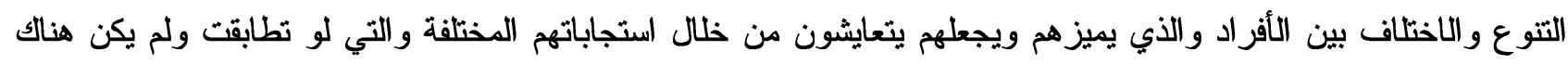

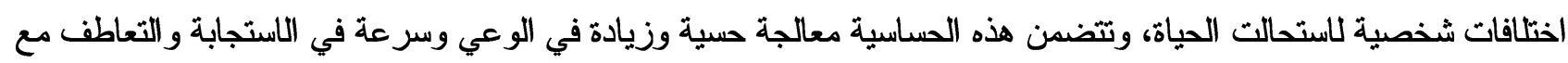
الآخرين بسبب زيادة التشيط في مناطق المخ المختلفة التي ترسل إثار ات للجهاز العصبي فيترجمها في صورة نبضات الأعصاب (الحدس) والذي يساعد الفرد على رؤية مشاعر الآخرين، حتى وإن كانت غير مدركة للبعض كماعر الغضب أو الاشمئزاز (البسيطة، والتي يدركها ذوو الحساسية من خلال تعبيرات الوجه أو العين فيستجيبون لها. (Acevedo, Aron, Sangster, Collins\& Brown, 2014,p. 1)

د. نموذج الإسنثارة النفسية المفرطة: Psychic overexcitability Model

قدم هذا النموذج (Dabrowski (1938 ليميز بالاستثارة النفسية المفرطة بين الموهوبين وغير الموهوبين؛ فالموهوبون يمتلكون ردود فعل خاصة وقدرات واستعدادات مختلفة نحو الاستجابة للمثيرات المختلفة يطلق عليها الاستثارة النفسية المفرطة (OE)، ويعبر عنها في صورة زيادة مشاعر الحساسية والوعي الشديد والانفعالات الشديدة، وقدم Dabrowski خمسة أنماط

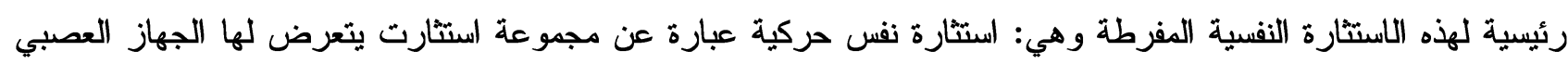

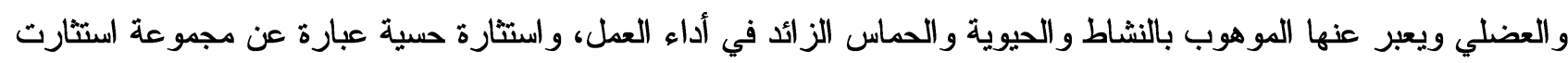

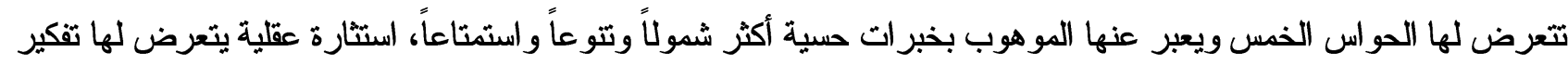

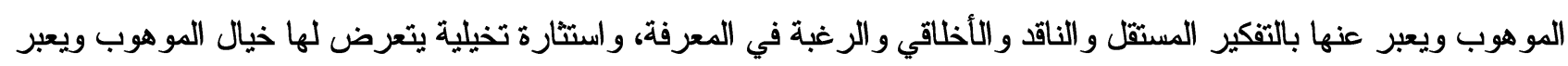

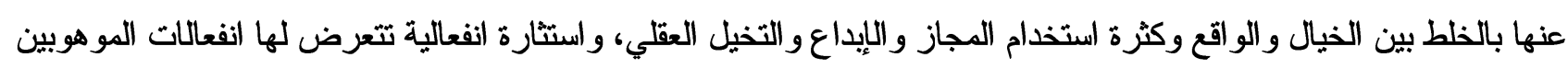
ويعبر عنها الموهوبون بالمشاعر الحادة والمفرطة والتماهي مع مشاعر الآخرين والتعاطف الشديد \& (Piechowski ) Calangelo, 1984, p.p.80-82)

وينظر هذا النموذج للحساسية الزائدة لدى الموهوبين نظرة شمولية لا تقتصر على الحساسية الانفعالية فقط- بالرغم من كونها المفهوم المركزي في هذه النظرية- بل يتتاول الأوجه المختلفة التي تميز ردود الأفعال الخاصة بالموهوبين في المجال

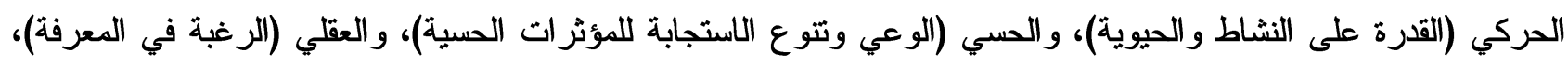

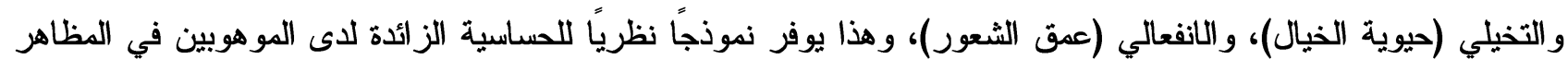
السلوكية المختلفة؛ ويعثبر هذا النموذج بمثابة مرجع شامل وموثوق ومصدر للكثير من الباحثين فيما يتعلق بالجوانب العاطفية للموهبة.

ويتضح من العرض السابق لنظريات ونماذج الحساسية الزائدة الاختلاف في التقسيرات التي تتبناها كل نظرية على حسب خلفياتها وتصور اتها النظرية؛ فبينما ترجع النظرية المعرفية الحساسية الزائدة لدى الموهوبين إلى تصور اتهم المعرفية، وتنظر

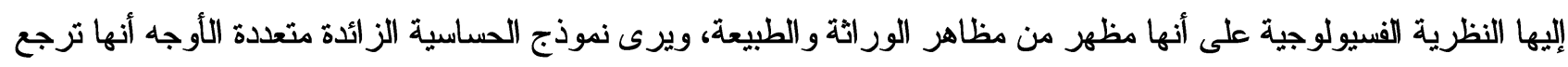
إلى الوعي الموسع والقدرة الكبيرة على التخيل، ينظر إليها نموذج الاستثارة النفسية المفرطة نظرة شمولية تؤكد على القدرة الكبيرة على الاستجابات للثيرات في المجال الحركي، والحسي، والعقلي، والتخيلي، والانفعالي، وهذا ما يؤكد عليه الباحث لملاعمته لطبيعة الموهوبين وتماشيه مع تميز قدر اتهم. 
وعلى جانب الاستفادة من التراث الأدبي الذي تتاول متغيري الدراسة وعلاتتها ببعض المتغيرات النفسية يعرض الباحث بعض هذه الدراسات على النحو التالي:

\section{(1) (1راسات تثاولت الواللية اليقمطة عقلياً:}

سعت دراسة (2019) Han et al., للكثف عن العلاقة بين الو الدية اليقظة عقلياً والاضطر ابات النفسية لدى الأبناء،

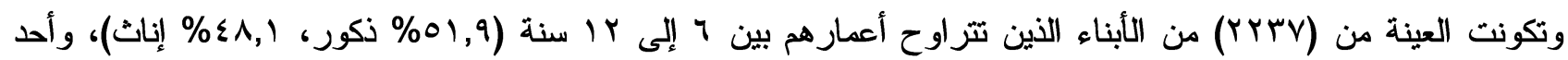

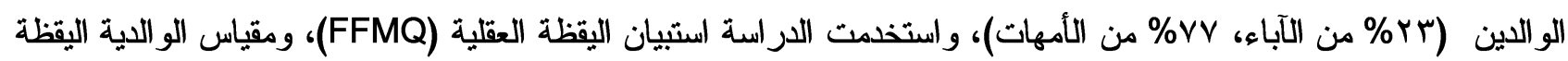

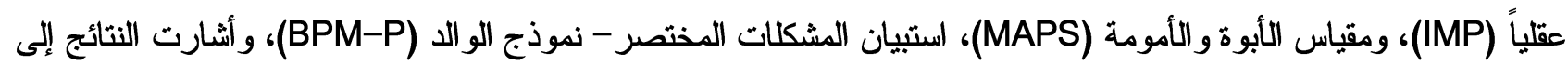

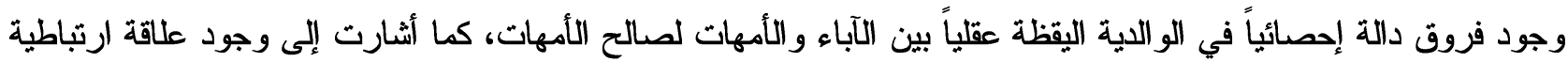
موجبة ودالة إحصائياً بين الو الدية اليقظة عقلياً وكل من مظاهر الو الدية الإيجابية والقدرة على استيعاب سلوك الأبناء. كما هدفت دراسة Gouveia, Canavarro,\& Moreira (2018) لدراسة العلاقة بين الوالدية اليقظة عقلياً وكل من الدائ اضطر ابات الأكل العاطفية والخجل من الجسم- كمشكلات يعاني منها المر اهقون - والدور الوسيط للتعاطف مع الذات في هذه

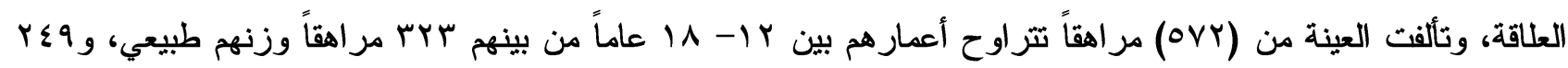

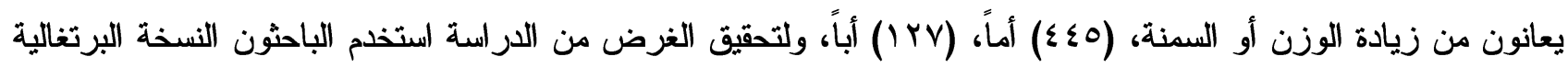

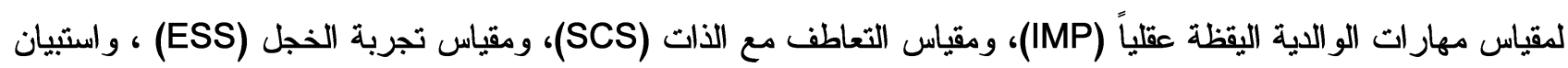

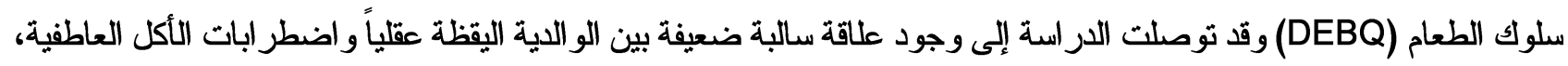
كما وجدت علاقة سالبة دالة بين الو الدية اليقظة عقلياً والخجل من الجسم من خلال مهار ات التعات التعاطف مع الذات لدى الدات المر اهقين،

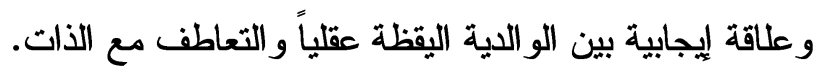
بينما سعت دراسة Moreira \& Canavarro (2018) للكثف عن العلاقة بين الو الدية اليقظة عقلياً وكل من التصرفات

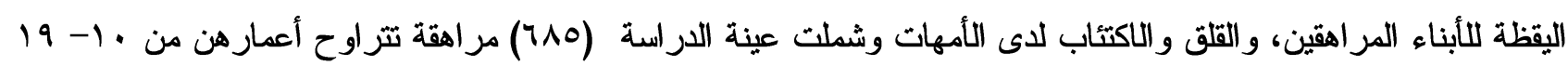
سنة من المدارس العامة بالبرتغال (من الصف الخامس إلى التاسع في التعليم الأساسي ومن الصفوف العاشر إلى الثاني عشر في

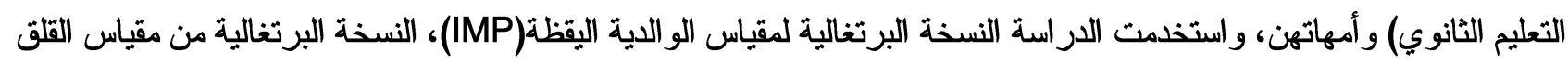

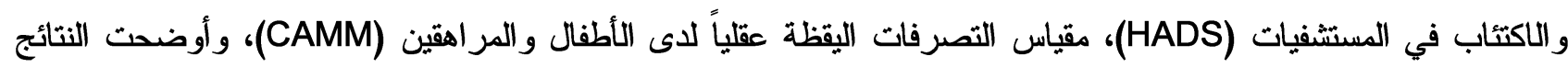

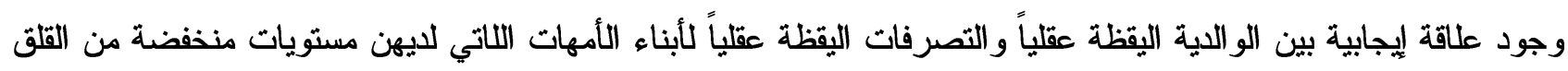
و الاكتئاب، وأظهرت النتائج عدم وجود تأثير دال إحصائياً لمستوى تعليم الأمهات في الو الدية اليقظة عقلياً. وكشفت دراسة (2018) Moreira, Gouveia,\& Canavarro, عن العاقة بين الوالدية اليقظة عقلياً و السعادة لاى وجى

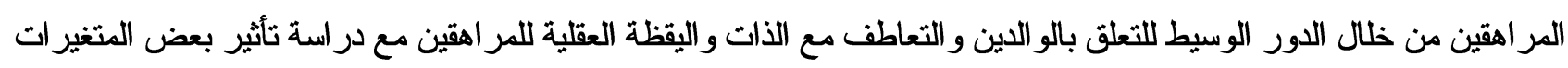

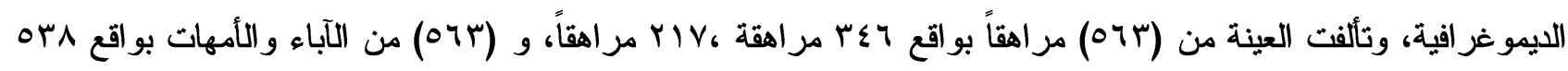

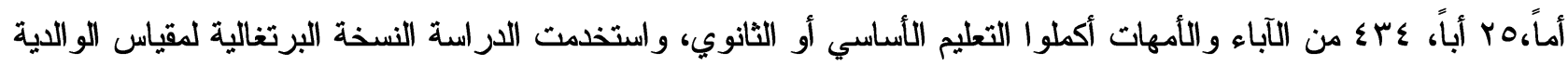

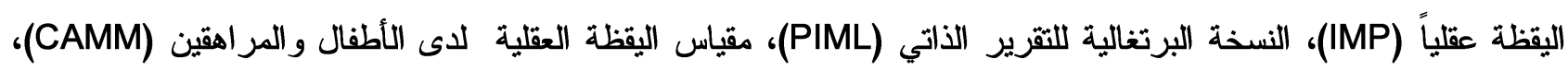

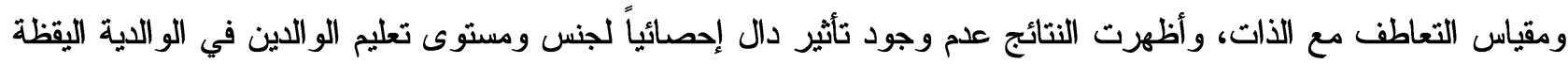

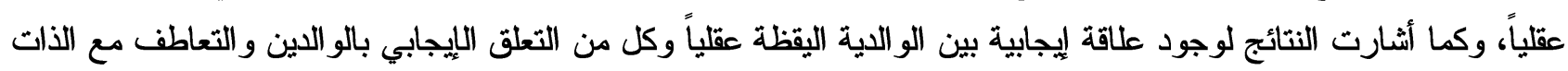
واليقظة العقلية للأبناء.

وكذللك كشفت دراسة Wang et al., 2018) عن العاقة بين الو الدية اليقظة عقلياً و المشكلات العاطفية للمر اهقين من خلال

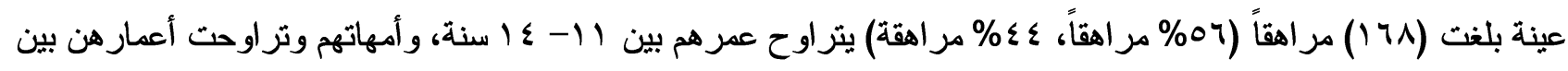

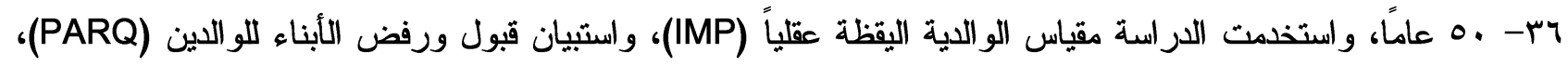


ومقياس الوعي اليقظ (MASS) للأبناء، واستبيان مظاهر القوة والضعف (SDQ) للتعرف على المشكلات العاطفية للمر اهقين، وأشارث النتائج إلى وجود ثأثير غير مباشر للو الدية اليقظة عقلياً على المشكلات العاطفية للمر اهقين من خلال دفء الأم و القدرة على اختيار الأساليب و الممارسات المناسبة لاستيعاب هذه المشكلات. كما حاولت در اسة (2016) Parent, Laura, Jennifer \& Forehand فحص العلاقة بين الو الدية اليقظة عقلياً وقدرة

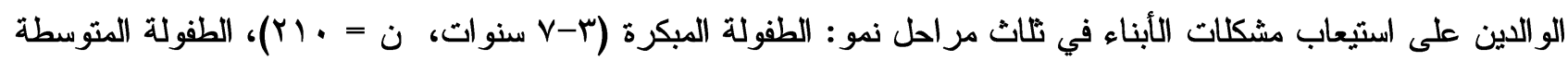

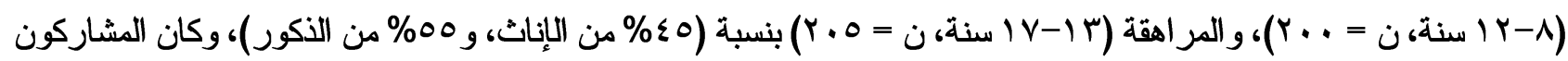

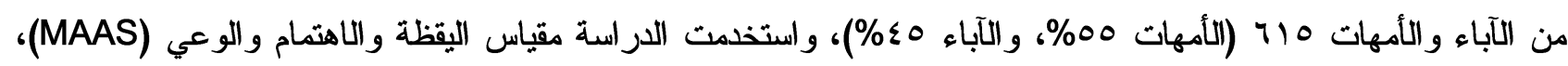

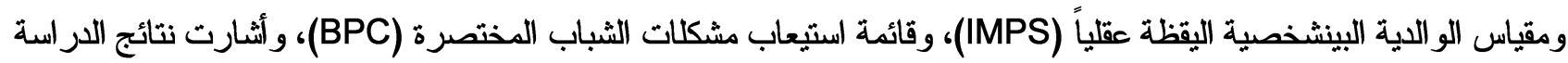

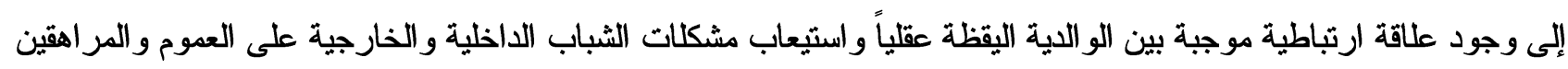

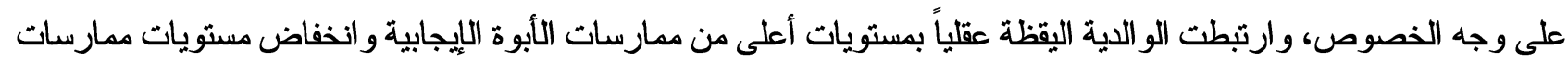

الأبوة و الأمومة السلبية.

بينما أجرى (2015) . Geurtzen, et al. دراسة هدفت إلى الكشف عن العلاقة بين الوالدية اليقظة عقلياً وكل من القلق وبعض المشكلات السلوكية لدى المر اهقين، وتم تطبيق قائمة بيك للأعر اض الاكتئابية، وقائمة سمة/ حالة القلق، ومقياس اليقظة

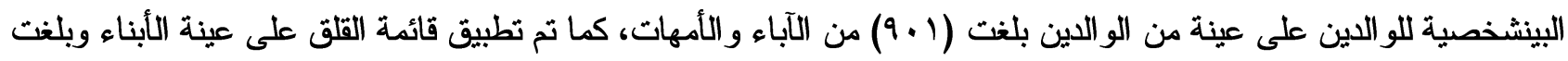

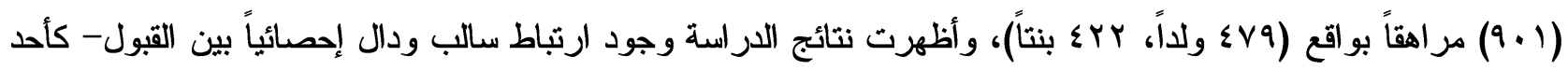

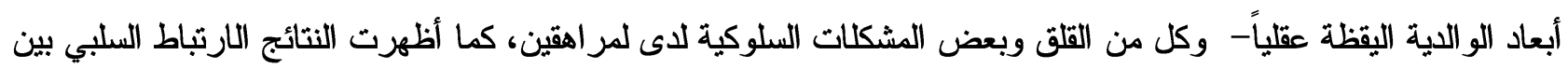
الو الدية اليقظة عقلياً وكلٍٍ من القلق و الاكتئاب لدى الو الدين.

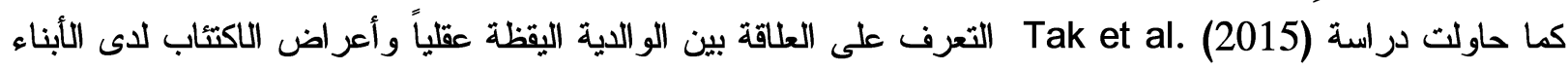

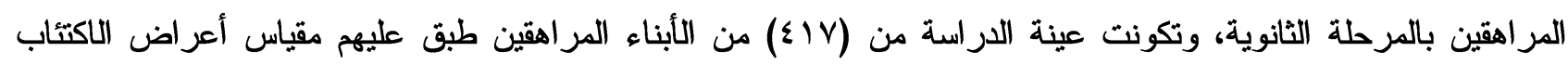

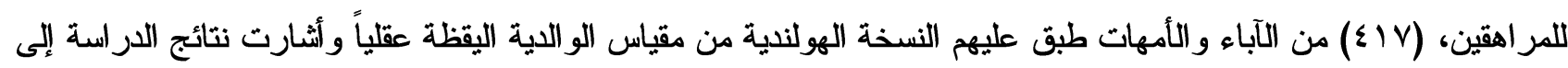

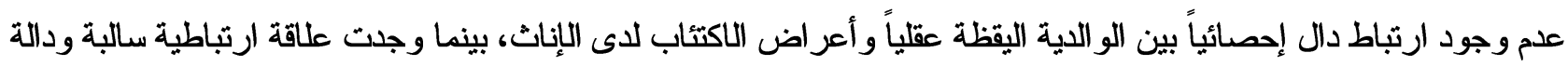

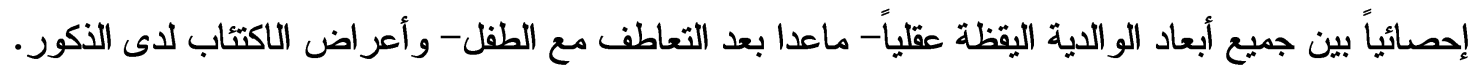

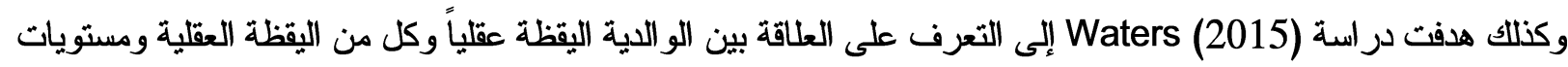

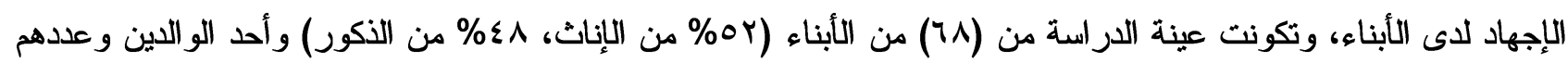

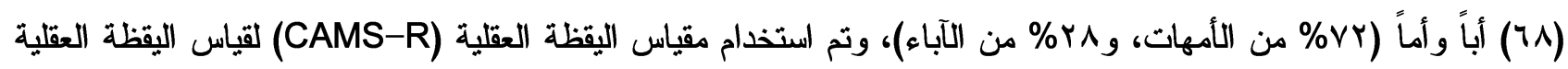

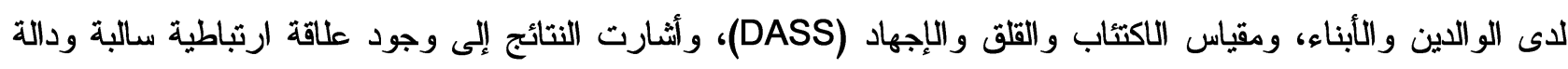

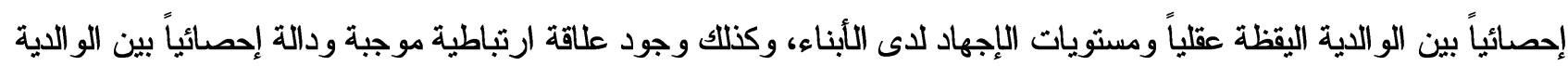
اليقظة عقلياً ومستويات اليقظة العقلية للأبناء، كما أنه يمكن التنبؤ بكل من مستويات الإجهاد و اليقظة العقلية لاى الأبناء من خلال الو الدية اليقظة عقلياً.

\section{(Y) ( دراسات تثاولت الحساسية الزائدة:}

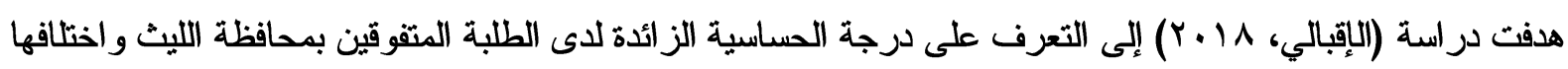

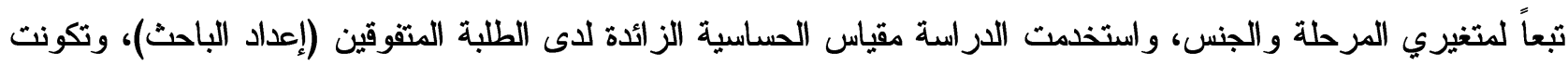
العينة من (• Y ( طالباً متفوقاً، وأشارت النتائج إلى أن درجة الحساسية لدى الطلبة المتفوقين كانت بدرجة مثوسطة، كذلك

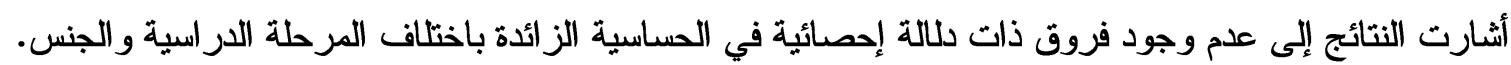


كما استهدفت دراسة داخل و علي (10 ب ( التعرف على درجة كل من الأفكار الوسو اسية والحساسية المفرطة لدى طلبة الجامعة والتعرف على الفرق في الأفكار الوسواسية والحساسية المفرطة على وفق متغير النوع ثم إيجاد العلاقة بين الأفكار الوسو اسية والحساسية المفرطة ولتحقيق أهداف البحث بنى الباحثان مقياس الأفكار الوسو اسية لطلبة الجامعة ومقياس الحساسية

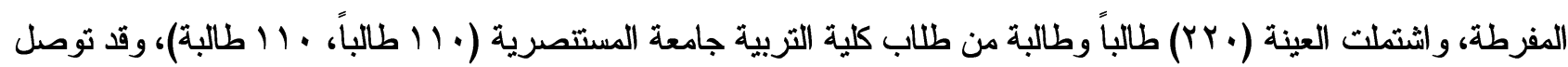
البحث إلى وجود أفكار وسو اسية وحساسية مفرطة لدى طلبة الجامعة، ووجود فروق في الأفكار الوسواسية و الحساسية المفرطة

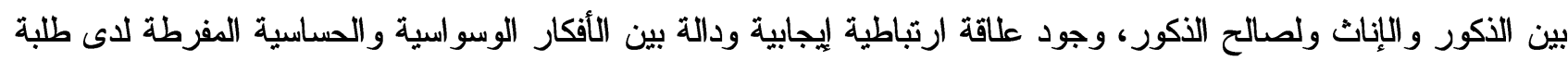

الجامعة.

وقد أجريت دراسة (2013) لتحديد مجالات ودرجة الحساسية الزائدة لدى عينة من الطلاب الموهوبين

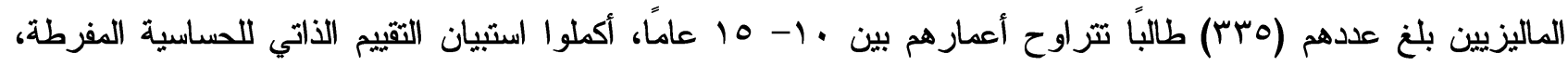
و أظهرت النتائج أن (1^^) من الطلاب الموهوبين لديهر مستوى واحد على الأقل من مستويات الحساسية المفرطة الخمسة، وأنه على الرغم من أن الطلاب الموهوبين لايهم ثقريبا نفس المستوى من الذكاء، لكن لايهم خصائص ودرجات مختلفة في الحساسية المفرطة.

كما هدفت در اسة الطائي (1) ب (1) إلى قياس الحساسية المفرطة لدى طلبة الجامعة، واستخدمت الدراسة مقياس الحساسية

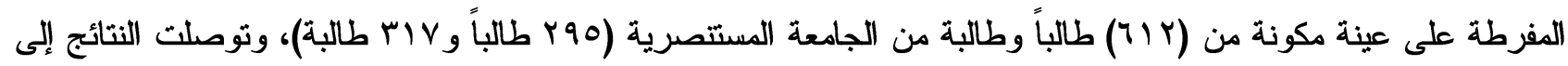
أن عينة البحث لديها حساسية مفرطة أعلى من المتوسط، كما يوجد فرق دال إحصائياً لصالح الإناث، وكذلك يوجد فرق دال إحصائياً لصالح التخصص الصح لائا حلمي.

وفي دراسة تجريبية هدفت دراسة (2010) Soons, Brouwers, \& Tomic إلى فحص آثار برنامج اليقظة العقلية

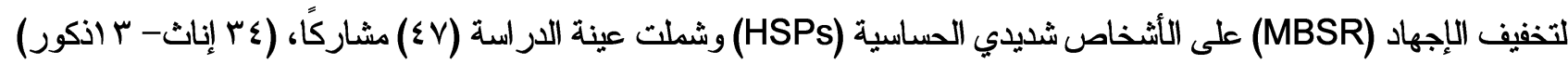
لمدة ثمانية أسابيع جلسة أسبو عياً لمدة ساعتين ونصف كتدريب مكثف لمهارات اليقظة العقلية، وأظهر المشاركون - بعد الأسابيع

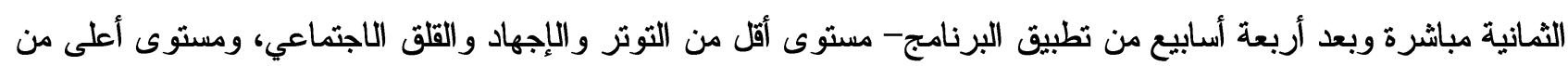
اليقظة العقلية وقبول الذات، والتعاطف، و النمو الشخصي، وتقدير الذات، وأظهرث النتائج أن برنامج (MBSR) يتمتع بالقدرة على مساعدة الأشخاص شديدي الحساسية (HSPs) على التعامل مع التوتز والقلق الاجتماعي، بالإضافة إلى تطوير قدراتهم المفترضة على التعاطف والنمو الشخصي وتقدير الذات، ومن ثم الثقليل من الآثار السلبية للحساسية الزائدة. وكثفت دراسة (2006) من العلاقة بين الحساسية الزائدة وكل من الإجهاد الذاتي ومظاهر اعتال الصحة

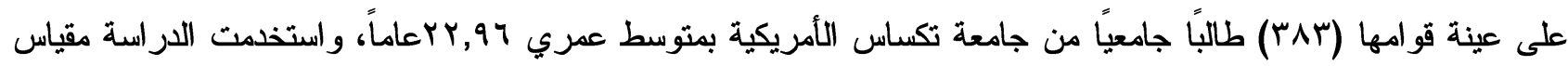
الحساسية العالية (HSP) ومقياس الإجهاد الذاتي (PSS)، وتقارير الأعراض الجسدية، وأشارت النتائج إلى ارتباط الحساسية الزائدة بشكل إيجابي بمستويات التوتز والإجهاد الذاتي وأعر اض اعنال الصاله الصحة. كما قارنت دراسة (2006) بين ثلاث مجمو عات من الطلاب الموهوبين الأتر الك -قشموا حسب قدر اتهم على الإبداع والقيادة والدافعية- في الصف العاشر وبلغ عددهم لII موهوباً من حيث حساسيتهم المفرطة في

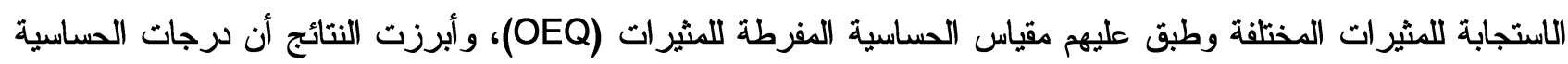
المفرطة للمثيرات التي حصل عليها الطلاب ذوو الموهبة العالية "الأكثر إبداعاً وقدرة على القيادة ودافعية" أعلى وذات دلالة إحصائية من أقرانهم ذوي الموهبة الأقل، كما أوضحت النتائج عدم وجود فروق بين الجنسين فيما يتعلق بالحساسية المفرطة 
بينما حاولت دراسة (2004) Dodd الكشف عن مستوى الحساسية الزائدة لدى عينة من الطلاب الموهوبين والعوامل

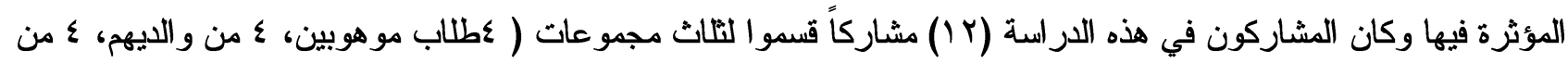

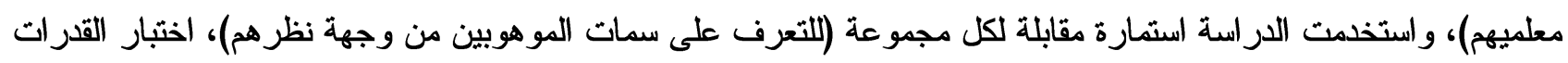
المعرفي الكندي (CCAT) )، اختبار الإنجاز الإقليمي (P.A.T.)، وأكدت النتائج على أن سمات الموهوبين في المجال المعرفي تتسم بالعمق والفهم، ومستوى التفكير العالي، والتفكير النقدي، وحل المشكلات، واتصال الأفكار، والقدرة على ربط الأفكار

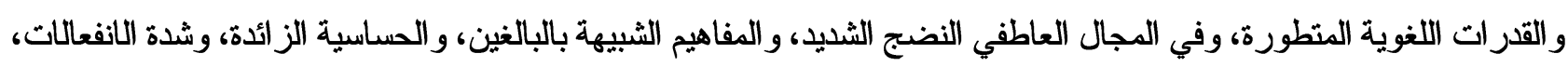

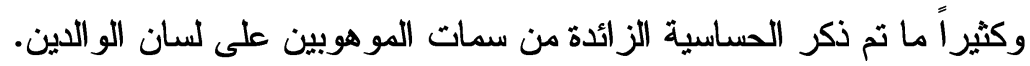

كما هدفت دراسة Donnell (2004) إلى الكشف عن العلاقة بين درجات الطلاب الموهوبين على اختبارات الإبداع وتصور اتهم الذاتية فيما يتعلق بالصداقة و الحساسية والتفكير المتباين، وتألفت عينة الدراسة من (ع 9) طالباً موهوباً ( (اك طالباً،

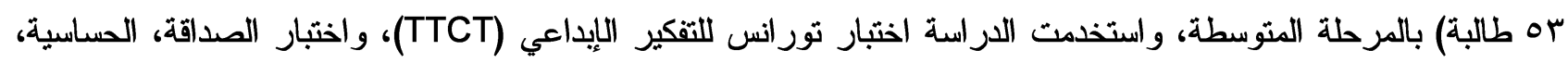
و التفكير المتباين (FSDTAS)، وكانت هناك علاقة سلبية بين درجات اختبار الإيداع و الصداقة، كما أوضحت النتائج علاقة إيجابية بين إبداع الطالب الموهوب وكل من مستويات الحساسية وتصورات التقكير المتباين بين الطلاب الموهوبين، ولا توجد فروق ذات

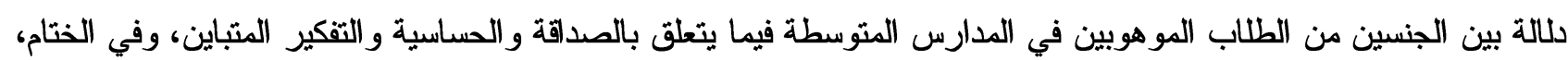

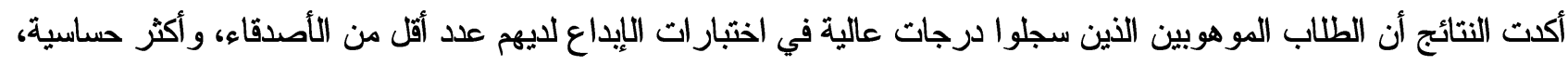
ويعتبرون أنفسهم مفكرين بشكل متباين أكثر من أقرانهم.

وفي ضوء مطالعة الدراسات السابقة التي تتاولت متغيري الدراسة الحالية- الوالدية اليقظة عقلياً والحساسية الزائدة يتضح موقع الدراسة الحالية من الدر اسات السابقة من خلال الآتي:

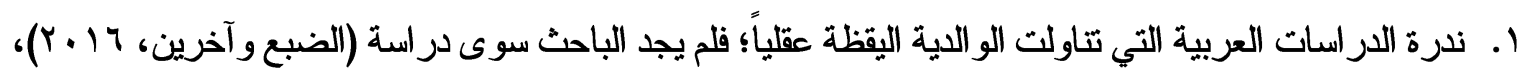
بالرغم من الاهتمام الملحوظ في الوسط البحثي الأجنبي بهذا المتغير. r. تتاولت الدراسات السابقة متغير الوالدية اليقظة عقلياً لاى عينات مختلفة من آباء وأمهات المر اهقين كدر استة Bogels et al. ولة Gouveia, Canavarro,\& Moreira (2018) (2013)، و آباء وأمهات الأطفال المخربين كدراسة (2005) Duma، وآباء و أمهات الأطفال حديثي الولادة كدراسة (2010) Duncan\& Bardacke، وآباء وأمهات المعاقين والذاتويين كدراسة الضبع وآخرين

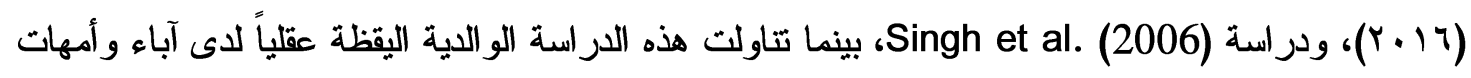

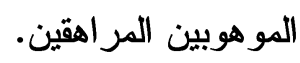
r. كذلك تتاولت الدراسات الحساسية الزائدة لدى عينات مختلفة من طلاب الجامعة العاديين كدر اسة داخل وعلي

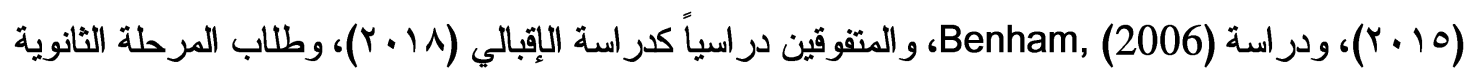

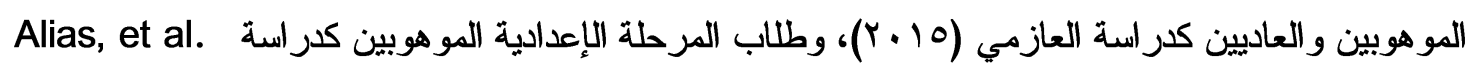
(2013)، ودراسة (2004) Donnell ، بينما تتاولت هذه الدراسة الحساسية الزائدة لدى الطلاب الموهوبين بالصف الأول الثانوي. ع. عدم وجود دراسات تتاولت العلاقة المباشرة بين الو الدية اليقظة عقلياً والحساسية الزائدة لدى الو الدين وأبنائهم المو هوبين.

\section{فيوض الألدراسة}

ا ـ توجد علاقة ارتباطية سالبة دالة إحصائياً بين الو الدية اليقظة عقلياً والحساسية الزائدة لدى أفراد عينة الدراسة. r. يظهر أفر اد عينة الدراسة من آباء وأمهات الطلاب المو هوبين مستوى متوسطاً من الو الدية اليقظة عقلياً. 
r. يظهر أفر اد عينة الدر اسة من الطلاب الموهوبين مستوى مرتفعاً من الحساسية الزائدة.

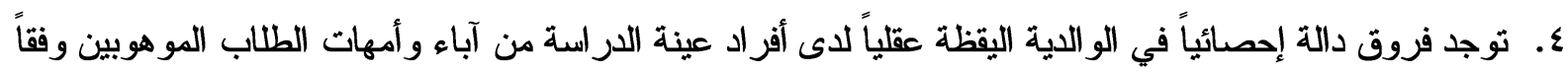

$$
\text { لمتغير الجنس (أب/ أم). }
$$

ه. لا توجد فروق دالة إحصائياً في الحساسية الزائدة لدى أفراد عينة الدر اسة من الطلاب الموهوبين وفقاً لمتغير الجنس

7 ـ . تسهم الو الدية اليقظة عقلياً في التتبؤ بالحساسية الزائدة لدى أفراد عينة الدر اسة من الطلاب الموهوبين.

مثرج الدراسة وإجراءاتهاء

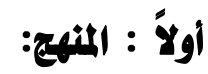

اعتمد الباحث على المنهج الوصفي الارتباطي وذلك لمناسبته لطبيعة الدراسة الحالية والتي تهدف إلى التعرف على التى الته

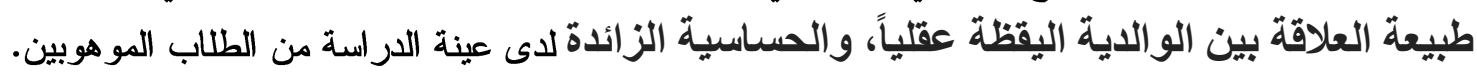

ثانياً : المينة:

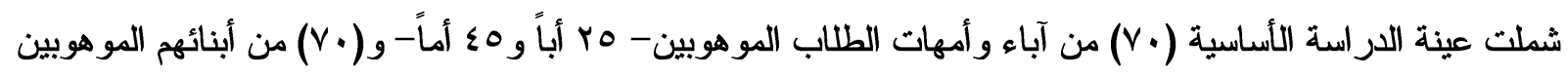

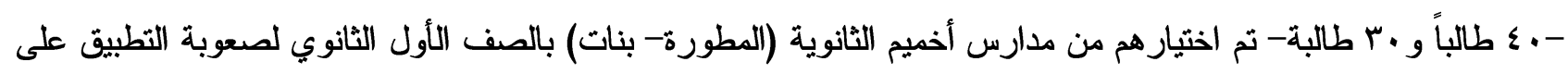
الصف الثاني والثالث، وقد كان المحك الأساسي في اختيارهم حصولهم على (ب0) درجة خام - ثقابل (90) في الرتبة المئينية-

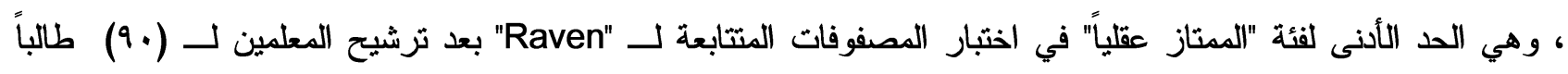

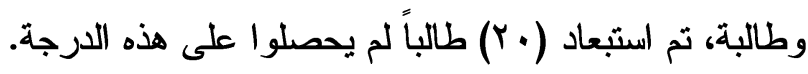

\section{ثالثاً ؛ أدوات الدراسة:}

اعتمدت الدراسة الحالية على استخدام مقياس الوالدية اليقظة عقلياً، (إعداد الباحث)، ومقياس الحساسية الزائدة (إعداد

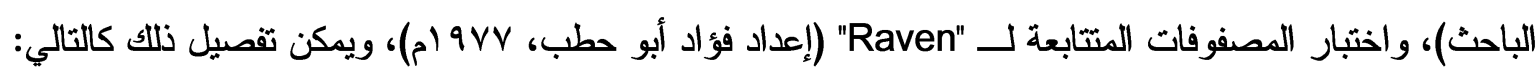

\section{(1) مقياس الوالدية اليقطة عقلياً:}

قام الباحث بإعداد مقياس الوالدية اليقظة عقلياً بما يتناسب مع البيئة العربية و المصرية من ناحية، وبما يتناسب مع عينة الدراسة الحالية وخصائصها السيكولوجية من ناحية أخرى، وذلك نظراً لعدم وجود أي مقاييس عربية- على حد علم الباحثتقيس هذا المتغير لدى هذه الفئة، وقد اعتمد الباحث في بناء المقياس على مجموعة من من الإجراءات هئ هي: (أ) تحديد الهدف من إعداد المقياس: تمثل في قياس مستوى الوالدية اليقظة عقلياً لدى آباء وأمهات الطلاب الموهوبين

بالمرحلة الثانوية.

(ب) تحديد مصادر اشتقاق أبعاد وعبار ات المقياس: من خلال الاطلاع على التراث النظري و البحثي السابق وثيق الصلة بالو الدية اليقظة عقلياً وتعريفها وأبعادها و النظريات المفسرة لها كما ورد في الإطار النظري للار اسة الحالية ودر اساتها السابقة،

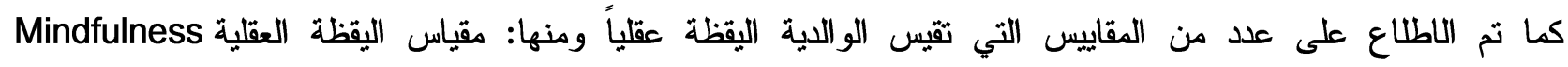
Questionnaire إعداد Mindfulness In Parenting Questionnaire (MIPQ) إعداد (Mindfulness in Parenting Scale المر اهقين Mindfulness in Parenting Scale إعداد (Duncan, 2007). 
(ج) تكوين المقياس في صورته الأولية: يتكون المقياس في صورته الأولية من (rا) عبارة تكشف عن الوالدية اليقظة

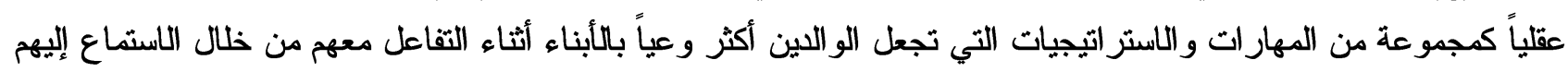
وقبولهم و الوعي الانفعالي والتحكم في الذات، مما يتيح للو الدين الاستجابة بشكل أكثر فعالية لحاجات الأبناء، وتوفير مناخ أسري

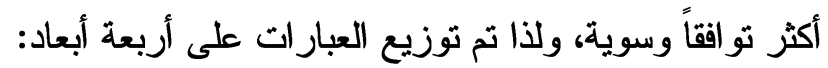
البعد الأول / الاستماع Listening : يعني الانتباه الكامل لمحتوى حديث الأبناء ومحاولة اكتشاف معانيه وعدم الانشغال عنه مع الاهتمام بلغة الجسد وتعبيرات الوجه. البعد الثاني/ القبول Acceptance: ويقصد به قبول سلوك الأبناء بدون أحكام سريعة وظاهرية وبدون نقد مما يسهل التعامل والاستجابة الأكثر فهماً البعد الثالث/ الوعي الانفعالي Emotional Awareness: يشير إلى القدرة على التعرف على مشاعر الذات و الأبناء وفهمه والتعرف على دوافعها وبالتالي إيجاد بدائل انفعالية مناسبة لردود الأفعال. البعد الرابع/ التحكم في الذات Self- control: ويقصد به التوقف قبل التصرفات لإنتئيار الممارسات الأكثر مناسبة أثناء التفاعل مع الأبناء في إطار ضبط الذات و التحكم في الانفعالات. (د) التحقق من صدق وثبات المقياس: تم تطبيق المقياس على عينة استطلاعية من (rr) طالباً موهوبا للتحقق من صدقه وثباته وذلك من خلال الخطوات الإجرائية التالية: د/1 الصدق: تم التحقق من صلاحية المقياس في قياس ما وضع لأجله من خلال الصدق الظاهري، وذلك بعرضه على

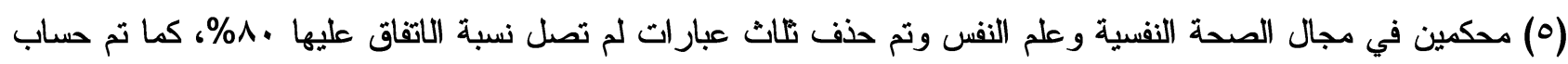
الصدق العاملي للمقياس من خلال تحديد البنية العاملية، وقد أظهرت نتائج التحليل العاملي لدرجات العينة الاستطلاعية بطريقة

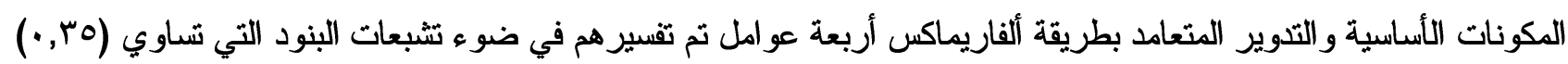

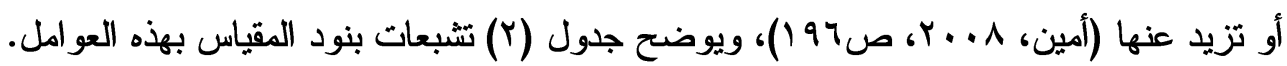
جدول (Y) التشبعات الجو هرية لبنود مقياس الو الدية اليقظة عقلياً

\begin{tabular}{|c|c|c|c|c|}
\hline \multicolumn{4}{|c|}{ تشبعات العو امل } & \multirow{2}{*}{ رقم العبارة } \\
\hline العامل الر ابع & العامل الثالث & العامل الثاني & العامل الأول & \\
\hline & & & $\cdot, \pi) \varepsilon$ & 9 \\
\hline & & & $\cdot, 4, \varepsilon$ & 0 \\
\hline & & & $\cdot, 091$ & ir \\
\hline & & & $\cdot, 0 \wedge \Lambda$ & 1 \\
\hline & & &., $0 \mathrm{O}$. & YI \\
\hline & & &., 007 & IV \\
\hline & & & $.0 \leqslant 4$ & $r v$ \\
\hline & & & $\cdot, 0 Y \wedge$ & rr \\
\hline & & &., 0.9 & rq \\
\hline & & & - ¿८9Y & ro \\
\hline & &., $7 \leqslant 0$ & & 1. \\
\hline & & " & & $1 \varepsilon$ \\
\hline & & $=$ & & 7 \\
\hline & &., 7.4 & & $Y$ \\
\hline & &., $0 \wedge$ & & rı \\
\hline & &., $0 \vee \varepsilon$ & & $r \varepsilon$ \\
\hline & &., $04 \pi$ & & 11 \\
\hline & &., $0 \leqslant \wedge$ & & $\overline{Y Y}$ \\
\hline & & $\cdot, 04 \varepsilon$ & & $\overline{Y Y}$ \\
\hline & &., $0 Y 1$ & & 11 \\
\hline & $\cdot, 0 \mathrm{VY}$ & & & rq \\
\hline & Y,OTY & & & $\mathrm{V}$ \\
\hline & $.0 \leqslant 1$ & & & 11 \\
\hline & . & & & ro \\
\hline &., 01. & & & TY \\
\hline &., 0.1 & & & ri \\
\hline & $\cdot, \varepsilon \wedge$. & & & 19 \\
\hline
\end{tabular}




\begin{tabular}{|c|c|c|c|c|}
\hline \multicolumn{4}{|c|}{ تشبعات العو امل } & \multirow{2}{*}{ رقم العبارة } \\
\hline العامل الرابع & العامل الثالث & العامل الثاني & العامل الأول & \\
\hline & $4,2 \times 1$ & & & 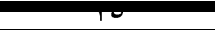 \\
\hline & $\cdot,\{\backslash 1$ & & & $r$ \\
\hline & $\cdot, \varepsilon \varepsilon$. & & & rr \\
\hline$\cdot, 711$ & & & & 17 \\
\hline$\bullet, 7 \ldots$ & & & & $\Lambda$ \\
\hline$\cdot, 0 \wedge \mu$ & & & & $\varepsilon$ \\
\hline$\cdot, 0 V M$ & & & & $1 Y$ \\
\hline$\cdot, 00 r$ & & & & $\varepsilon$. \\
\hline$\cdot, 0 \leqslant 9$ & & & & $r \Lambda$ \\
\hline •,OH. & & & & ry \\
\hline $.01 \mathrm{~V}$ & & & & $r$. \\
\hline$\cdot 0, \mathrm{~V}$ & & & & rY \\
\hline$\cdot, \sum 97$ & & & & $Y \varepsilon$ \\
\hline$r, \wedge \varepsilon r$ & $\varepsilon,{ }^{\prime}$, & $\varepsilon$, or. & $\varepsilon, \wedge 7 \mu$ & الجذر الكامن \\
\hline $\mathrm{V}, \mathrm{VI}$ & $9, Y \wedge$ & $1 \cdot$, ry & 11,10 & النسبة المئوية للتباين \\
\hline
\end{tabular}

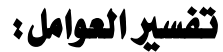

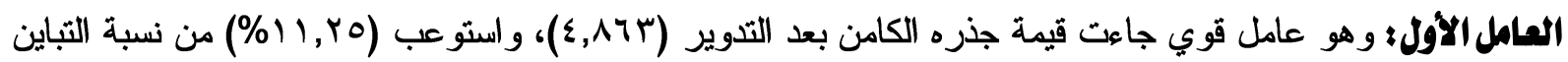

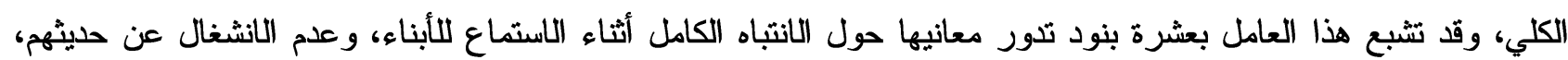

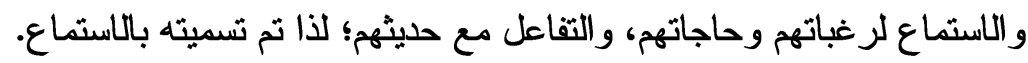

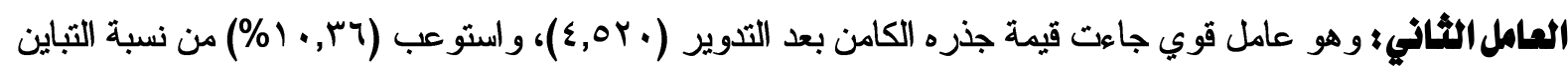
الكلي، وقد تشبع هذا العامل بعشرة بنود تدور معانيها حول قبول سلوك الأبناء بطريقة إيجابية، وعدم النقد، وعدم الحكم الظاهري؛ لذا تم تسميته بالقبول.

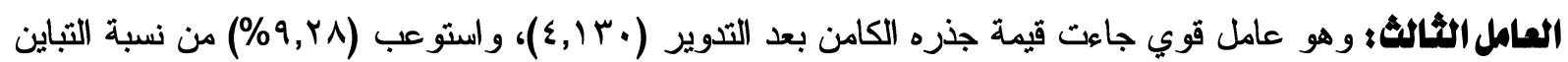
الكلي، وقد تشبع هذا العامل بعشرة بنود تدور معانيها حول القدرة على التعرف على مشاعر الذات ومشاعر الأبناء، وقراءة

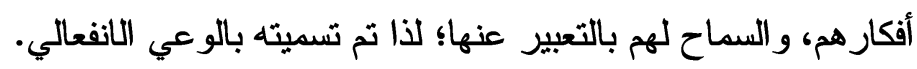

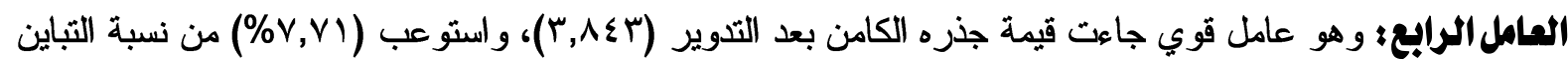
الكلي، وقد تشبع هذا العامل بعشرة بنود تدور معانيها حول القدرة على التحكم في الانفعالات، والصبر على الأبناء، والتحكم في الحالة المزاجية؛ لذا تم تسميته بالتحكم في الذات.

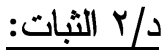

قام الباحث في البحث الحالي بالتأكد من ثبات المقياس بطريقتين:

جدول (r) ثبات مقياس الو الدية اليقظة عقلياً باستخدام معامل ألفا لكرونباخ ومعامل التجزئة النصفية

\begin{tabular}{|c|c|c|}
\hline معامل التجزئة النصفية لسبيرمان -براون & معامل ألفا لكرونباخ & الأبعاد \\
\hline$\cdot, \wedge Y$ & $\cdot, \mathrm{V} 7$ & الاستماع \\
\hline$\cdot, \wedge$. & $\cdot, \mathrm{V} \varepsilon$ & القبول \\
\hline$\cdot, \vee \vee 9$ & $\cdot, \mathrm{VM}$ & الوعي الانفعالي \\
\hline$\cdot, \mathrm{VT}$ & $\cdot, \mathrm{V}$. & التحكم في الذات \\
\hline$\cdot, \vee \wedge$ & $\cdot, \vee \varepsilon$ & مقياس الو الدية اليقظة عقلياً ككل \\
\hline
\end{tabular}

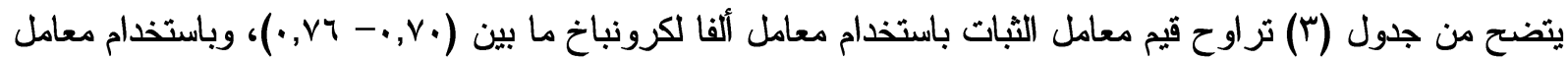

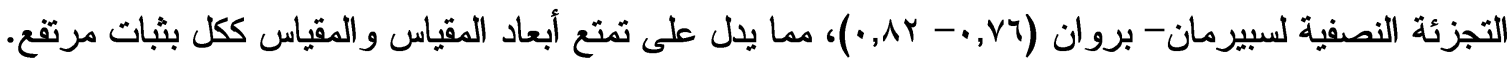




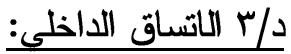

وذللك من خلال حساب معاملات الارتباط بين درجة كل مفردة من مفردات المقياس والدرجة الكلية للمقياس، وحساب معاملات الارتباط بين كل مفردة من مفردات المقياس والبعد الذي تنتمي إليه، وحساب مصفوفة معاملات الارتباط بين الأبعاد

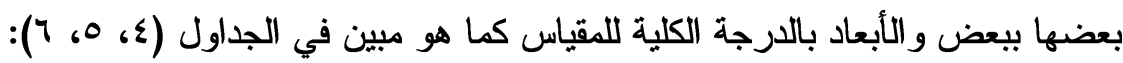

جدول (ع) معاملات الارتباط بين درجة كل مفردة من مفردات المقياس و الدرجة الكلية للمقياس

\begin{tabular}{|c|c|c|c|c|c|}
\hline الدلّية & معامل الدفرة الدياطة & العبارة & مستّية & بالدارجة المثلة الكلية & العبارة \\
\hline$\cdot, \cdot 1$ &., $07 Y$ & YI & $\cdot, \cdot 1$ & T & 1 \\
\hline$\cdot, \cdot 1$ & $\cdot, T \leqslant \mu$ & TY & $\cdot, \cdot 1$ &, $0 \leqslant$. & Y \\
\hline$\cdot, \cdot 1$ & $\cdot, 0 \mathrm{VI}$ & TM & $\cdot, \cdot 1$ & $\cdot, \leqslant 9 \wedge$ & $\Gamma$ \\
\hline$\cdot, \cdot 1$ & $\cdot, \leqslant \vee 0$ & $Y \leq$ & $\cdot, \cdot 1$ & $\cdot, 0, Y$ & $\varepsilon$ \\
\hline$\cdot, \cdot 1$ & $\cdot, 0, \xi$ & TO & $\cdot, \cdot 1$ & $\cdot, 0 M 1$ & 0 \\
\hline$\cdot, \cdot 1$ &., 074 & YY & $\cdot, \cdot 1$ & $\cdot, \leqslant 9 \lambda$ & 7 \\
\hline$\cdot, \cdot 1$ &., 019 & TV & $\cdot, \cdot 1$ & $\cdot, \leqslant \vee$. & $\bar{V}$ \\
\hline$\cdot, \cdot 1$ & . & TA & $\cdot, \cdot, 1$ & $\cdot, \Sigma T Y$ & $\Lambda$ \\
\hline$\cdot, \cdot 1$ & $\cdot, \leqslant 70$ & rq & $\cdot, \cdot 1$ &., $01 \pi$ & 9 \\
\hline$\cdot, \cdot 1$ & $\cdot, \leqslant 7 \mathrm{~V}$ & $r$. & $\cdot, \cdot 1$ & $\cdot, \leqslant 9 \wedge$ & 1. \\
\hline$\cdot, \cdot 1$ &., $0 \vee 7$ & TI & $\cdot, \cdot, 1$ & $\cdot, 0, Y$ & 11 \\
\hline$\cdot, \cdot 1$ &., 7.7 & TY & $\cdot,+1$ & $\cdot, \leqslant \wedge \uparrow$ & IT \\
\hline$\cdot, \cdot 1$ & $\cdot, 0 \wedge Y$ & r & $\cdot, \cdot 1$ & $\cdot, 0 \leqslant \mu$ & $\pi$ \\
\hline$\cdot, \cdot 1$ &., $0 \mathrm{VN}$ & TE & $\cdot, ., 1$ & $\cdot, 7 \cdot 1$ & $1 \varepsilon$ \\
\hline$\cdot, \cdot 1$ & $\cdot, \leqslant 9$. & ro & $\cdot, ., 1$ &., 049 & 10 \\
\hline$\cdot, \cdot 1$ & $\cdot, \leqslant 70$ & ry & $\cdot, \cdot, 1$ &., $0 \vee 7$ & 17 \\
\hline$\cdot, \cdot 1$ & $\cdot, \leqslant \vee q$ & TV & $\cdot, \cdot 1$ & $\cdot, 711$ & IV \\
\hline$\cdot, \cdot 1$ & $\cdot, 0 \leqslant \mu$ & rᄉ & $\cdot, \cdot 1$ & $\cdot, \leqslant 99$ & 11 \\
\hline$\cdot, \cdot 1$ &., 09. & rq & $\cdot, \cdot 1$ &., 071 & 19 \\
\hline$\cdot, \cdot 1$ &.,$\leqslant 0 \leqslant$ & $\varepsilon$. & $\cdot, \cdot 1$ & $\cdot, \leqslant V \mid$ & Y. \\
\hline
\end{tabular}

جدول (0) معاملات الارتباط بين درجة كل مفردة و البعد الذي تنتمي إليه

\begin{tabular}{|c|c|c|c|c|c|c|c|}
\hline مستّية الدلي & ارثباطل & البعد & المفردم & الدكتّية & مل & البعد & مقرّم \\
\hline$\cdot, \cdot 1$ & $\cdot, O V M$ & \multirow{10}{*}{ الانفعالَي } & $r$ & $\cdot, \cdot 1$ & $\cdot, 7 r \leq$ & \multirow{10}{*}{ الاستماع } & 1 \\
\hline$\cdot, \cdot 1$ &., $07 \leq$ & & $\mathrm{V}$ & $\cdot, \cdot 1$ & $\cdot, 7 \leq 0$ & & 0 \\
\hline$\cdot, \cdot 1$ &., $0 Y 1$ & & 11 & $\cdot, \cdot 1$ &., $0 \wedge \mu$ & & 9 \\
\hline$\cdot, \cdot 1$ & $\cdot, 0 \leqslant \mu$ & & 10 & $\cdot, \cdot 1$ & $\cdot, 71 Y$ & & 11 \\
\hline$\cdot, \cdot 1$ & י & & 19 & $\cdot, \cdot 1$ &., $09 \mu$ & & 18 \\
\hline$\cdot, \cdot 1$ &., 701 & & TY & $\cdot, \cdot 1$ & $\cdot, 7 \mu$ & & YI \\
\hline$\cdot, \cdot 1$ & $\cdot, \leqslant 9 \wedge$ & & YV & $\cdot, \cdot 1$ &., $0 Y Y$ & & Yo \\
\hline$\cdot, \cdot 1$ &., $0 Y 1$ & & PI & $\cdot, \cdot 1$ &., $07 \pi$ & & rq \\
\hline$\cdot, \cdot 1$ &., 079 & & ro & $\cdot, \cdot 1$ &., 09 . & & PY \\
\hline$\cdot, \cdot 1$ &., $07 \mathrm{~V}$ & & rq & $\cdot, \cdot 1$ & $\cdot, 0 \leqslant \mu$ & & rV \\
\hline$\cdot, \cdot 1$ &., $0 \vee \wedge$ & \multirow{10}{*}{ الانفعكماتي في } & $\varepsilon$ & $\cdot, \cdot 1$ &., $0 Y Y$ & \multirow{10}{*}{ القبول } & $Y$ \\
\hline$\cdot, \cdot 1$ &., 09 . & & $\Lambda$ & $\cdot, \cdot 1$ &., $0 \leqslant 7$ & & 7 \\
\hline$\cdot, \cdot 1$ & $\cdot, T V Y$ & & 17 & $\cdot, \cdot 1$ & $\cdot, 7 \leq \mu$ & & 1. \\
\hline$\cdot, \cdot 1$ &., $7 \% 0$ & & 19 & $\cdot, \cdot 1$ & $\cdot, 7 \cdot 1$ & & $1 \varepsilon$ \\
\hline$\cdot, \cdot 1$ & •, & & Y. & $\cdot, \cdot 1$ & $\cdot, 7 Y I$ & & 11 \\
\hline$\cdot, \cdot 1$ &., 711 & & YE & $\cdot, \cdot 1$ & $\cdot, 7 \leqslant \mu$ & & Yr \\
\hline$\cdot, \cdot 1$ &., $09 \mathrm{~V}$ & & YN & $\cdot, \cdot 1$ &., 701 & & ry \\
\hline$\cdot, \cdot 1$ &., $0 \vee 7$ & & PY & $\cdot, \cdot 1$ & $\cdot, \leqslant 9 \wedge$ & & P. \\
\hline$\cdot, \cdot 1$ &., $0 \wedge 9$ & & Pq & $\cdot, \cdot 1$ &., 0.1 & & TE \\
\hline$\cdot, \cdot 1$ & $\cdot, 0 \leqslant \mu$ & & $\varepsilon$. & $\cdot, \cdot 1$ & $\cdot, 0 M Y$ & & r人 \\
\hline
\end{tabular}

جدول (T) معاملات الارتباط بين الأبعاد بعضها ببعض و الأبعاد بالدرجة الكلية للمقياس اله

\begin{tabular}{|c|c|c|c|c|}
\hline التحكم في الذات & الوعي الانفعالي & القبول & الاستماع & الأبعاد \\
\hline & & & - & الاستماع \\
\hline & & - & ת & القبول \\
\hline & - & י & $\cdot, T Y I$ & الوعى الانفعالى \\
\hline- & $\cdot, T \leqslant V$ & . & שוT, & التحكم في الذات \\
\hline$\cdot, \mathrm{V} 7 \mathrm{I}$ & $\cdot, \mathrm{V} T \mathrm{Y}$ & $\cdot, \mathrm{V} \circ \mathrm{V}$ & $\cdot, \vee \vee \neg$ & المقياس ككل \\
\hline
\end{tabular}


يتضح من جدول (ع، 0، 7) معاملات الارتباط بين درجة كل مفردة من مفردات المقياس والدرجة الكلية للمقياس، ومعاملات الارتباط بين كل مفردة من مفردات المقياس والبعد الذي تتنمي إليه، ومعاملات الارتباط بين الأبعاد بعضها بيعض ونه و الأبعاد بالدرجة الكلية للمقياس دالة إحصائياً عند مستوي ( ( .,. )، مما يدل ذلك على تمتع المقياس باتساق داخلي. (ه) تكوين المقياس في صورته النهائية: يتكون المقياس في صورته النهائية من (•ع) عبارة تم صياغتها بصياغة موجبة وسالبة موزعة على أبعاد المقياس على النحو المبين في الجدول الآتي:

جدول (V) توزيع البنود على أبعاد المقياس في صورته النهائية

\begin{tabular}{|c|c|c|}
\hline العبار ات السالبة & أرقام العبار ات الموجبة & الأبعاد \\
\hline$r v 696061$ & Tr & 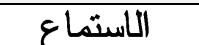 \\
\hline r. (I) ( & rᄉ 6 6 \& & القبول \\
\hline 19610 & 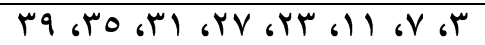 & الو الو الانفعالى \\
\hline r & E & التحكم في الذات \\
\hline
\end{tabular}

(Y) مقياس الهساسية الززائلة

قام الباحث بإعداد مقياس الحساسية الزائدة بما يتتاسب مع البيئة العربية والمصرية من ناحية، وبما يتتاسب مع عينة الدراسة الحالية وخصائصها السيكولوجية من ناحية أخرى، وذلك نظراً لعدم وجود أي مقاييس عربية- على حد علم الباحثتقيس هذا المتغير لدى هذه الفئة، وقد اعتمد الباحث في بناء المقياس على مجموعة من الإجراءات هي: (أ) تحديد الهدف من إعداد المقياس: تمثل هدف المقياس في قياس مستوى الحساسية الزائدة لدى الطلاب الموهوبين بالمرحلة الثانوية.

(ب) تحديد مصادر اشتقاق أبعاد وعبار ات المقياس: من خلال الاطلاع على التراث النظري و البحثي السابق وثيق الصلة بالحساسية الزائدة وتعريفها وأبعادها و النظريات المفسرة لها كما ورد في الإطار النظري للار اسة الحالية ودر اساتها السابقة، كما تم الاطلاع على عدد من المقاييس التي تقيس الحساسية الزائدة ومنها: مقياس الحساسية الزائدة لدى الطلبة المتفوقين، إعداد

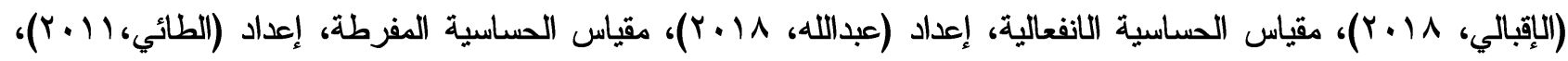
مقياس الحساسية المفرطة للمثيرات Overexcitability Questionnaire. (OEQ) إعداد Oakmaci-Guzel\& Akarsu) (Arron \& Aron, إعداد The Highly Sensitive Person scale (HSP) 2006)

(ج) تكوين المقياس في صورته الأولية: يتكون المقياس في صورته الأولية من (Y؟) عبارة تكشف عن الحساسية الزائدة

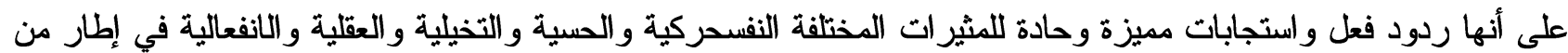
الوعي بالذات و انفعالاتها و الوعي بالآخرين و انفعالاتهم، ولذا تم توزيع العبارات على خمسة أبعاد:

البعد الأول / المجال النفسحكي (Psychomotor ES): يقصد بها فائض من النشاط والطاقة و المنافسة مع الأقران تظهر في الحركة الزائدة و السلوك الاندفاعي و الحماس والكلام السريع وتحدي الذات بأداء المهام الصعبة و التطبيق العملي في الحياة.

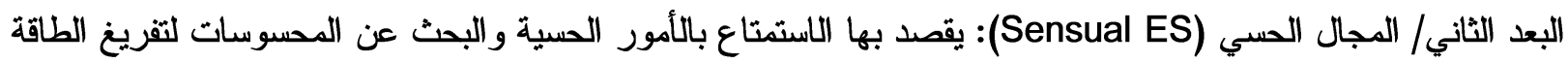

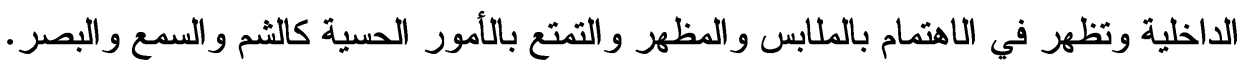
البعد الثالث/ المجال التخيلي (Imaginational ES): وتشير إلى الاستغراق في الخيال وأحلام اليقظة وتثتت الانتباه وتظهر في استخدام المجاز في التعبيرات الشفوية كتعبير عن سعة خيال الموهوبين. البعد الرابع/ المجال العقلي (Intellectual ES): تعبر عن نشاط عقلي واسع ومتسارع يظهر من خلال حب المعرفة و السعي لاكتسابها ومحاولة فهم الحقائق و الاهتمام بالقضايا العامة و الأخلاقية واستقلال التفكير و الفضول وحب الاستطلاع و التخطيط 
البعد الخامس/ المجال الانفعالي (Emotional ES) : يقصد بها وفرة المشاعر والعواطف التي تظهر في التعاطف مع الآخرين و المبالغة في الانفعالات وعدم تقبل النقد و الشعور بالذنب. (د) التحقق من صدق وثبات المقياس: تم تطبيق المقياس على عينة استطلاعية من (rس) طالباً مو هوبا للتحقق من صدقه وثباته وذلك من خلال الخطوات الإجر ائية التالية: د/1 الصدق: تم التحقق من صلاحية المقياس في قياس ما وضع لأجله من خلال الصدق الظاهري، وذلك بعرضه على

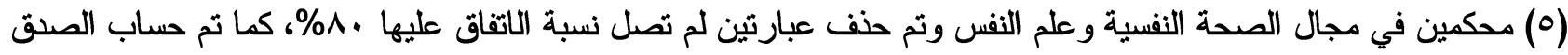
العاملي للمقياس من خلال تحديد البنية العاملية، وقد أظهرت نتائج التحليل العاملي لدرجات العينة الاسنطلاعية بطريقة المكونات الأساسية و التذوير المتعامد بطريقة ألفاريماكس أربعة عو امل تم تفسيرهم في ضوء تشبعات البنود التي تساوي (Oب, •) أو تزيد

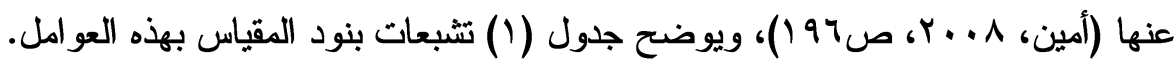
جدول (^) التشبعات الجوهرية لبنود مقياس الو الدية اليقظة عقلياً

\begin{tabular}{|c|c|c|c|c|c|}
\hline \multicolumn{5}{|c|}{ تشبعات العوامل } & \multirow{2}{*}{ رقم العبارة } \\
\hline العامل الخامس & العامل الر ابع & العامل الثالث & العامل الثاني & العامل الأول & \\
\hline & & & & $\cdot, 79 \wedge$ & YI \\
\hline & & & &., $70 \varepsilon$ & 17 \\
\hline & & & & - (TYו & 1 \\
\hline & & & &., 091 & 7 \\
\hline & & & &., $07 \mu$ & ry \\
\hline & & & & $\cdot, 0 \leqslant Y$ & rq \\
\hline & & & &., $0 Y 1$ & YY \\
\hline & & & &., 0.9 & r \\
\hline & & & & $\cdot, \sum 9 \wedge$ & 11 \\
\hline & & & $\cdot, 7 \varepsilon r$ & & $\mathrm{~V}$ \\
\hline & & & $\cdot, 7 Y Y$ & & YY \\
\hline & & & $\cdot, 7 \cdot V$ & & IV \\
\hline & & &., 091 & & $Y$ \\
\hline & & &., $0 \wedge \mathrm{r}$ & & IY \\
\hline & & &., $0 \mathrm{VI}$ & & rY \\
\hline & & &., $00 \mathrm{r}$ & & TV \\
\hline & & 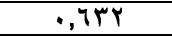 & & & rT \\
\hline & & . & & & rA \\
\hline & & $\cdot, 7) \mathrm{V}$ & & & $\pi$ \\
\hline & & $\cdot, 7 \cdot 1$ & & & $\Lambda$ \\
\hline & &., $09 Y$ & & & $r$ \\
\hline & &., $0 \wedge$. & & & 11 \\
\hline & &., 007 & & & Yr \\
\hline &., 091 & & & & 19 \\
\hline &., $0 \mathrm{~V}$. & & & & $1 \varepsilon$ \\
\hline & .074 & & & & 9 \\
\hline &., 07. & & & & $\varepsilon$ \\
\hline &., 001 & & & & rq \\
\hline &., $0 \leqslant$. & & & & rV \\
\hline &., $0 Y 9$ & & & & $r \varepsilon$ \\
\hline &., $01 \mu$ & & & & $T \varepsilon$ \\
\hline צוד, צי & & & & & rᄉ \\
\hline - & & & & & ro \\
\hline$\cdot, 71 \mathrm{~V}$ & & & & & $\varepsilon$. \\
\hline., $09 \varepsilon$ & & & & & YO \\
\hline$\cdot, 0 \wedge \Lambda$ & & & & & r. \\
\hline$\cdot, 0 \mathrm{VN}$ & & & & & 0 \\
\hline$\cdot, 07 Y$ & & & & & 1. \\
\hline., $0 \leqslant 9$ & & & & & $r$. \\
\hline .,Orr & & & & & 10 \\
\hline r,rYq & r,vOA & $\varepsilon, 1,1$ & $\varepsilon, \Gamma)$ & $\varepsilon, 0 Y 1$ & الجذر الكامن \\
\hline 0,91 & $7, \wedge V$ & $\Lambda, Y Y$ & $9,1 \varepsilon$ & $1 \cdot, 1 \varepsilon$ & النسبة المئوية للفباين \\
\hline
\end{tabular}




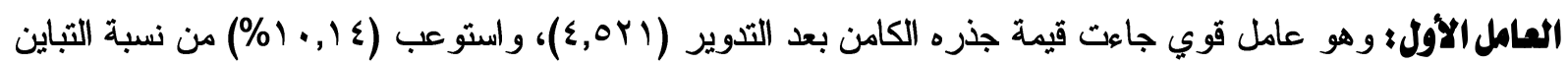

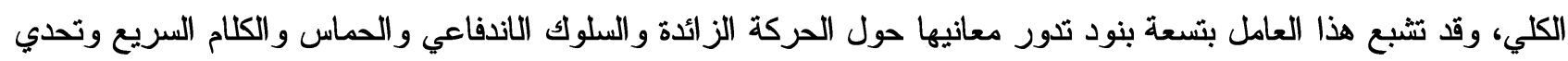
الذات بأداء المهام الصعبة؛ لذا تم تسميته بالمجال النفسحركي.

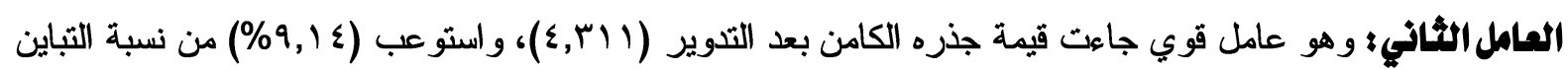

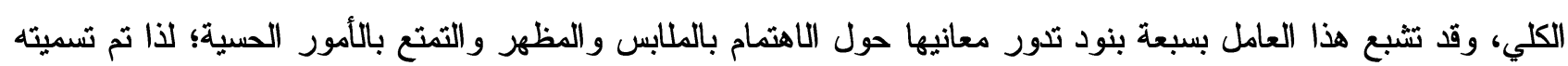
بالمجال الحسي.

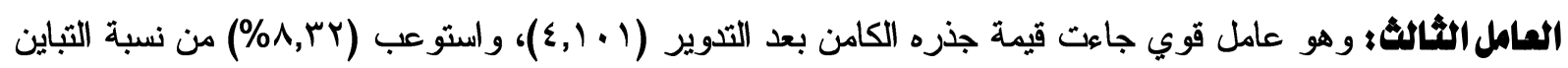

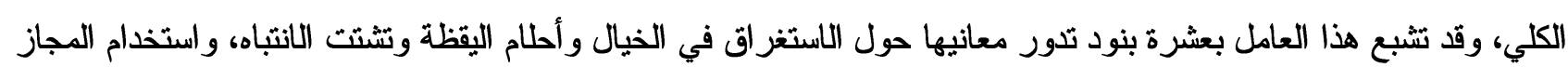
في التعبيرات الثفوية؛ لذا تم تسميته بالمجال التخيلي.

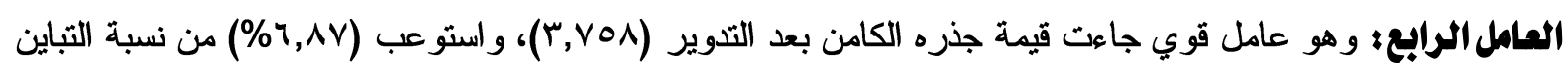

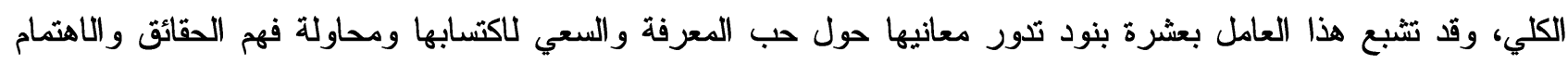

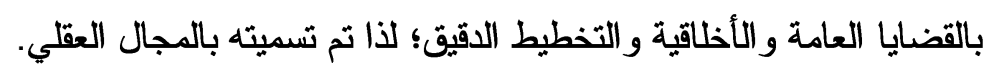

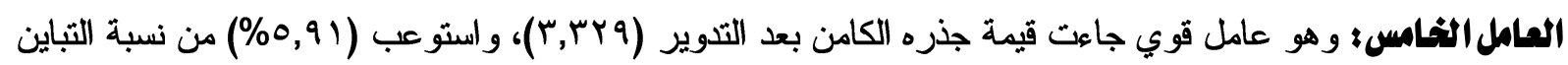

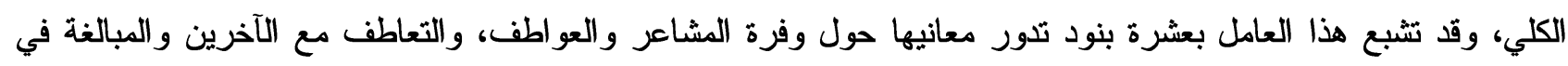

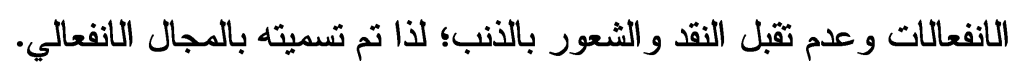

\section{د/}

قام الباحث في البحث الحالي بالتأكد من ثبات المقياس بطريقتين:

جدول (9) ثبات مقياس الو الدية اليقظة عقلياً باستخدام معامل ألفا لكرونباخ ومعامل التجزئة النصفية

\begin{tabular}{|c|c|c|}
\hline معامل التجزئة النصفية لسبيرمان كراون & معامل ألفا لكرونباخ & الأبعاد \\
\hline$\cdot, \Lambda \tau$ & $\cdot, \mathrm{V \Lambda}$ & المجال النفسحركى \\
\hline 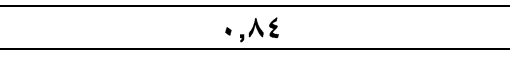 & $\cdot, \mathrm{v} 7$ & الـجال الحسى \\
\hline$\cdot, \Lambda Y$ &., $\mathrm{VO}$ & المجال التخيلّي \\
\hline$\cdot, \Lambda$ & $\cdot, \mathrm{v4}$ & المجال العقلى \\
\hline$\cdot, \Lambda \cdot$ & $\cdot, \mathrm{V} \varepsilon$ & المجال الانفعالى \\
\hline ,... & $\cdot, \mathrm{v} \varepsilon$ & 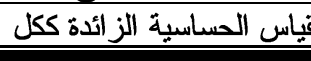 \\
\hline
\end{tabular}

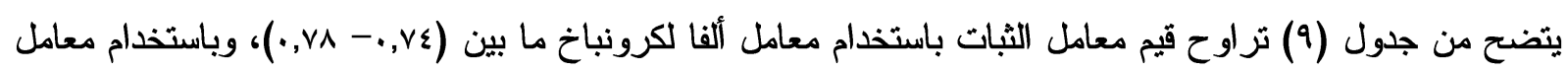

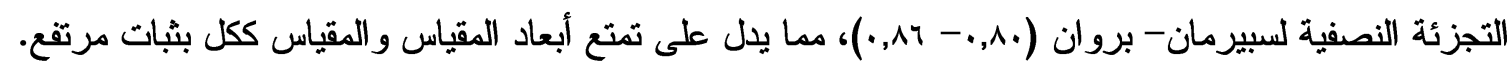
د/ب الاتساق الداخلي:

وذلك من خلال حساب معاملات الارتباط بين درجة كل مفردة من مفردات المقياس والدرجة الكلية للمقياس، وحساب

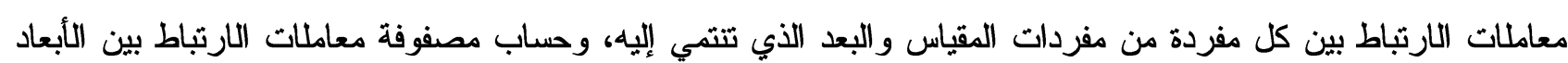

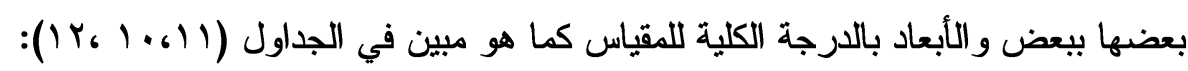
جدول (· () معاملات الارتباط بين درجة كل مفردة من مفردات المقياس والدرجة الكلية للمقياس 


\begin{tabular}{|c|c|c|c|c|c|}
\hline الدلآلّي & 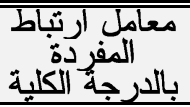 & العبارة & مستئية & معامل الرثبة الدباطة & العبارة \\
\hline$\cdot, \cdot 1$ &., $01 Y$ & TI & $\cdot, \cdot 1$ &., $0 Y 1$ & $T$ \\
\hline$\cdot, \cdot 1$ &., $0 Y \leqslant$ & YY & $\cdot, \cdot 1$ & $\cdot, 7, \mu$ & $\bar{Y}$ \\
\hline$\cdot, \cdot 1$ & $\cdot, \leqslant \vee \wedge$ & TY & $\cdot, \cdot 1$ &., $07 \pi$ & $r$ \\
\hline$\because, \cdot 1$ &., 074 & TE & $\bullet,+1$ & $\cdot, O Y Y$ & $\xi$ \\
\hline$\cdot, \cdot 1$ & $\cdot, \Sigma \wedge \vee$ & Yo & $\cdot, \cdot 1$ & $\cdot, \leqslant 9 \wedge$ & 0 \\
\hline$\cdot, \cdot 1$ & $\cdot, \leqslant 9 r$ & FY & $\cdot, \cdot 1$ & $\cdot, \leqslant \vee \uparrow$ & 7 \\
\hline$\cdot, \cdot 1$ & $\cdot, \leqslant \wedge 0$ & TV & $\cdot, \cdot 1$ & $\cdot, \leqslant 7 T$ & V \\
\hline$\cdot,+1$ & $\cdot, 0, \varepsilon$ & TA & $\bullet,+1$ &., 0.9 & $\Lambda$ \\
\hline$\cdot,+1$ &., 017 & rq & $\cdot,+1$ & $\cdot, 0 \leqslant \mu$ & 9 \\
\hline$\cdot, \cdot 1$ & $\cdot, \leqslant \vee 0$ & $r$. & $\cdot, \cdot 1$ & , THY & 1. \\
\hline$\cdot,+1$ & $\cdot, \leqslant \leqslant \mu$ & Tा & $\cdot,+1$ &., $07 \mathrm{~V}$ & 11 \\
\hline$\cdot, \cdot 1$ & $\cdot, \varepsilon Y q$ & TY & $\cdot, \cdot 1$ &.,$T Y Y$ & TY \\
\hline$\cdot, \cdot 1$ &., 07. & r & $\cdot, \cdot 1$ &., $0 \wedge \varepsilon$ & $1 \pi$ \\
\hline$\cdot, \cdot 1$ &., $0 K \pi$ & $\Gamma \leqslant$ & $\cdot, \cdot 1$ &., $07 \leqslant$ & $1 \leqslant$ \\
\hline$\cdot,+1$ & $\cdot, \leqslant 97$ & ro & $\cdot, \cdot 1$ & $\cdot, 00 r$ & 10 \\
\hline$\cdot, \cdot 1$ & $\cdot, 0 \leqslant 1$ & rq & $\cdot, \cdot 1$ & $\cdot, 7 \cdot 1$ & 17 \\
\hline$\cdot, \cdot 1$ & $\cdot, \leqslant 99$ & rV & $\cdot, \cdot 1$ &., $0 M \mu$ & IV \\
\hline$\bullet,+1$ & $\cdot, 0 \mathrm{~N}$ & rर & $\cdot, \cdot 1$ & $\cdot, 0 . V$ & 11 \\
\hline$\cdot, \cdot 1$ & ע T", & rq & $\cdot, \cdot 1$ & $\cdot, 7 \ldots$ & 19 \\
\hline$\cdot, \cdot 1$ & $\cdot, \leqslant 9 V$ & $\xi$. & $\cdot, \cdot 1$ &., $07 \pi$ & $r$. \\
\hline
\end{tabular}

جدول (1') معاملات الارتباط بين درجة كل مفردة والبعد الذي تتنمي إليه

\begin{tabular}{|c|c|c|c|c|c|c|c|}
\hline الدستّةي & الارتباط & البعد & المفرقدمة & مستّية & الارثبامل & البعد & المفرُدة \\
\hline$\cdot, \cdot 1$ &., $07 \varepsilon$ & \multirow{8}{*}{ العقجي } & $\varepsilon$ & $\cdot, \cdot 1$ & $\cdot, 091$ & \multirow{9}{*}{ النفسجركي المجال } & 1 \\
\hline$\cdot, \cdot 1$ & $0,0 \leqslant \Gamma$ & & 9 & $\cdot, \cdot 1$ & $\cdot, 7 \varepsilon r$ & & 7 \\
\hline$\because, \cdot 1$ & $\cdot$, OYP & & Tद & $\cdot, \cdot 1$ & $\cdot, \pi / V$ & & 11 \\
\hline$\because, 1$ & $\Leftrightarrow \leqslant 9$. & & 19 & $\cdot, 1$ &., $0 \wedge \mathrm{Y}$ & & 17 \\
\hline$\cdot, \cdot 1$ & $\cdot, 0,1$ & & Tद & $\cdot,+1$ & $\cdot, 0 \wedge \mathrm{V}$ & & रा \\
\hline$\cdot, \cdot 1$ &., $07 \mathrm{~V}$ & & रq & $\cdot,+1$ & $\cdot, 0 \wedge \mathrm{Y}$ & & rq \\
\hline$\cdot, \cdot 1$ & $\cdot, 0 \leqslant \Gamma$ & & एद & $\cdot, \cdot 1$ & $\cdot, 01 \%$ & & Tा \\
\hline$\cdot, \cdot 1$ & $\bullet, 0 Y \varepsilon$ & & TV & $\cdot, \cdot 1$ & $\cdot, 0 \leqslant T$ & & ry \\
\hline$\because, \cdot 1$ & $\cdot, 711$ & \multirow{9}{*}{ الانفعالي } & 0 & $\cdot, \cdot 1$ & $\cdot$, OY & & rq \\
\hline$\because, \cdot 1$ &., 7.9 & & 1. & $\cdot, \cdot 1$ & $\because, 0 \vee 7$ & \multirow{7}{*}{ الحجي } & T \\
\hline$\cdot, \cdot 1$ & $\bullet, 07 \varepsilon$ & & 10 & $\cdot, \cdot 1$ & $\cdot, 0 \leqslant \Gamma$ & & V \\
\hline$\because, \cdot 1$ & $\bullet, 7 \ldots$ & & Y. & $\cdot, \cdot 1$ & $\cdot, 0 V Y$ & & Tr \\
\hline$\cdot, \cdot 1$ & 0,079 & & Yo & $\cdot, \cdot 1$ & $\cdot, 299$ & & IV \\
\hline$\cdot, \cdot 1$ &., 071 & & T. & $\because, \cdot 1$ & $\cdot, 0, r$ & & TY \\
\hline$\cdot, \cdot 1$ & $\cdot, 0 \vee \Lambda$ & & To & $\cdot,+1$ & $\cdot, 0 \leqslant T$ & & TV \\
\hline$\cdot, \cdot 1$ &., $07 \mathrm{~V}$ & & Tर & $\cdot, \cdot 1$ & $\cdot, 0 \leqslant \Lambda$ & & TY \\
\hline$\cdot, \cdot 1$ & $\cdot, 0 \wedge \mathrm{V}$ & & $\varepsilon$. & $\cdot, \cdot 1$ &., 09 & \multirow{7}{*}{ التخبلي } & $r$ \\
\hline & & & & $\cdot, \cdot 1$ & $\cdot, 71$. & & $\Lambda$ \\
\hline & & & & $\bullet, \cdot 1$ & $\cdot, 0 \leqslant \mu$ & & $\pi$ \\
\hline & & & & $\cdot,+1$ & $\cdot, 01 Y$ & & 11 \\
\hline & & & & $\bullet, \cdot 1$ & $\cdot, \varepsilon \vee \bar{T}$ & & ז \\
\hline & & & & $\cdot, \cdot 1$ & $\cdot, 0$ Y & & Yर \\
\hline & & & & $\cdot, \cdot 1$ &., $0 Y 1$ & & Tr \\
\hline
\end{tabular}

جدول (Y I ) معاملات الارتباط بين الأبعاد بعضها ببعض و الأبعاد بالدرجة الكلية للمقياس

\begin{tabular}{|c|c|c|c|c|c|}
\hline الآنفعاليى & العقلى & التخجالي & الحجى & النفسحركى المجال & الأبعاد \\
\hline & & & & - & المجال النفسحركى \\
\hline & & & - & צזוT, & المجال الحسى \\
\hline & & 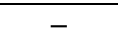 &., $0 \wedge \varepsilon$ &., $0 \wedge \mathrm{V}$ & المجال التخيلي \\
\hline & - & . &., 041 &., $\mathrm{OVH}$ & المجال العقلى \\
\hline 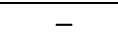 &., $0 \wedge \mathrm{N}$ &., $0 \leqslant$. &., $0 \mathrm{VI}$ &., 007 & المجال الانفعالى \\
\hline$\cdot, \mathrm{\vee} 91$ &., $\mathrm{VA}$. & $\cdot, \mathrm{V} 70$ & $\cdot, \mathrm{V} r \varepsilon$ & $\cdot, V I Y$ & المقياس ككل \\
\hline
\end{tabular}

يتضح من جدول (• (، 1)، Y Y) معاملات الارتباط بين درجة كل مفردة من مفردات المقياس و الدرجة الكلية للمقياس،

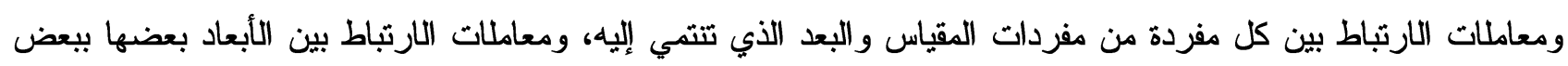
و الأبعاد بالدرجة الكلية للمقياس دالة إحصائياً عند مستوي ( 1 (., ) )، مما يدل ذلك على تلى تمتع المقياس باتساق داخلي. 
(0) تكوين المقياس في صورته النهائية: يتكون المقياس في صورته النهائية من (•ع) عبارة تم صياغتها بصياغة موجبة وسالبة موزعة على أبعاد المقياس على النحو المبين في الجدول الآتي:

جدول (r ا) توزيع البنود على أبعاد المقياس في صورته النهائية

\begin{tabular}{|c|c|c|}
\hline العبار ات السالبة & أرقام العبار ات الموجبة & الأبعاد \\
\hline 1161 & 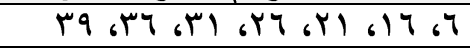 & المجال النفسحركي \\
\hline IV & TY, & المجال الحسى \\
\hline (4) & 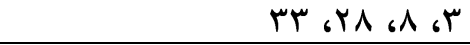 & المجال التخيلي \\
\hline$r \varepsilon, 1 \varepsilon$ & rV 6 Y 96 r & المجال العقلى \\
\hline ro 6. & 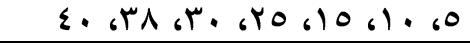 & 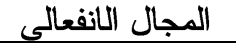 \\
\hline
\end{tabular}

وتم استخدام مقياس ليكرت ذي التدريج الخماسي للتعبير عن استجابات أفراد الدراسة على جميع فقرات المقياسين على التى النحو الآتي: ( دائماً، غالباً، أحياناً، نادراً، أبداً)، بحيث يتم إعطاء القيمة الوزنية (ب) إلى دائماً، (ع) إلى غالباً، (ب) إلى إلى أحياناً،

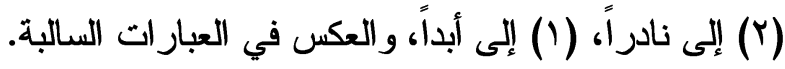
وبهدف الحكم على درجة استجابات أفراد عينة الدراسة على أبعاد المقياسين، تم حساب المدى لمستويات الاستجابة وهو

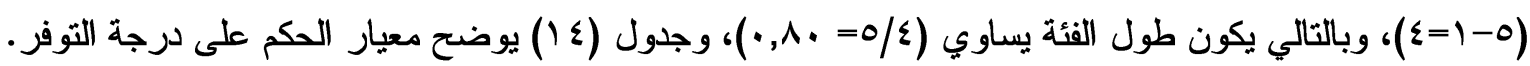
جدول (ع () معيار الحكم على استجابات أفراد عينة الدراسة على المقياسين

\begin{tabular}{|c|c|c|c|c|c|}
\hline منخفضة جدا & منخفضة & متوسطة & مرتفعة & مرتفعة جداً & المتوسط الحسابي درجة التوفر \\
\hline $1, \ldots$ & $1, \wedge$. & $r, T$. & $\boldsymbol{r}, \varepsilon$. & $\varepsilon, Y$. & من \\
\hline $1, \vee 9$ & $r, 09$ & q, & $\varepsilon, 19$ & $0, \ldots$ & إلٍ \\
\hline
\end{tabular}

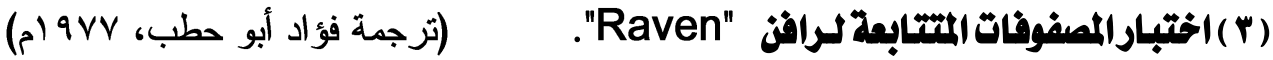

استخدم الباحث اختبار المصفوفات المتتابعة لــ "Raven"-ترجمة فؤاد أبو حطب (9VV () - بهدف تحديد المستوى العقلي العام للطلاب، وذلك لاختيار مجموعة الدراسة من الطلاب الموهوبين، وتم اختيار هذا الاختبار لعدة اعتبارات وهي: إنه من أكثر التر

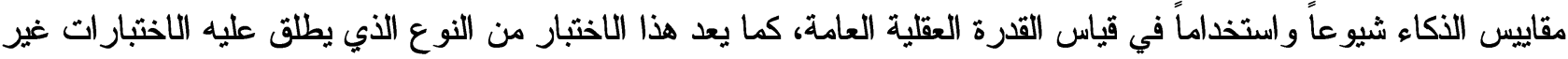

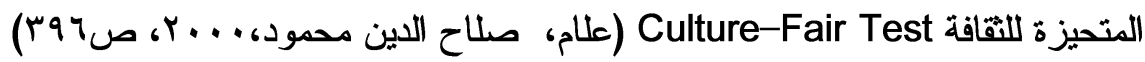

V. توجد علاقة ارتباطية سالبة دالة إحصائياً بين الو الدية اليقظة عقلياً والحساسية الزائدة لدى أفراد عينة الدراسة. ^. يظهر أفر اد عينة الدراسة من آباء و أمهات الطلاب المو هوبين مستوى متوسطاً من الو الدية اليقظة عقلياً. 9. يظهر أفر اد عينة الدر اسة من الطلاب الموهوبين مستوى مرتفعاً من الحساسية الزائدة.

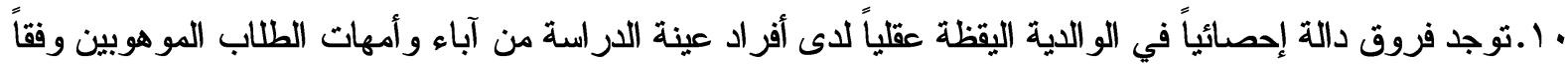

$$
\text { لمتغير الجنس (أب/ أم). }
$$

ا الـا توجد فروق دالة إحصائياً في الحساسية الزائدة لدى أفر اد عينة الدراسة من الطلاب الموهوبين وفقاً لمتغير الجنس (ذكر/ أنثى) r ا.تسهم الو الدية اليقظة عقلياً في التنبؤ بالحساسية الزائدة لدى أفراد عينة الدر اسة من الطلاب المو هوبين.

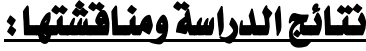

\section{النتائج المتماتلح بـالفرف الأول؛}

ونصه: توجد علاقة ارتباطية سالبة دالة إحصائياً بين الو الدية اليقظة عقلياً والحساسية الزائدة لدى أفراد عينة الدراسة. وللتأكد من صحة هذا الفرض تم حساب مصفوفة معاملات الارتباط المتبادلة بين الدرجة الكلية وأبعاد كل من الو الدية اليقظة

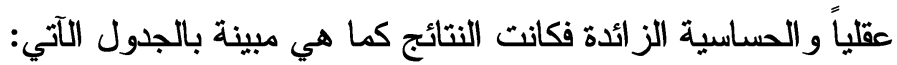


جدول (IV) مصفوفة معاملات الارتباط بين الو الدية اليقظة عقلياً و الحساسية الزائدة لدى عينة الدراسة

\begin{tabular}{|c|c|c|c|c|c|c|c|}
\hline الدساسة الكلية & المجال الانفعالي & المجال العقلي & المجال التخيلي & المجال الحسي & النفسركي & ومستوى الدلات الآلة & المتغير \\
\hline$* * ., 091-$ & $* *,, 7) \varepsilon-$ & $* *, .0 \mathrm{~V} \cdot-$ & $* *, 07 r-$ & $* *,, 7.1-$ & $* *$, orl - & قيمة معامل الارتباط & \multirow[t]{2}{*}{ الاسثماع } \\
\hline$\cdot, \cdot 1$ &.,+1 & $\cdot, \cdot 1$ & $\cdot, \cdot 1$ & $\cdot, \cdot 1$ &.,$\cdot 1$ & مستوى الدلالة & \\
\hline$\left.*_{*}^{*}, \varepsilon \vee\right\urcorner-$ & $* *, 0 \cdot 1-$ & $* *,, \Sigma \vee \wedge-$ & $* * ., 01 Y-$ & $* * ., 09 r-$ & $* *,,\{70-$ & قيمة معامل الارتباط & \multirow[t]{2}{*}{ القبول } \\
\hline$\cdot,+1$ &.,+1 & $\cdot,+1$ & $\cdot,+1$ & $\cdot,+1$ &,++1 & مستوى الدلالة & \\
\hline$* * .$, orq - & $* * ., 011-$ & $* * ., 071-$ & $* * ., 019-$ & $* *, 0 \leqslant Y-$ & **.,orr - & قيمة معامل الارتباط & \multirow{2}{*}{ الانفعالي عي } \\
\hline$\cdot,+1$ & $\cdot,+1$ & $\cdot, \cdot 1$ & $\cdot, \cdot 1$ & $\cdot, \cdot 1$ & $\cdot, \cdot 1$ & مستوى الدلالة & \\
\hline$* *, 0 \leqslant Y-$ & $* * .$, orv - & $* *$, orq - & 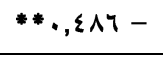 & $* *$, * ₹9r - & $* *$, orv - & قيمة معامل الارتباط & \multirow{2}{*}{ في الذاتم } \\
\hline$\cdot, \cdot 1$ & $\cdot,+1$ & $\cdot, \cdot 1$ & $\cdot, \cdot 1$ & $\cdot, \cdot 1$ & $\cdot,+1$ & مستوى الدلالة & \\
\hline 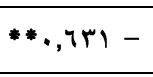 & $* *$, IYY - & $* * ., 094-$ & $* * ., 097-$ & **.,Trr - & $* *, y \cdot r-$ & قيمة معامل الارتباط & \multirow{2}{*}{ اللوالية الإلية } \\
\hline,++1 & $\cdot,+1$ &,++1 & $\cdot,+1$ & $\cdot,+1$ &,++1 & مستوى الدلالة & \\
\hline
\end{tabular}

* * القيمة دالة عند مستوى 1 * , .

يتضح من جدول (IV) على مستوى الدرجات الكلية وجود علاقة ارتباطية سالبة بين الدرجة الكلية للوالاية اليقظة عقلياً و الدرجة الكلية للحساسية الزائدة، وبلغت قيمة معامل ارتباط بيرسون (- ابا7, • ) وهي دالة إحصائياً عند مستوى (1 • , •)، أما على مستوى أبعاد الو الدية اليقظة عقلياً، فقد جاءت المعاملات مرتبطة ارتباطاً سالباً ودالاً إحصائياً عند مستوى دلالة إحصائل إلهائية (1 •., •) بالدرجة الكلية للحساسية الزائدة، ويشير ذلك إلى أنه كلما زادث الو الدية اليقظة عقلياً انخفضت الحساسية الزائدة، وكلما انخفضت الو الدية اليقظة عقلياً زادت الحساسية، مما يؤكد على الحاجة إلى التعامل مع الأبناء بطريقة واعية في إطار من القبول و الاستماع و الوعي الانفعالي والتحكم في الذات مما يؤدي بدوره إلى التقليل من الحساسية الزائدة، ويمكن تفسير هذه النتيجة في ضوء المحاور الآتية:

تجاوز أنظمة الثواب والعقاب التقاليلية؛ تعمل الوالدية اليقظة عقلياً على الابتعاد عن أنظمة الثواب والعقاب التقليدية (كالتعزيز و الإهمال و النقد الشديد) وتفعيل أنظمة الثواب و العقاب في إطار من اليقظة العقلية للوالدين (كالاستماع بانتباه، و النقد

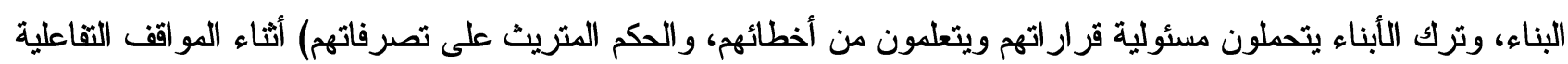

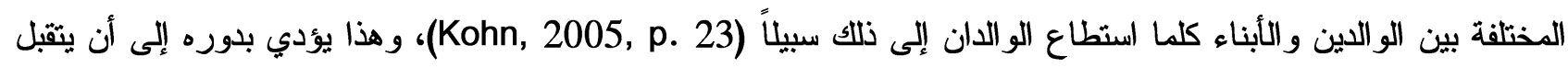

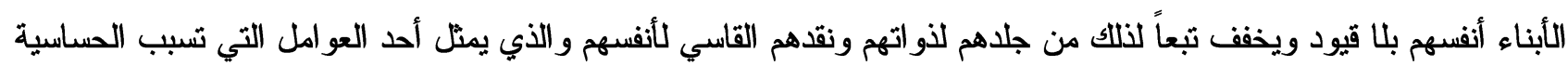
الز ائدة لديهم، و أفرد الباحث مكاناً في تفسير هذه النتيجة لأنظمة الثو اب و العقاب وذلك لأهميتها في التربية على العموم وفي التقليل من مظاهر الحساسية لدى الموهوبين بوجه خاص؛ فالأبناء الموهوبون قد يتقبلون التوجيه المبني على الأحكام المتريثة والقبول و الاستماع و الوعي و التحكم في الذات من قبل الآباء والأمهات بشكل بعيد عن العساسية و الرفضاء.

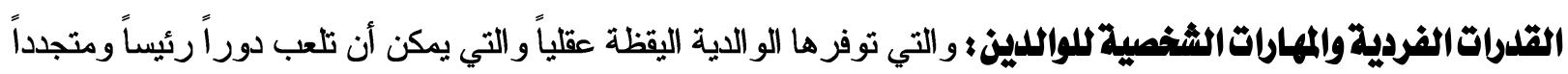

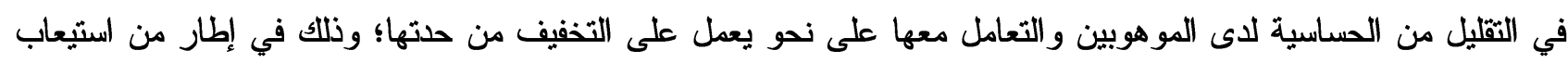

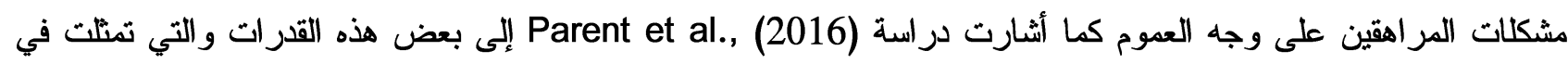

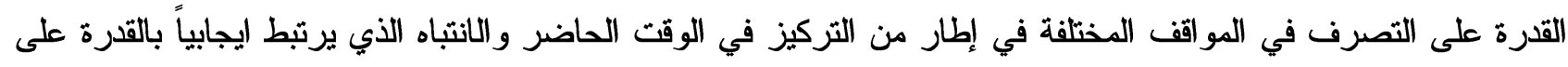

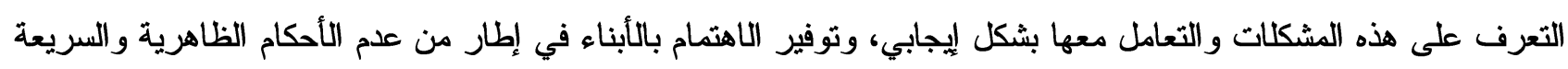
على تصرفاتهم مما يسمح بالحكم المتريث على هذه المشكلات و السير في اتجاه استيعابها، و التنظيم الذاتي الذي يمكن الو الدين من التحكم في انفعالاتهم والتعامل المنضبط مع هذه المشكلات، وانخفاض مستويات القسرية والتسلط و التحكم غير الفعال ويمثل

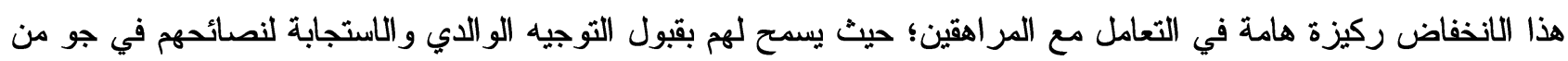


الدفء و الأريحية، وترتبط صر احة الو الدين ارتباطاً سالباً مع ممارسات الأبوة و الأمومة السلبية و التي تزيد من مشكلات المر اهقين

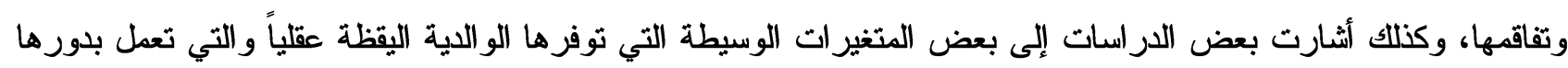

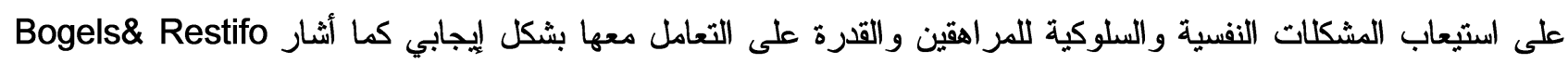

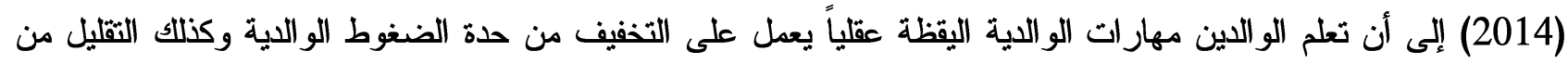

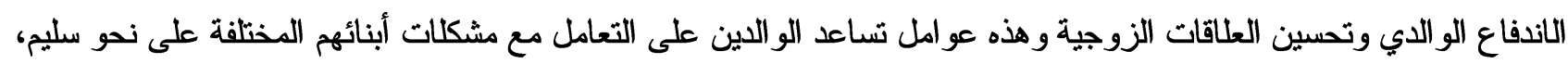

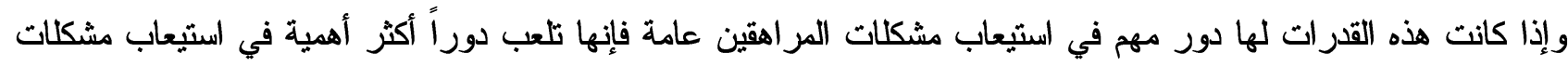

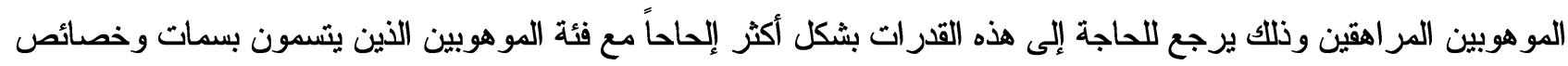

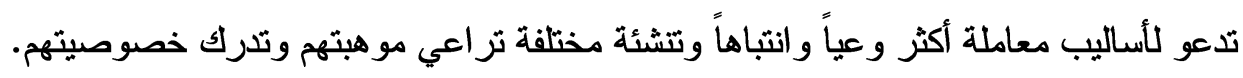

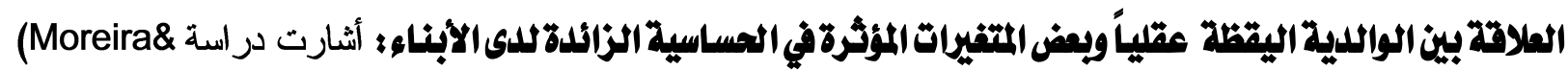

الى أن الو الدية اليقظة عقلياً ترتبط إيجابياً باليقظة العقلية لاى الأبناء؛ فكلما تحلى الو الدان بقدر من اليقظة العقلية كلما زادت اليقظة العقلية لاى الأبناء في ظل توفير قدر من الاهتمام والرحمة في التفاعلات بين الو الدين و الأبناء وهذا يمثل بيئة أسرية مثلى لتتمية اليقظة العقلية للأبناء؛ ومن ناحية أخرى هذه اليقظة ترتبط سلبياً بالحساسية الزائدة لدى الأبناء (Freshwater, 2017; Soons, Brouwers\& Tomic, 2010) حيث تلعب دوراً رئيسيًا في: تنظيم و إدارة العو اطف بقدر يسمح بالتقليل من الحساسية في المو اقف المختلفة، فهم الذات ومطالبها وحاجاتها وبالتالي الاستجابة للمثيرات

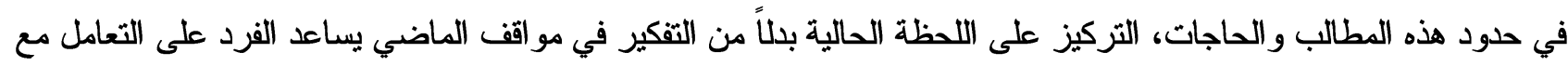

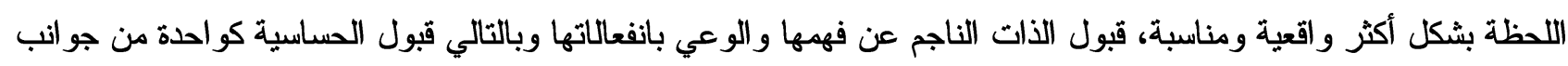

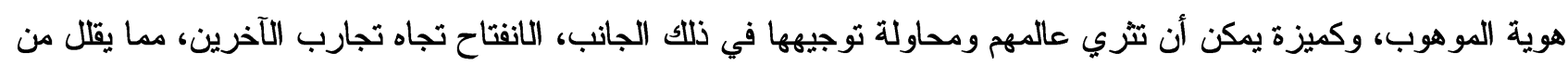
فرص استجابة الموهوب بطريقة اعتيادية وغير مرنة ومفرطة ويزيد من فرص استجابته التفاعلية بدون حساسية، كما أشارت

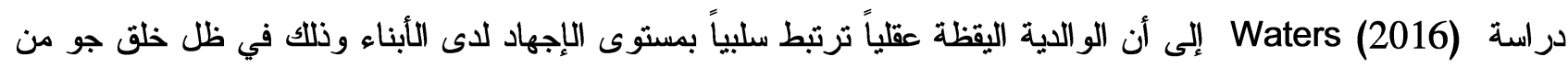

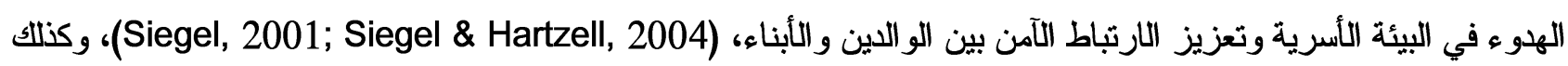

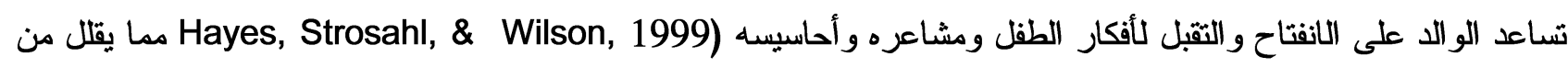

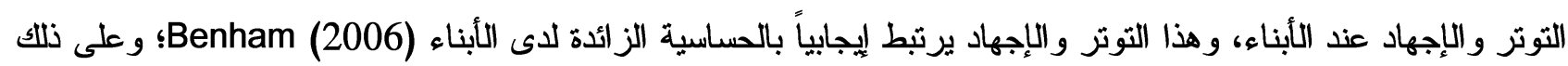

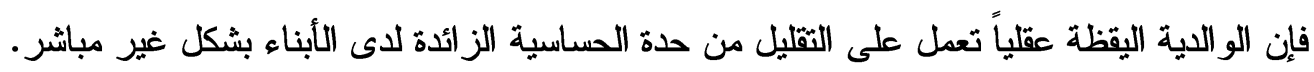

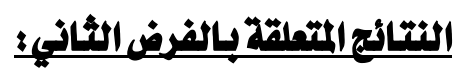

ونصه: يظهر أفر اد عينة الدر اسة من آباء وأمهات الطلاب الموهوبين مستوى" متوسطاً من الو الدية اليقظة عقلياً. وللتأكد من صحة هذا الفرض نم حساب المتوسطات والانحر افات المعيارية لمقياس الو الدية اليقظة عقلياً وأبعاده ثم مقارنتها بمعيار الحكم على المتوسط لبيان درجة توفر كل بعد؛ فكانت النتائج كما هي مبينة بالجدول الآتي:

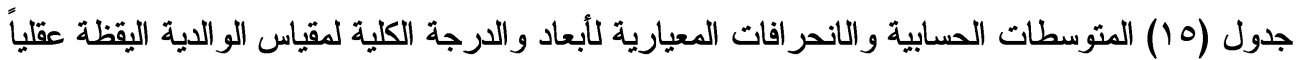

\begin{tabular}{|c|c|c|c|}
\hline درجة التوفر & الانحر اف المعياري & المتوسط الحسابى & الأبعاد \\
\hline متوسطة & $r, V \varepsilon Y$ & $r, 1 \wedge$ & الاستماع \\
\hline متوسطة & r,IMr & r, ro & القبول \\
\hline متوسطة & $r, T \leqslant 1$ & $r, i v$ & الوعى الانفعالي \\
\hline متوسطة & rו, & $r, r$. & التحكم في الذات \\
\hline متوسطة & r,909 & r, r & الدرجة الكلية لمقياس الو الدية اليقظة عقلياً \\
\hline
\end{tabular}

يتبين من جدول (10) أن درجة الوالدية اليقظة عقلياً لاى عينة الدراسة جاءت منوسطة؛ حيث بلغ متوسطها الحسابي

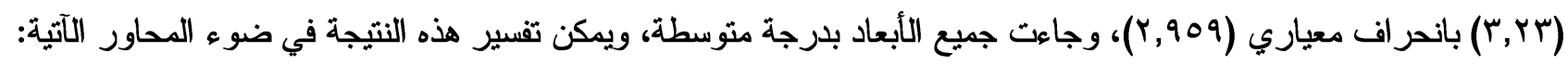


طبيعة المرحلة العمرية للأبناء:حيث تتسم هذه المرحلة بمحاولات الاستقلال المستمرة من جانب المراهق، وهذه المحاولات

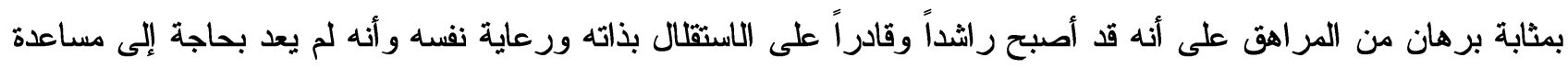

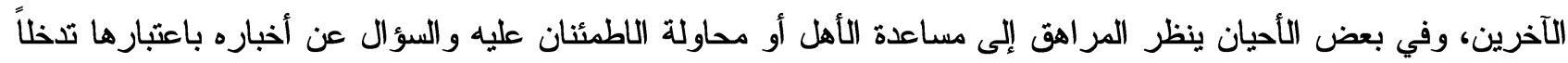
في شؤونه الخاصة، فيرفض ذلك ويقابله بعدم القبول، فيصبح الأهل أمام مأزق حقيقي؛ إذ كيف يمكنهم مساعدة أبنائهم إذا كانت

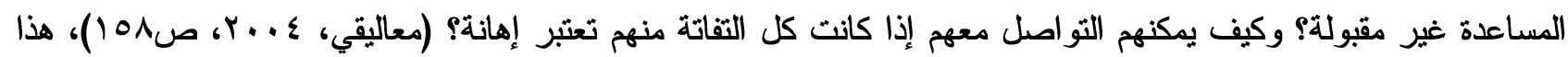

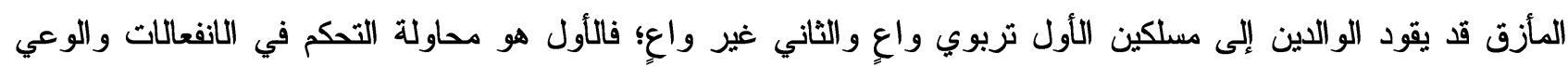

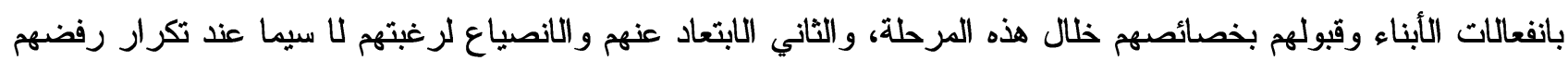

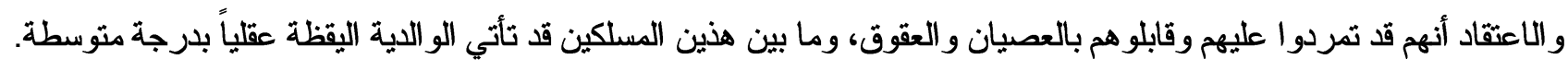

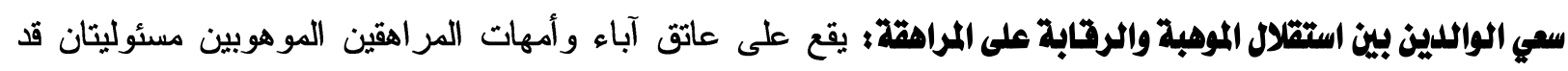
تتعارضان أحياناً وهما مسئولية حماية المر اهث، ومسئولية الحفاظ على الموهبة؛ فحماية المراهت تثضمن ثوفير البيئة المناسبة لنموه، وتوفير الاحتياجات المادية والنفسية له، ومحاولة صياغة شخصيته وتكوين معالم توجهاته ومفاهيمه نحو ذاته ونحو العالم

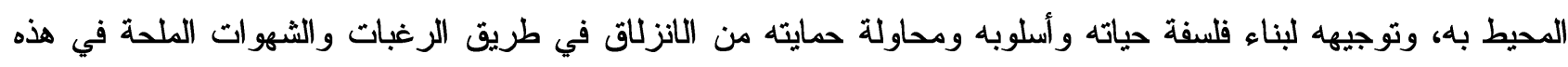

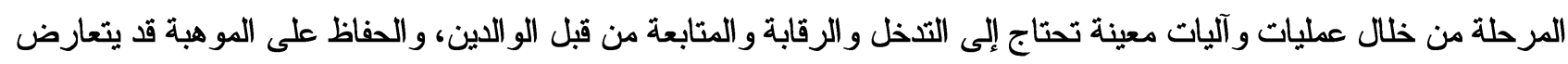

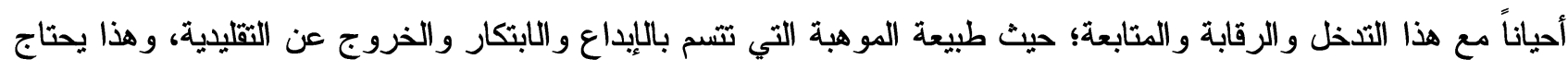
إلى نوع من التوسط في إدارة عملية تنشئة المراهق الموهوب ما بين الرقابة والاستقلال؛ فهذه التشئة إن لم تأخذ في حسبانها

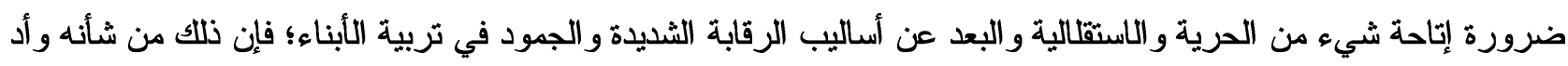
أنماط التفكير ذات الصلة بالمو هبة والإبداع، وعليه فإن الأسر ذات الوعي التربوي المرتفع تدرك حتمية الوسطية في تربية أبنائها

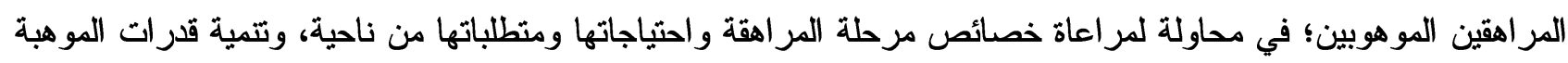

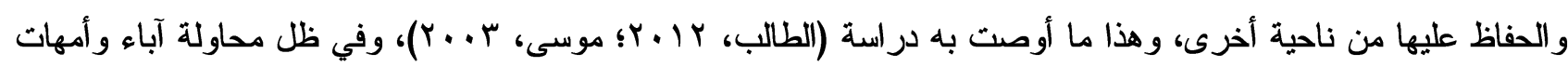
المو هوبين المر اهقين الوصول إلى هذا التوسط قد تأتي هذه النتيجة في إطار من المعقولية و المنطقية.

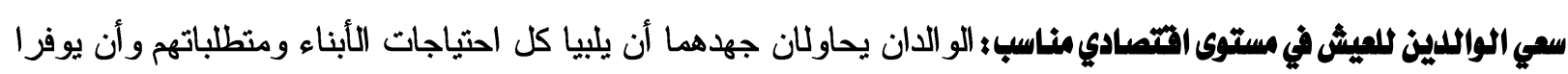
لهم مستوى راقٍ من المعيشة الاقتصادية و الاجتماعية و التعليمية بما يتناسب مع مو هبتهم وقدراتهم، وهذه المحاولات قد تأخذ من

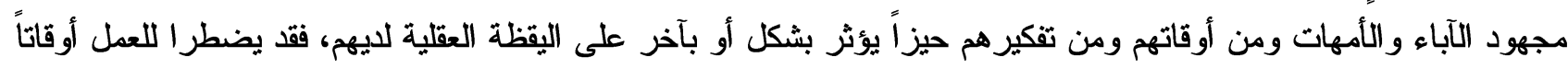

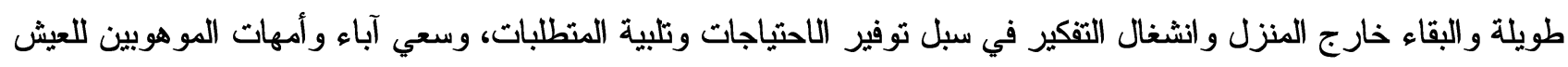

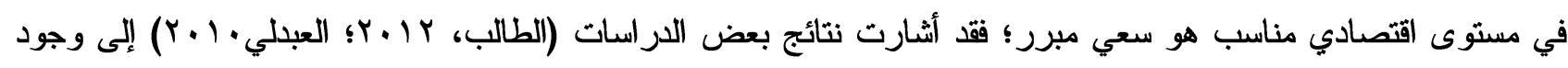

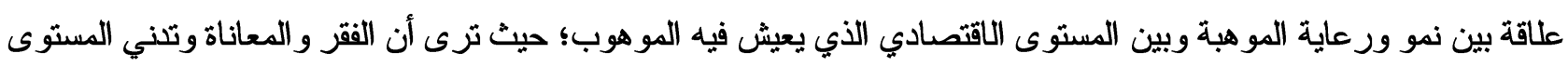

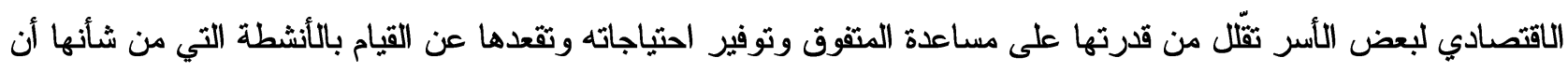
تثري مو هبته وتزيد من حصيلته المعرفية، ومن جهة أخرى قد يؤثر ذلك على صحته النفسية ويولد لايه بعض مشاعر التهر الإحباط و الشعور بالعجز مما ينعكس على مو هبته بشكل سلبي ويجعله يستشعر المناخ النفسي الأسري عموماً على نحو سلبي؛ فالبئئة

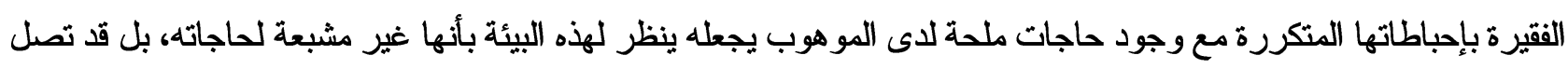

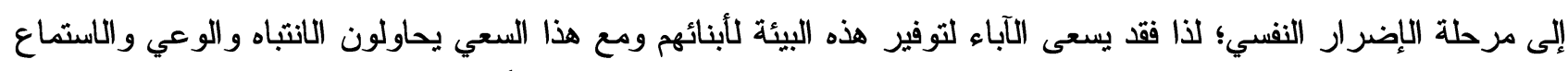
و الحضور مع أبنائهم، وما بين هذا السعي وهذه المحاولات قد ثأتي الوالدية اليقظة عقلياً متوسطة.

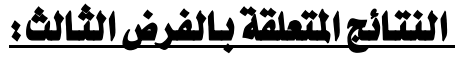

ونصه: يظهر أفر اد عينة الدر اسة من الطلاب الموهوبين مستوى مرتفعاً من الحساسية الزائدة. 
وللتأكد من صحة هذا الفرض تم حساب المتوسطات والانحر افات المعيارية لمقياس الحساسية الزائدة ثم مقارنتها بمعيار الحكم على المتوسط لبيان درجة توفر كل بعد؛ فكانت النتائج كما هي مبينة بالجدول الآتي:

\begin{tabular}{|c|c|c|c|}
\hline درجة التوفر & الانحر اف المعياري & المتوسط الحسابي & الأبعاد \\
\hline 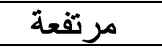 & r,TVO & $\varepsilon, \varepsilon \varepsilon$ & المجال النفسركى \\
\hline مر تفعة & $r, \Lambda \leqslant r$ & $\varepsilon, 01$ & المجال الحسي \\
\hline مرتفعة & r,Tr. & $\varepsilon, \mu_{Y}$ & المجال التخيلي \\
\hline مرتفعة - مرية & r,vor & $\varepsilon, r_{0}$ & المجال العقلى \\
\hline 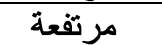 & $\Gamma, \Sigma \wedge \uparrow$ & $\varepsilon, r$. & المجال الانفعالى \\
\hline مر تفعة & $r, T \vee V$ & $\varepsilon, \Gamma \wedge$ & الدرجة الكلية لمقياس الحساسية الزائدة \\
\hline
\end{tabular}

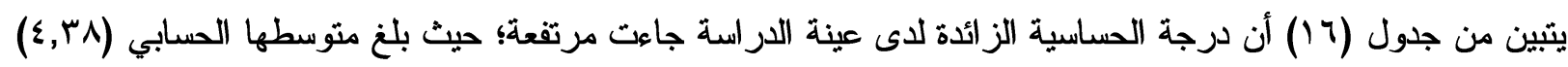

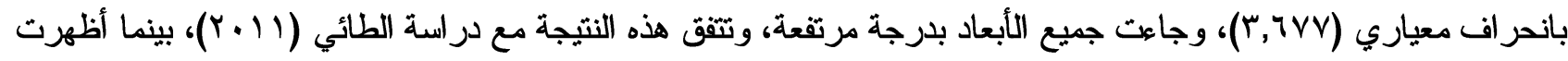

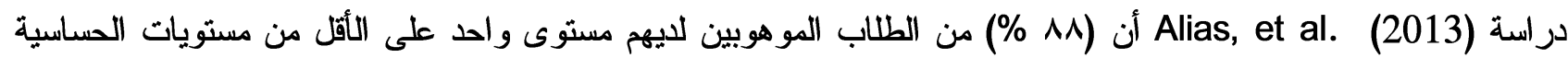
المفرطة الخمسة بشكل مرتفع، كما أظهرت أنه ليس كل الطلاب الموهوبين لديهم نسبة عالية من الحساسية المفرطة، وأنه على مانى الرغم من أن الطلاب المو هوبين لايهم ثقريبا نفس المستوى من الذكاء، لكن لديهم خصائص مختلفة في الحساسية المفرطة، ويمكن تفسير هذه النتيجة في ضوء المحاور الآتية:

طبيعة المرحلحالعمرية؛ هناك فترات عمرية معينة يمر بها الفرد في مراحل النمو تزداد فيها حساسيته للمو اقف والأحداث

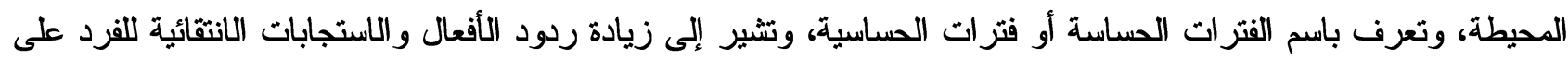
كل ما يحدث في الواقع المحيط وفي العالم من حوله، ويظهر ذلك في مظاهر النمو المختلفة (الإدراكي، والفكري، والعاطفي، والكئ و الشخصي، والحركي، والاجتماعي). (Shavinina, 1999, p. 26)، وتعد مرحلة المراهقة أحد هذه الفترات التي تتسم بالحساسية، وهذا أمر طبيعي في هذه الفترة التي يكون فيها المر اهق موزع الانفعالات بين ذاتين: الذات الحقيقية والذات المثلى؛

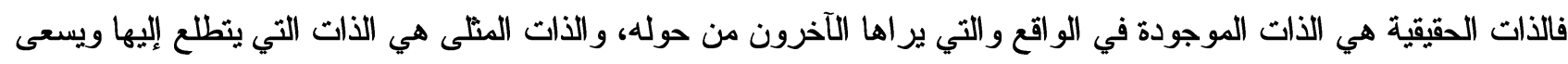

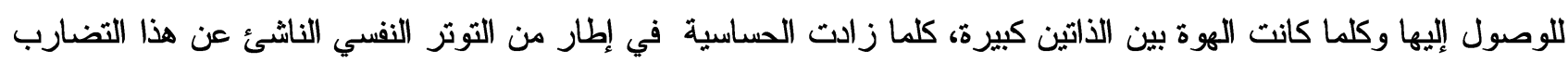

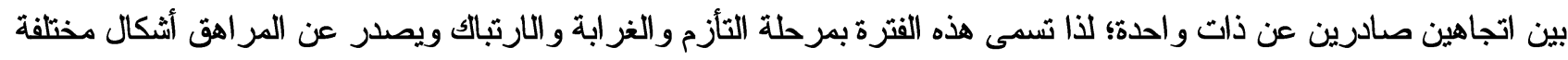
من السلوك تكشف عن مدى ما يعانيه من حساسية زائدة لأن المراهق يعاني فيها صعوبة فهر محيطه و إثباع حاجاته النفسية

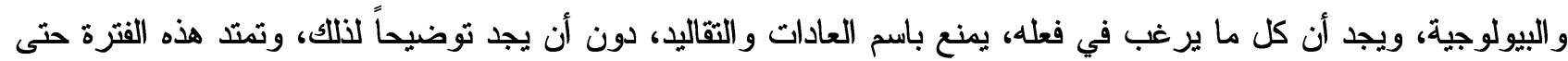

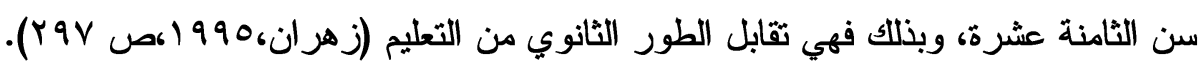

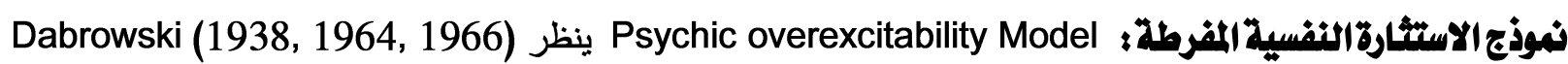
إلى الحساسية الزائدة على أنها أحد مظاهر النمو الأساسية والمميزة للموهوب خاصة في فترة المراهقة وترجع هذه الحساسية

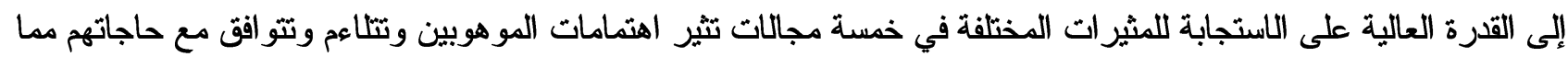

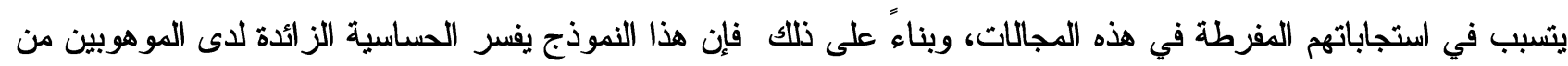

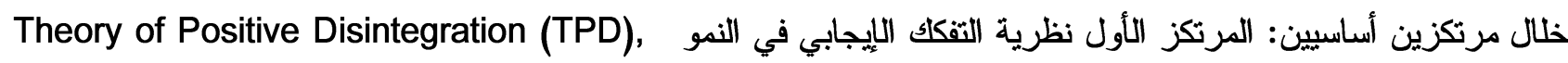
حيث تقسر هذه النظرية نمو الفرد الموهوب تفسيراً مختلفاً عن نظريات النمو الأخرى في أربعة

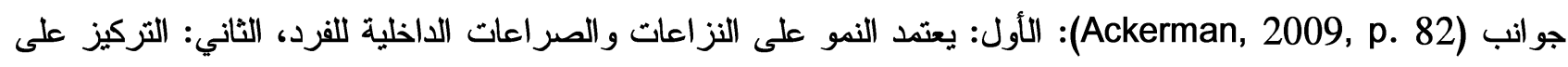
الأدوار العاطفية المؤثرة في النمو، الثالث: النمو الإيجابي يتضمن عملية التفكك حيث تستبدل المستويات الدنيا والضعيفة "غير مميزة للشخصية" من بنية الثخصية بالمستويات العليا والقوية "المميزة للشخصية". الرابع: لا يرتبط النمو بمرحلة عمرية معينة إلا أن عملية التقكك غالبًا ما تظهر بشكل واضح خلال سنوات المراهقة عندما يتطور القلق بسبب الصراع فيثير المشاعر السلبية

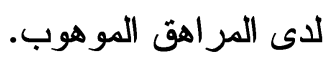


ومن خلال هذه الجوانب الأربع يستطيع الباحث تفسير النتيجة الحالية حيث تكثر الصراعات والأدوار العاطفية في مرحلة المراهقة والتي تمثل عند Dabrowski الفرضية الأساسية في التطور السريع والنمو المتزايد للمراهق (مارد وعبد الكاظم،

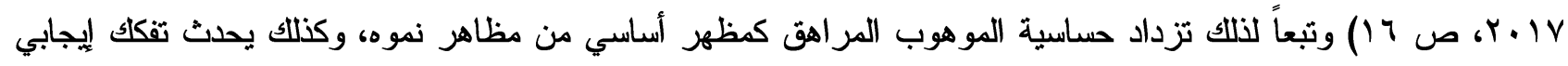

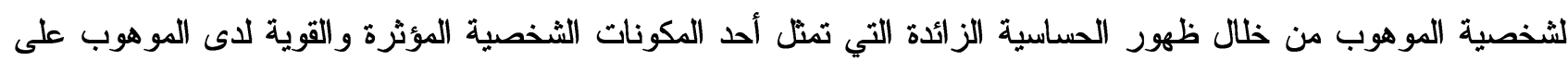
حساب بعض الخصائص الأخرى غير المميزة لشخصيته. و المرتكز الثاني ملاءمة مجالات الحساسية الخمسة لحاجات وخصائص الموهوبين؛ حيث أشارت دراسة (الإقبالي، 1 1 ـ ب؛

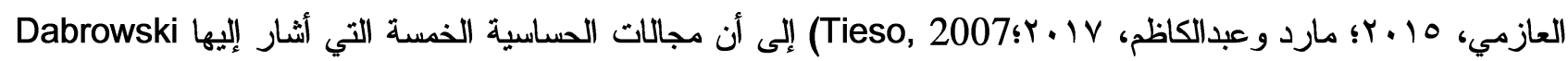
تثو افق مع خصائص الموهوبين وحاجاتهم؛ فالحساسية في المجال الحركي يعبر عنها بالحركة الزائدة، والحماس في العمل،

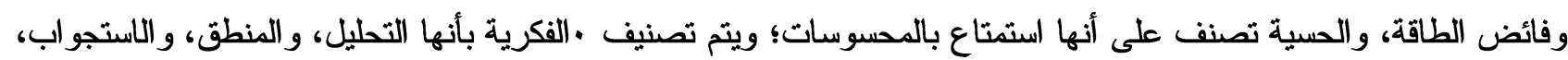

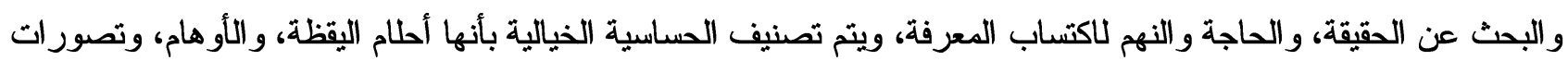
قوية من الخبرة، وتصنف الحساسية العاطفية بأنها قوة الروابط مع الآخرين ومشاعر التعاطف و الشعور بالوحدة العاطفية، وهذا التاؤم و التو افق بين خصائص المو هوبين ومجالات الحساسية يؤدي إلى زيادة الحساسية عند هذه الفئة.

خمسائص وسمات الموهوبين: وكذلك يعزو الباحث هذه النتيجة إلى الخصائص و السمات المميزة للموهوبين والتي تعمل كمحركات لزيادة الحساسية عندهم؛ فالمراقبة الشديدة للبيئة و التفكير العميق والتقصص و الاستغراق بشكل أكثر في فهم سلوك

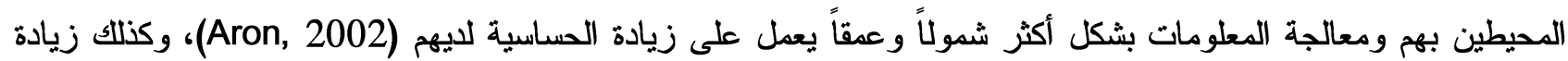
الوعي لاى هذه الفئة وتعديه من انفعالاتهم وسلوكهم لانفعالات وسلوك الآخرين يزيد ويقوي من استجاباتهم وردود أفعالهم تجاه ولهاه هذه الانفعالات و السلوكيات (Mendaglio, 1995) وكذلك تكوين ارتباطات شرطية عالية للمواقف و الأشخاص و الأماكن التي وني تؤثر في الانفعالات يؤدي لتكرار هذا التأثر في المواقف المشابهة في إطار من الذاكرة الوجدانية القوية التي تعمم التجارب المتشابهة، وكذلك ميل المو هوبين للأحكام القاسية على أنفسهم ونقدهم الشديد لذو اتهم، كل هذه الخصائص تؤدي إلى زيادة الحساسية

عند هذه الفئة.

\section{النقائج المتماقلحبالفرض الرابع:}

ونصه: توجد فروق دالة إحصائياً في الوالدية اليقظة عقلياً لدى أفراد عينة الدراسة من آباء وأمهات الطلاب الموهوبين وفقاً لمتغير الجنس (أب/ أم). وللتأكد من صحة هذا الفرض تم استخدام اختبار "ت" لحساب دلالة الفروق بين المتوسطات على مقياس الو الدية اليقظة عقلياً فكانت النتائج كما هي مبينة بالجدول الآتي: جدول (1) نتائج اختبار "ت" لحساب دلالة الفروق بين المتوسطات على مقياس الو الدية اليقظة عقلياً

\begin{tabular}{|c|c|c|c|c|c|c|c|}
\hline الدلالة & قتيمة & الحرجة & المعياري الانحراف & المستوسطي & العدد & التباين & الو الدياس \\
\hline \multirow{2}{*}{$\cdot, \cdot 1$} & \multirow{2}{*}{$r, \cdot 1 \varepsilon$} & \multirow{2}{*}{71} & $0,17 \pi$ & 171,19 & ro & أب & \multirow{2}{*}{ عقليا } \\
\hline & & & $0,7 \cdot \varepsilon$ & IV.,Tr & $\varepsilon 0$ & أم & \\
\hline
\end{tabular}

يتضح من جدول (1) أنه نوجد فروق ذات دلالة إحصائية عند مستوى (1 +. •) بين متوسطات درجات الآباء و الأمهات

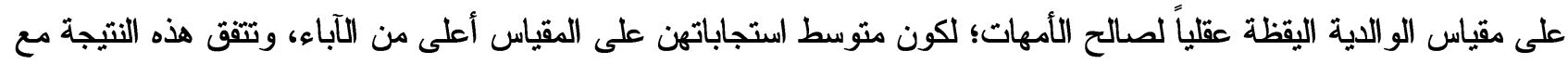

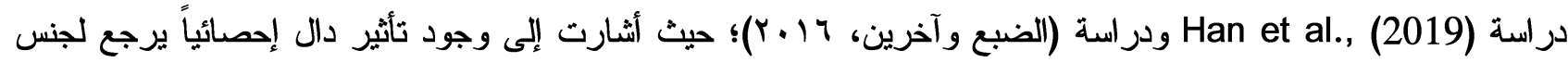

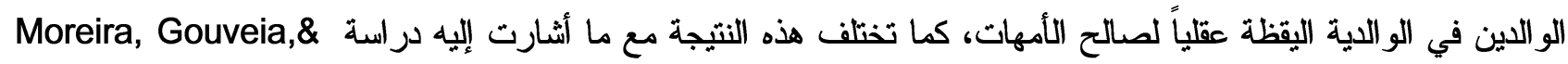
Canavarro, (2018) 
الاختاف في النتائج إلى اختاف طبيعة المجتمعات وثقافتها و التي تؤثر بشكل واضح في أساليب الو الدية المختلفة وعادات الأسر

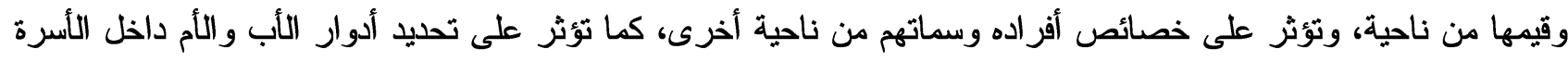

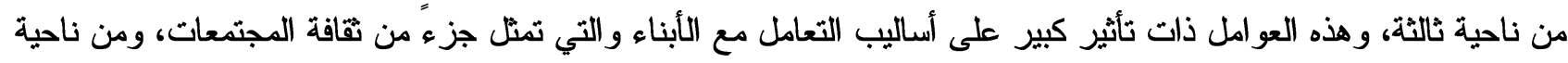

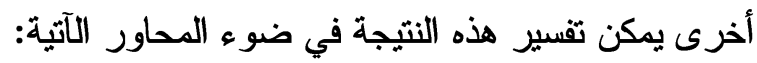

القيود الزمنية وضغوط العمل على الآباء؛ تقع على عاتق الآباء مسئوليات كثيرة تؤدي لبعض القيود الزمنية والضغوط، و هذه القيود والضغوط قد تكون مسئولة جزئياً عن ابتعاد الآباء عن القيام بدور أكثر نشاطاً في الاهنمام بأبنائهم والاستماع إليهر على نحو يعكس التتافس المجتعي المتزايد والأعباء الاقتصادية الكبيرة والتي تحتم على الآباء العمل لساعات أطول وأكناء وأكثر وقداء

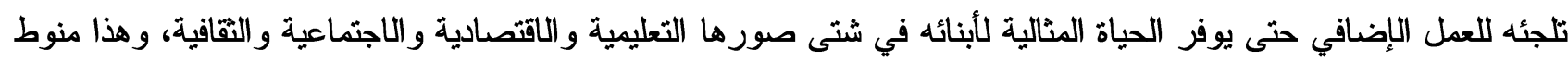
في الأصل بالآباء ومن مسئولياتهم الرئيسة حتى وإن ساعدتهم الأمهات (Hoghughi and Long, 2004, p. 380) ويؤدي وفئي

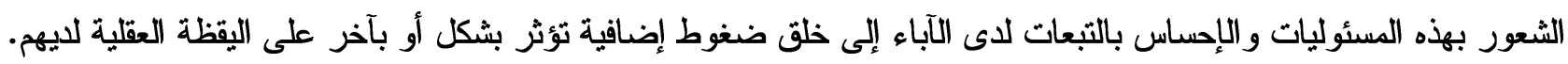
بعض الأساليب الواللية السالييلة؛ تختلف طبيعة علاقات الأبناء مع الآباء عنها مع الأمهات وهذا الاختاف يظهر في مر احل

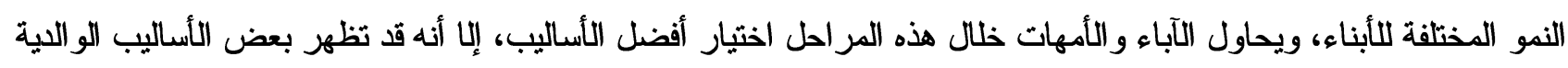
السلبية في علاقة الأبناء مع الآباء بشكل أوضح من علاقته مع الأمهات، ومنها الأسلوب العدائي والتحكمي (كالسيطرة الزائدة)، و أسلوب العنف والقسوة (كالصر اخ والتهديد)، وأسلوب التحكم المادي (كالانضباط بالضغوط المادية)، وأسلوب النقد الشديد،

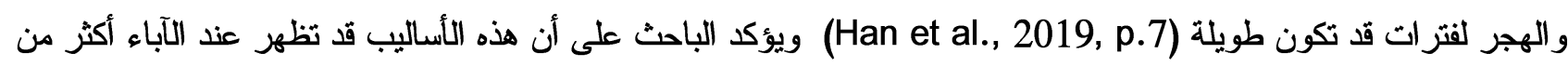
الأمهات نظراً لطبيعة الرجل الواقعية والعقلانية بشكل أكثر من الطبيعة العاطفية من ناحية، ولقوامة الرجل الرجل على أبنائه وأسرته

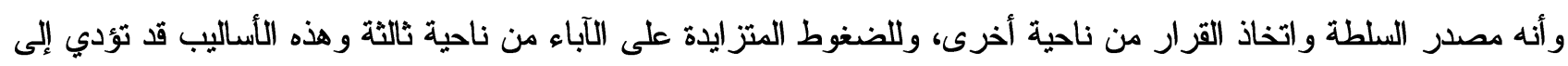
سلوكيات سلبية من الأبناء وتتعارض مع أساليب وآليات الو الدية اليقظة عقليةاً. طبيعة الأمهات اتستطيع الأمهات التعبير عن مشاعرها تجاه أبنائها بشكل عاطفي أوضح من الآباء، كما أنها تستخدم بعض

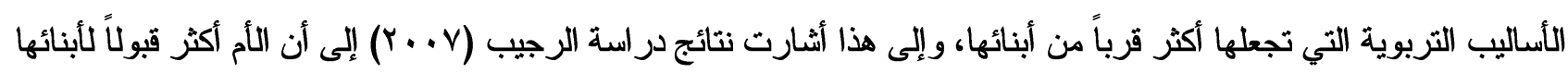

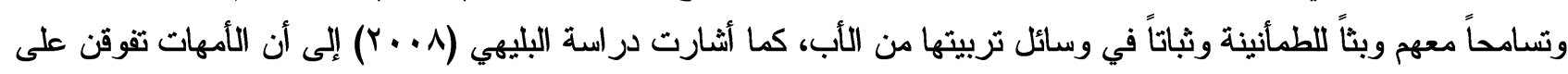

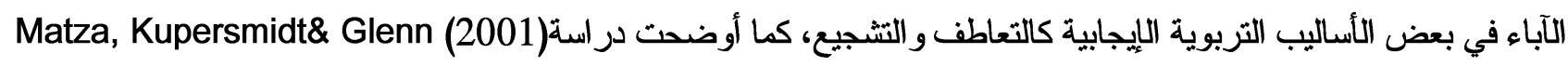
أن الأبناء يحصلون على الاستقالية من ناحية أمهاتهم أكثر من آبائهم، وهذا يجعلهم كمر اهقين راضين عن تلبية رغباتهر التئي يسعون إليها في هذه المرحلة العمرية.

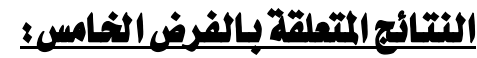

ونصسه: لا توجد فروق دالة إحصائياً في الحساسية الزائدة لدى أفراد عينة الدراسة من الطلاب الموهوبين وفقاً لمتغير الجنس

وللتأكد من صحة هذا الفرض تم استخدام اختبار "ت" لحساب دلالة الفروق بين المتوسطات على مقياس الحساسية الزائدة،

فكانت النتائج كما هي مبينة بالجدول الآتي:

جدول (9 1) نتائج اختبار "ت" لحساب دلالة الفروق بين المتوسطات على مقياس الحساسية الزائدة

\begin{tabular}{|c|c|c|c|c|c|c|c|}
\hline مستوى & قيمة اختبار & الدرجة & المعياري & الحستوسط & العدد & التباينر & \\
\hline \multirow{2}{*}{ ג', } & \multirow{2}{*}{$1, \cdot r \varepsilon$} & \multirow{2}{*}{$4 \Lambda$} & $\varepsilon, 9 \wedge Y$ & $100, \mathrm{rr}$ & $r$. & طالب & \multirow{2}{*}{ الز ائدة } \\
\hline & & & $\varepsilon, T Y I$ & $10 \xi,{ }^{\prime}$ & $\varepsilon$. & طالبة & \\
\hline
\end{tabular}

يتضح من جدول (9 (1) أنه لا توجد فروق ذات دلالة إحصائية بين متوسطات درجات الطلاب الموهوبين على مقياس

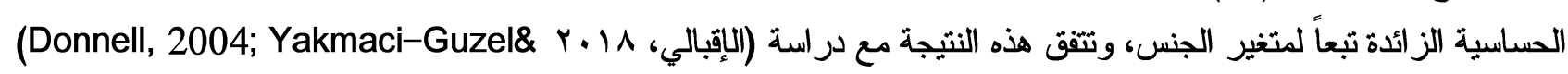


A Akarsu,2006)

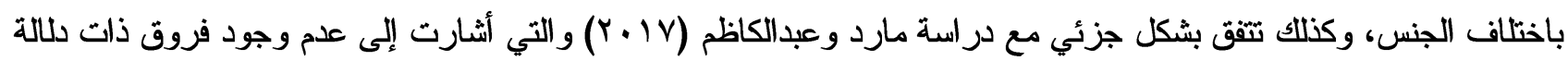
إحصائية في الحساسية الز ائدة لدى الطلاب الموهوبين باختاف الجنس في المجالات (النفسحركية، الحسية، التخيلية، العقلية) بينما

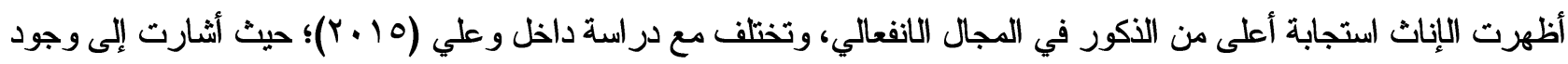

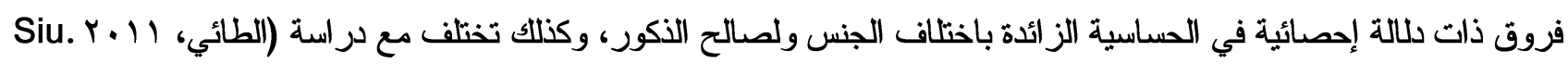
2010)؛ حيث أشارت إلى وجود فروق ذات دلالة إحصائية في الحساسية الزائدة باختلاف الجنس ولصالح الإناث، ويفسر الباحث هذا الاختاف في تأثير الجنس على الحساسية الزائدة في ضوء اختلاف عينة الدراسة في هذه الدراسات عن عينة الدراسة

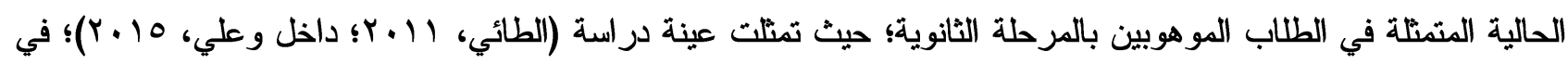
طلاب الجامعة، بينما كانت عينة دراسة (2010) . Siu. من الأطفال الموهوبين بهونج كونج، وهذه الفئات تختلف عن فئة المو هوبين

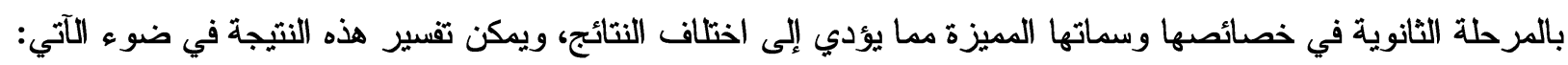

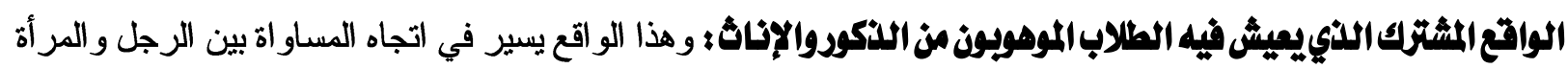
في كثير من المناحي كالدر اسة والعمل، وهذا يتضح في تداخل الأدوار بين الرجل و المر أة في مجتمعاتتا بشكل متسار ع وملحوظ؛ فالمرأة دخلت ميدان العمل وتتافس الرجل في معظم ميادين العمل المختلفة وذلك في إطار من اهنمام الأسرة بتعليم البنات

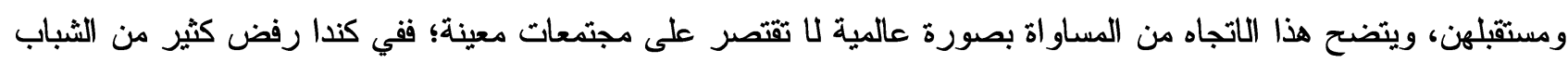

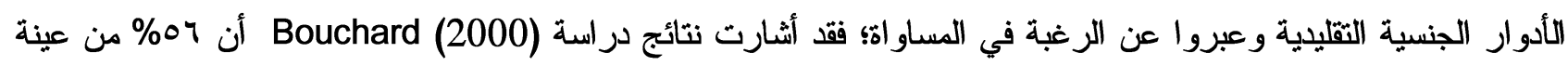

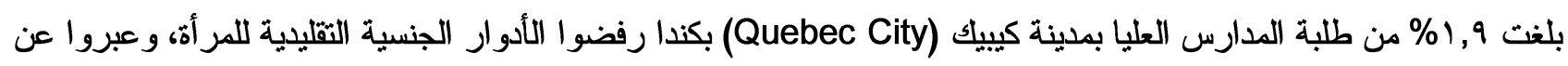
رغبتهن في مشاركة الرجل في معظم أدواره، وكل هذه عو امل قد تؤدي إلى عدم وجود اختافات في النمو العاطفي ولا الانفعالات تزجع لمتغير الجنس.

الأنعاط العادللة في التعامل مع الأبناء؛ يسعى غالب الآباء والأمهات إلى توفير أنماط عادلة في التعامل مع أبنائهر هذه الأنماط بعيدة عن التقرقة المبنية على الجنس ولا الشكل ولا القدرات، ولعل هذا ما توفره الوالدية اليقظة عقلياً؛ حيث يتعامل الو الدان في ظل الو الدية اليقظة عقلياً بمبدأ المساواة مع جميع الأبناء وهذه المساواة مبنية على إدراك الفئ الفروق الفردية بين الأبناء ومحاولة التعامل معها بالشكل اللائق الذي لا يخل بهذا المبدأ بل بعمل على ترسيخه في إطار من القبول و الوعي الانفعالي و التحكم

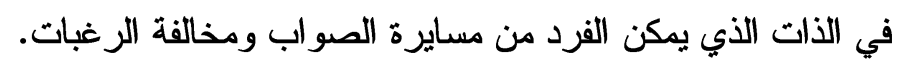

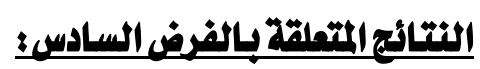

ونصه: تشهم الو الدية اليقظة عقلياً في التتبؤ بالحساسية الزائدة لدى أفراد عينة الدراسة من الطلاب الموهوبئ. وللتأكد من صحة هذا الفرض تم حساب تحليل الانحدار المتعدد (باستخدام الطريقة "Enter") لمعرفة مدى تأثير الوالدية

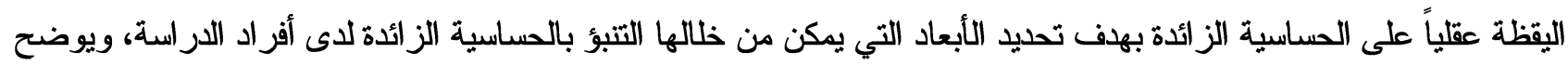
جدول (·r)، (Y) (Y) نتائج هذا التحليل.

جدول (·r) نتائج تحليل التباين ومعامل الارتباط المتعدد ومعامل التحديد لنموذج الاندار المتعدد بين الحساسية الزائدة وأبعاد الوالدية اليقظة عقلياً

\begin{tabular}{|c|c|c|c|c|c|c|c|}
\hline $\begin{array}{l}\text { التحديد } \\
\text { R2 } \\
\text { Re }\end{array}$ & $\begin{array}{c}\text { معامل الارنتباط } \\
\text { R } \\
\text { R }\end{array}$ & $\begin{array}{l}\text { الإحصائية } \\
\text { Sig. } \\
\text { Sigلة }\end{array}$ & $\begin{array}{c}\text { المحسوبة } \\
\text { F }\end{array}$ & $\begin{array}{c}\text { المربعات } \\
\text { MS } \\
\text { Mتوسط }\end{array}$ & الحربية & $\begin{array}{c}\text { المربعات } \\
\text { SS }\end{array}$ & المصدر \\
\hline., $.9 Y$ & $\cdot, r \cdot r$ & $\cdot, \cdots 1$ & 7, rYo & $19 \mathrm{~V}, 07 \mathrm{~V}$ & $\varepsilon$ & AOr,VIr & الانحدار \\
\hline & & & & rq, ए०५ & 70 & $90 \% \varepsilon, \varepsilon 10$ & الخطاً \\
\hline & & & & & 79 & $1 . r \wedge \Lambda, 1 Y \wedge$ & المجموع \\
\hline
\end{tabular}

جدول (Y) معاملات الانحدار المتعدد ودلالتها الإحصائية الو الدية اليقظة عقلياً 


\begin{tabular}{|c|c|c|c|c|c|}
\hline الإحصائية & قيمة "ت" & معامل الانحدار & المعياري & الانحدار & الاستر اتيجيات \\
\hline$\cdot, \ldots$ & $* * *,, \vee \leqslant Y$ & & $7, Y \backslash 1$ & rq, ह10 & الثابت \\
\hline$\cdot, \cdots$ & ***0, & •, $\varepsilon \Psi Y$ & $\cdot, r \leqslant 0$ & צזו, & الاستماع \\
\hline$\bullet, \ldots$ & $* * * \varepsilon, 9 \wedge \vee$ & . rAV & $\cdot,\{0\rceil$ & $\cdot$, OVr & القبول \\
\hline$\cdot, \ldots$ & $* * * \varepsilon, 119$ & סדות & צדז,י & •, AYo & الو عى الانفعالى \\
\hline$\cdot, \ldots$ & ***: $\varepsilon, Y \mu$. & - r ז & $\cdot, \varepsilon \varepsilon \Psi$ & $\cdot, V Y I$ & التحكم في الذات \\
\hline
\end{tabular}

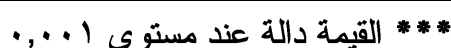

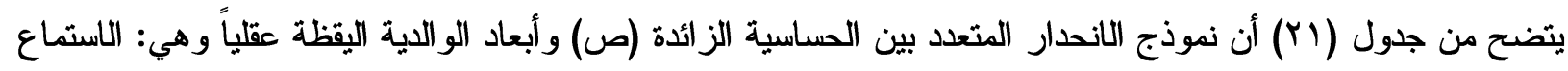

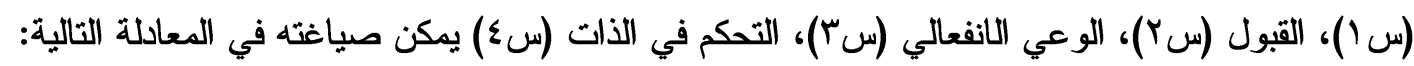

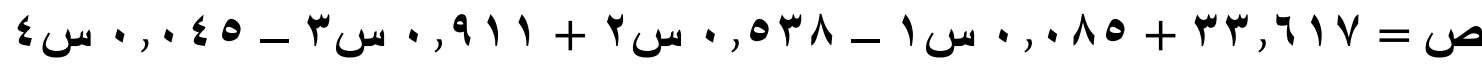
ويشير هذا النموذج إلى: - المقدار الثابت =

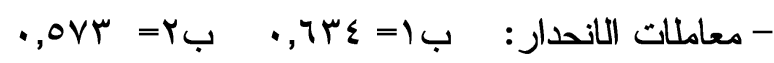
.

صالاحية نموذج الاذجدار المقدرو:

يمكن الحكم على صلاحية نموذج الانحدار المقدر من خلال التعليق على نتائج الانحدار المتعدد لأبعاد الوالدية اليقظة عقلياً

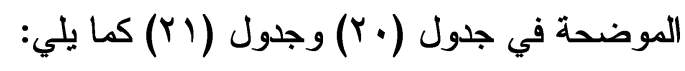

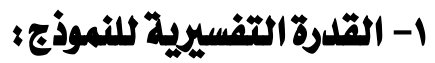

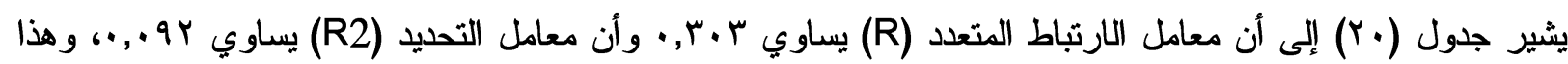

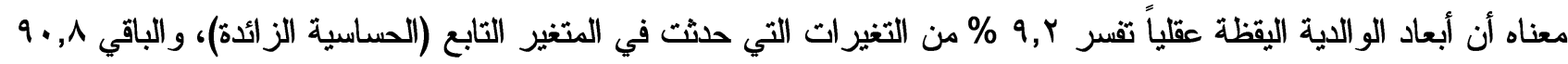

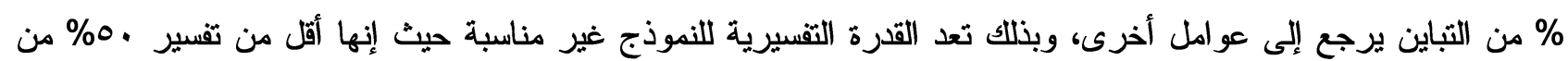
تباين الحساسية الزائدة لأفر اد الدر اسة.

\section{r- الدلالة الإحصائية الكالية للنموذج:}

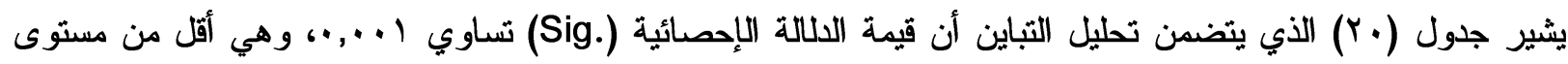
المعنوية ا٪، وبالتالي فإن نموذج الانحدار دال إحصائياً "معنوي"، ومن ثم يمكن استخدام نموذج الانحدار المقدر في التنبؤ بالحساسية الزائدة لأفراد الدراسة.

\section{ץ- الدلاكلة الإحصائية الجزئية للنموذج؛}

يتضح من جدول (1) الذي يتضمن معاملات الانحدار المتعدد ودلالتها الإحصائية أن هذه المعاملات جاءت متباينة ، ويمكن توضيح هذه النتائج فيما يلي: قيمة الثابت في المعادلة تساوي ( معادلة التبؤ أمر ضروري وجوهري. يلاحظ أن جميع معاملات الانحدار دالة إحصائياً، وهذه النتيجة تشير إلى أن الاستماع، القبول، الوعي الانفعالي، التحكم في والتي الذات يصلح استخدامهم كمنبئات بالحساسية الزائدة، وهذه النتيجة تتفق بشكل غير مباشر مع دراسة (2015) Waters و والتي

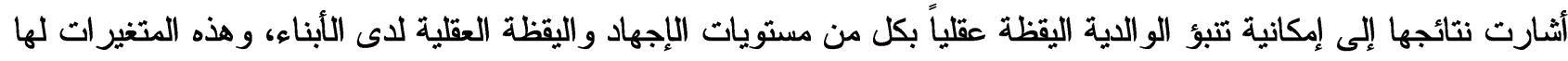
ارتباط بالحساسية الزائدة لدى الأبناء؛ فترتبط الحساسية الزائدة إيجابياً بمستويات الإجهاد و التوتز لدى التهائ الأبناء، كما ترتبط سلبياً باليقظة العقلية لاى الأبناء. 
ويمكن تفسير هذه النتيجة في ضوء ما توفره الو الدية اليقظة عقلياً من ضبط للنفس وتحكم في الانفعالات يجعل الو الدين أكثر

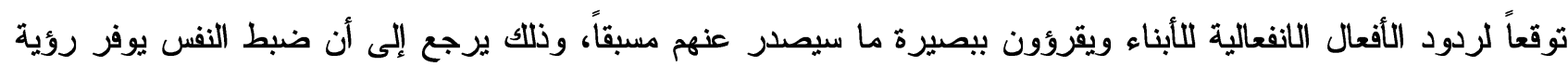

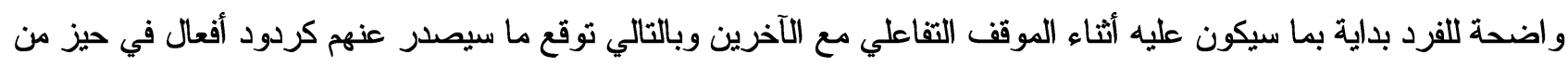

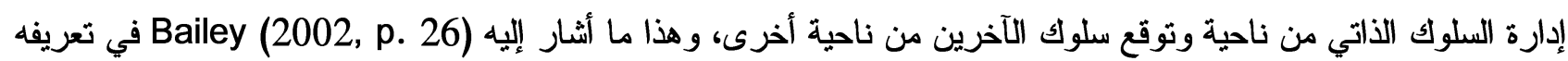
لضبط النفس على أنه إدراك للأفكار الذاتية ووعي بالمشاعر الخاصة يجعل الفرد مديراً لسلوكه ومتوقعاً لسلوك الآخرين في إطار

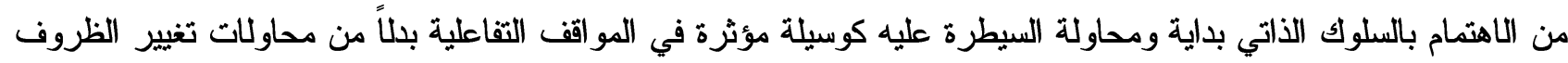
المحيطة، وهذا يؤهل الفرد لتوقع ما سيصدر عن الآخرين من سلوك.

\section{توصيات اللداسلة:}

'. تلبية الحاجات النفسية و الاجتماعية للموهوبين من خلال وضع برامج تعليمية وتربوية بالإضافة إلى البرامج الإرشادية

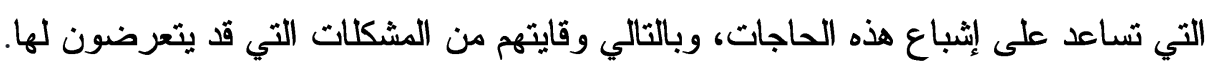
r. . وضع بر امج إرشادية للو الدين لتتمية الو الدية اليقظة عقلياً لديهم أثناء التفاعل مع الأبناء المو هوبين لما لها من أثر فعال

$$
\text { في نموهم السوي، والتكيف و المضي نحو النجاح و الإنجاز. }
$$

r. إجر اء المزيد من الدر اسات التي نتناول الو الدية اليقظة عقلياً لدى آباء وأمهات فئات أخرى من ذوي الاحتياجات التربوية الخاصة ومقارنتها بالو الدية اليقظة عقلياً لدى آباء و أمهات أقر انهم العاديين.

ع. تقديم دورات تأهيلية وإرشادية للطلاب الموهوبين لتنمية الثقة في ذواتهم وتطوير الوعي الذاتي و القبول الذاتي و الفعالية الذاتية ومن ثم الاستفادة من الجوانب الإيجابية لخصائصهم وسماتهم.

\section{مراجيع الدباسباد}

\section{أولَّ: المراجع المربية}

أبو هو اش، راضي محمد (Y I • Y). مشكلات الطلبة الموهوبين والمثفوقين في مدينة الباحة من وجهة نظرهم. المجلة

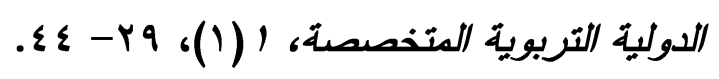

الإقبالي، لافي أحمد (1 ا • Y). الحســاسـية الزائدة لدى الطلبة المتفوقين بمحافظة الليث، المجلة الدولية التربوية

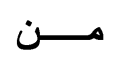

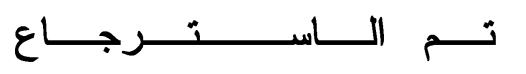

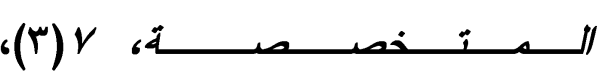

http://iijoe.org/v7/IIJOE_14_03_07_2018.pdf

أمين، أسامة ربيع (V . . Y). التحليل الإحصائي باستخدام برنامج spss. القاهرة: مكتبة الأنجلو المصرية. البليهي، عبد الرحمن (1 . . r). أساليب المعاملة الوالدية كما بيركها الأبناء وعلاقتها بالتوافق النفسي. دراسة ميد/نية على طلاب المرطلة الثانوية بمدينة بريدة (رسـالة ماجستير، جامعة نايف العربية للعلوم الأمنية، كلية

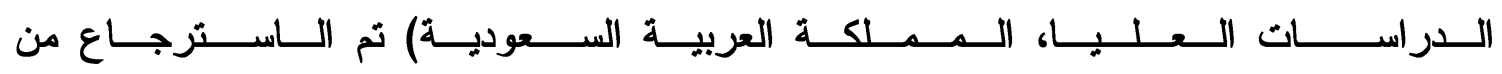
https://books.islamway.net/1/82/844/master2.pdf

جيمس ث. ويــب، جانيب ل. غور، إدورد ر. أمنيد، آرلين ر. ديفرايز (r ا ـ r). دليل الوالدين في تربية الأطفال الموهوبين، ترجمة شفيق علوانة، الرياض: مكتبة العبيكان. 
داخل، مهدي و علي، صفاء (10 r). الافكار الوسو اسية وعلاقتها بالحساسية المفرطة لدى طلبة الجامعة. مجلة آداب

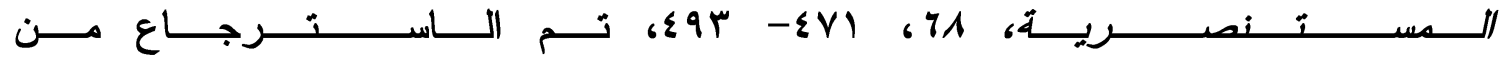

\section{https://search.mandumah.com/Record/637159}

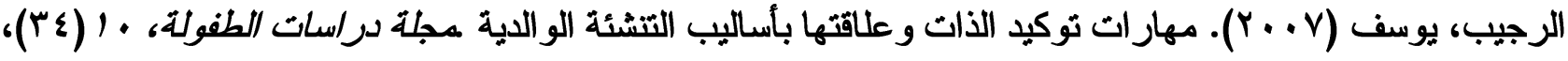

$$
\text { . } \vee \wedge-\varepsilon \vee
$$

زهران، حامد عبد السلام (990) (190). علم النفس النمو، طه ، القاهرة: عالم الكتب للنشر. الضبع؛ فتحي، طلب، أحمد وسليمان، عمرو (Y ( ا Y). الو الدية اليقظة عقلياً وعلاقتها بكفاءة المواجهة لدي عينة من

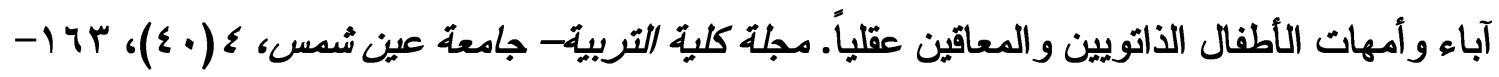

\section{r.}

الطالب، محمد (Y ( ا Y). البيئة الأســرية الداعمة لنمو الموهبة كما يدركها التاميذ الموهوبون وعلاقتها ببعض المتغيرات الديمغرافية "در اسة ميدانية على تلاميذ مدارس الموهوبين بولاية الخرطوم. المجلة العربية

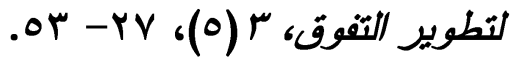

الطائي، مريم مهذول (1 (1 r، • 1- 1 ( أكتوبر). الحسـاسية المفرطة لدى طلبة الجامعة. المؤتمر العلمي العربي الثامن لرعاية الموهوبين و المتفوقين الموهبة و الإبداع منعطفات هامة في حياة الشعوب. المجلس العربي file://C:/Users/ENG-AHMED/Downloads/6710- للمو هوبين و المتفوقين. تم الاسترجاع من 002-000-016x.pdf

العازمي، مشــعل حمود (0 1 • Y، 9 1- O 0بايو ). الاستثارات الفائقة وبعض أبعاد الشخصية لدي كل من الطلاب الموهوبين وأقرانهم العـاديين بالمرحلة الثانوية بدولة الكويت، المؤتمر الدولي الثاني للموهوبين و المتفوقين - تحت شـــعار" نحو اســتراتيجية وطنية لرعاية المبتكرين"، الإمارات العربية المتحدة، تم http://iijoe.org/v7/IIJOE_14_03_07_2018.pdf الاسترجاع من

عبدالله، مالك (1 ( • r). الحساسية الانفعالية وعلاقتها بالتلكؤ الأكاديمي لدى طلبة الجامعة. مجلة كلبة التربية جامعة

$$
\text { واسط، • •r. Vq }
$$

العبدلي، ســميرة (• ( • ( ). مستوى وعي الأسرة بدورها في رعاية الطفل الموهوب، مجلة بحوث التربية النوعية

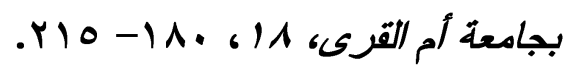

علام، صلاح الدين محمود ( . . r). القياس والثقويم النفسي التربوي أساسياته وتطبيقاته وتوجيهاته المعاصرة. القاهرة: دار الفكر العربي.

عياصــرة، سامر و إسماعيل، نور(Y ( Y). سمات وخصائص الطلبة المو هوبين و المتفوقين كأساس لنطوير مقاييس

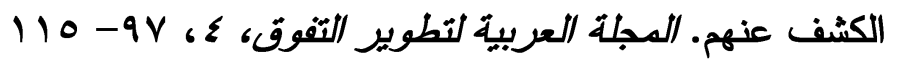

مارد، عدنان وعبد الكاظم، مازن (Y V V V). أنماط الاستثار ات الفائقة لدى الطلبة المتميزين و العاديين في المدارس

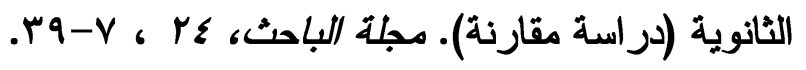


معاليقي، عبد اللطيف (ع • r). المراهقة أزمة هوية أم أزمة حضـارة، ط، بيروت: شركة المطبوعات للتوزيع و النشر -

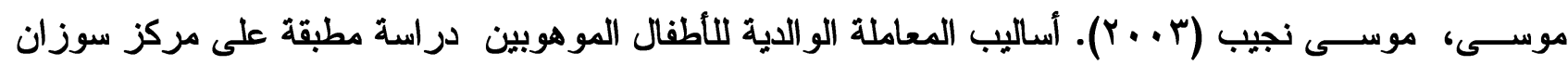

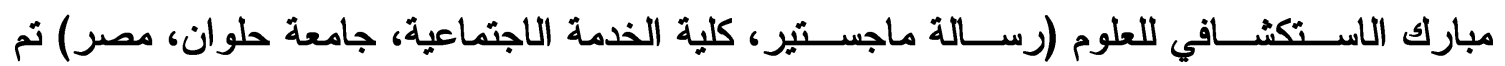
http://www.gulfkids.com/pdf/Dad_muhobeen.pdf الاسترجاع من

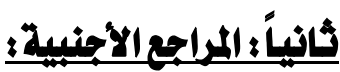

Acevedo, B., Aron, E., Sangster, M-D., Collins, N., \& Brown, L. (2014). The highly sensitive brain: An fMRI study of sensory processing sensitive and response to others' emotions. Brain and Behavior, 4, 580-594. Retrieved from http://doi.org/6h3

Ackerman, C. M. (2009). The essential elements of Dabrowski's Theory of Positive Disintegration and how they are connected. Roeper Review, 31, 81-95. doi:10.1080/02783190902737657

Alias, A., Rahman, S., Abd Majid, R. \& Yassin, S. (2013). Dabrowski's Overexcitabilities Profile among Gifted Students. Asian Social Science, 9 (16), 120- 125. DOI: $10.5539 / a s s . v 9 n 16 p 120$

Amend, E. (2009). Dabrowski Theory: Possibilities and implications of misdiagnosis, missed diagnosis, and dual diagnosis in gifted individuals. In S. Daniels, \& M. M. Piechowski (Eds.), Living with intensity (pp. 33-56). USA: Great Potential Press Daniels.

Aron, E. \& Aron, A. (1997). Sensory-processing sensitivity and its relation to introversion and emotionality. Journal of Personality\& Social Psychology, 73, 345-368.

Aron, E. (2002). The highly sensitive child. New York: Broadway Books.

Baer, R. A., Walsh, E., \& Lykins, E. L. (2009). Assessment of mindfulness. In F. Didonna (Ed.). Clinical handbook of mindfulness (pp. 153-168). New York, NY: Springer.

Baer, R., Smith, G., Hopkins, J., Krietemeyer, J., \& Toney, L. (2006). Using self-report assessment methods to explore facets of mindfulness. Assessment, 13, 27-45. doi:10.1177/1073191105283504

Bailey, B. (2002). Easy to Love, Difficult to Discipline. New York: Harper Collins.

Benham, G. (2006). The Highly Sensitive Person: Stress and physical symptom reports. Personality and Individual Differences, 40, 1433-1440. doi:10.1016/j.paid.2005.11.021

Bishop, S. R., Lau, M., Shapiro, S., Carlson, L., Anderson, N. C., Carmody, J...Devins, G. (2004). Mindfulness: A proposed operational definition. Clinical Psychology: Science and Practice, 11(3), 230-241. doi:10.1093/clipsy/bph077

Bogels, M., Hellemans, J., van Deursen, S., Römer, M., \& van der Meulen, R. (2013). Mindful Parenting in mental health care: effects on parental and child 
psychopathology, parental stress, parenting, co-parenting and marital functioning. Mindfulness 5, 536-551. doi: 10.1007/s12671-013-0209-7.

Bogels, S., \& Restifo, K. (2014). Mindful parenting. New York: Springer.

Bogels, S., Hellemans, J., van Deursen, S., Romer, M.,\& van der Meulen, R. (2013). Mindful parenting in mental health care: effects on parental and child psychopathology, parental stress, parenting, co-parenting, and marital functioning. Mindfulness 5, 536-551. doi: 10.1007/s12671-013-0209-7

Bogels, S., Lehtonen, A.\& Restifo, K. (2010). Mindful parenting in mental health care. Mindfulness, 1(2):107-120.

Bouchard, L. L. (2004). An instrument for the measure of Dabrowskian overexcitabilities to identify gifted elementary students. The Gifted Child Quarterly, 48(4), 339-349. Retrieved from http://dx.doi.org/10.1177/001698620404800407

Bouchard, P.,\& St-Amant , J. (2000). Gender Identities and School Success. The Alberta Journal of Educational Research, 46 (3), 281-83.

Bruin, E., Zijlstra, B., Geurtzen, N., van Zundert, R., van de Weijer-Bergsma, E., \& Hartman, E. (2014). Mindful parenting assessed further: Psychometric properties of the Dutch version of the Interpersonal Mindfulness in Parenting scale (IM-P). Mindfulness, 5(2), 200-212. Retrieved from https://doi.org/10. 1007/s12671-012-0168-4.

Cash, M., \& Whittingham, K. (2010). What facets of mindfulness contribute to psychological well-being and depressive, anxious and stress-related symptomatology? Mindfulness 1, 177-182. doi: 10.1007/s12671-010- 0023-4

Coatsworth, J., Duncan, L., Greenberg, T.\& Nix, R. (2010). Changing parents' mindfulness, child management skills and relationship quality with their youth: Results from a randomized pilot intervention trial. Journal of Child and Family Studies, 19(2), 203-217.

Coleman, L. J., \& Cross, T. L, Suphh- Yamin, T.\& Neber, H.(2016). Being Gifted in School: An Introduction to Development, Guidance, and Teaching (2nd Edition) . Gifted and Talented International, 22(1), 86-87 http:// org doi/abs/10.1080/15332276.2007.11673489

Coleman, S. (2015). Mindful Parenting and Raising an African Male College Graduate: A Phenomenological Study Exploring Parental Influences and their Son's Academic Achievement (Doctoral dissertation, College of Education and Leadership, Cardinal Stritch University)

Cooper, T. (2015). Thrive: The highly sensitive person and career. Ozark, MO: Invictus Publishing, LLC.

Corthorn, C. (2018). Benefits of Mindfulness for Parenting in Mothers of Preschoolers in Chile. Frontiers in Psychology, 9, [1443]. doi: 10.3389/fpsyg.2018.01443

Corthorn, C., \& Milicic, N. (2015). Mindfulness and parenting: a correlational study of non-meditating mothers of preschool children. J. Child Fam. Stud. 25, 16721683. doi: 10.1007/s10826-015-0319-z 
Coyne, L. W., \& Wilson, K. G. (2004). The role of cognitive fusion in impaired parenting: An RFT analysis. International Journal of Psychology and Psychological Therapy, 4, 469-486.

Dabrowski , $\mathrm{k}$ (1996): Multilevelness of Emotional and instinctive functions , part (1), Theory and description of levels of behavior. Poland: Lublin.

Daniels, S., \& Meckstroth, E. (2009). Nurturing the sensitivity, intensity, and developmental potential of young gifted children. In S. Daniels, \& M. M. Piechowski (Eds.), Living with intensity (pp. 33-56). USA: Great Potential Press Daniels.

Dawe, S.\& Harnett, P., (2007). Reducing potential for child abuse among methadonemaintained parents: results from a randomized controlled trial. Journal of Substance Abuse and Treatment, 32(4):381-390.

Dehkordian, P., Hamid, N., Beshlideh, K.\& Mehrabizade, M. (2017). The Effectiveness of Mindful Parenting, Social Thinking and Exercise on Quality of Life in ADHD Children. Int J Pediatr, 5(2), 4295-4302. DOI:10.22038/ijp.2016.7900

Dishion, T. J., Burraston, B., \& Li, F. (2003). A multimethod and multitrait analysis of family management practices: Convergent and predictive validity. In $B$. Bukoski \& Z. Amsel (Eds.), Handbook for drug abuse prevention theory, science, and practice. New York: Plenum.

Dodd, A. (2004). Heightened Sensitivity of Gifted Students: An Exploratory Multiple Case Study (Master Thesis, Calgary University Ottawa, Canada).

Donnell, P. (2004). The Relationship Between Middle School Gifted Students' Creativity Test Scores and Self-Perceptions Regarding Friendship, Sensitivity, and Divergent Thinking Variables (Doctoral dissertation, Texas A\&M University).

Dumas, J. (2005). Mindfulness-based parent training: Strategies to lessen the grip of automaticity in families with disruptive children. Journal of Clinical Child and Adolescent Psychology, 34(4), 779- 791. doi:10.1207/s15374424jccp3404_20

Duncan, G. (2007). Assessment of Mindful Parenting Among Parents of Early Adolescents: Development and Validation Scale of the Interpersonal Mindfulness in Parenting Scale. (Doctoral dissertation, Pennsylvania State University)

Duncan, L., \& Bardacke, N. (2010). Mindfulness-based childbirth and parenting education: promoting family mindfulness during the perinatal period. $J$. Child Fam. Stud. 19, 190-202. doi: 10.1007/s10826-009-9313-7

Duncan, L.G., Coatsworth, J. D., \& Greenberg, M.T. (2009). A model of mindful parenting: Implications for parent-child relationships and prevention research. Clinical Child \& Family Psychology Review, 12(3), 255-270. doi: 10.1007/s10567-009-0046-3

Freshwater, E. (2017). Therapy and Highly Sensitive Personalities (Master Thesis, The Faculty of the Adler Graduate School). Retrieved from https://alfredadler.edu/sites/default/files/Erin\%20Freshwater\%20MP\%2020 17.pdf 
Gagne, F. (1995). From giftedness to talent: A developmental model and its impact on the language of the field. Roeper Review. 18(2)103-111.

Geurtzen, N., Scholte, R., Engels, R., Tak, Y., \& van Zundert, R. (2015). Association between mindful parenting and adolescents' internalizing problems: nonjudgmental acceptance of parenting as core element. Journal of Child and Family Studies, 24(4), 1117- 1128.

Gouveia, M., Canavarro, M.\& Moreira, H. (2018). Is Mindful Parenting Associated With Adolescents' Emotional Eating? The Mediating Role of Adolescents' Self-Compassion and Body Shame. Frontiers in Psychology,9, [2004]. doi: 10.3389/fpsyg.2018.02004

Gouveia, M., Carona, C., Canavarro, M., \& Moreira, H. (2016). Self-compassion and dispositional mindfulness are associated with parenting styles and parenting stress: The mediating role of mindful parenting. Mindfulness, 7(3), 700-712. Retrieved from https://doi.org/ 10.1007/s12671-016-0507-y.

Han, Z., Ahemaitijiang, N. Yan, J, Hu, X., Parent, J., Dale, C. ... Singh N., (2019). Parent Mindfulness, Parenting, and Child Psychopathology in China. Mindfulness, 1, 1- 9 Retrieved from https://doi.org/10.1007/s12671-019-01111$\underline{\mathbf{z}}$

Harnett, P., \& Dawe, S. (2012). Review: The contribution of mindfulness-based therapies for children and families and proposed conceptual integration. Child and Adolescent Mental Health, 17(4), 195-208. doi:10.1111/j.14753588.2011.00643. $x$

Hayes, S. C., Strosahl, K., \& Wilson, K. G. (1999). Acceptance and Commitment Therapy: An Experiential Approach to Behavior Change. New York: Guilford Press.

Hoghughi, M., \& Long, N. (Eds.). (2004). Handbook of parenting: Theory and research for practice. London: SAGE.

Kabat-Zinn, J. (2003). Mindfulness-based interventions in context: Past, present, and future. Clinical Psychology: Science and Practice, 10(2), 144-156. doi:10.1093/clipsy/bpg016

Kohn, A. (2005). Unconditional Parenting. New York: Atria Books.

Laurent, H., Duncan, L., Lightcap, A.\& Khan, F. (2019). Mindful parenting predicts mothers' and infants' hypothalamic-pituitary-adrenal activity during a dyadic stressor. Dev. Psychology, 53 (3), 417-424. Retrieved from https-wwwclinicalkey-com.mplbci.ekb.eg/\#!/content/2-s2.0-27893234

Lovecky, D. (1992). Exploring social and emotional aspects of giftedness in children. Roeper Review. 15(1), 18-25.

Matza, L., Kupersmidt, J.\& Glenn D. (2001). Adolescents' Perceptions and Standards of Their Relationships with Their Parents as a Function of Sociometric Status. Journal of Research on Adolescence, 11(3), 245-272.

McCaffrey, M. (2015). Mindfulness In Parenting Questionnaire (MIPQ): Development and Validation of a Measure of Mindful Parenting. (Doctoral dissertation, Nova Southeastern University) 
Medeiros, C., Gouveia, M., Canavarro, M.\& Moreira, H. (2016). The indirect effect of the mindful parenting of mothers and fathers on the child's perceived wellbeing through the child's attachment to parents. Mindfulness, 7(4), 916927. Retrieved from https://doi.org/10.1007/s12671-016-0530-z.

Mendaglio, S. (1995). Sensitivity among gifted persons: A multi-faceted perspective. Roeper Review. 17(3), 169-172.

Mendaglio, S. (2003). Heightened multifaceted sensitivity of gifted students: Implications for counseling. The Journal of Secondary Gifted Education. 14(2),72-82.

Mendaglio, S. (2012). Overexcitabilities and giftedness research: A call for a paradigm shift. The Journal for the Gifted, 35(3), 207-219.

Moreira, H., \& Canavarro, M. C. (2017). Psychometric properties of the Interpersonal Mindfulness in Parenting Scale in a sample of Portuguese parents. Mindfulness, 8(3), 691-706. doi:10.1007/s12671-016-0647-0

Moreira, H., Gouveia, M.,\& Canavarro, M. (2018). Is mindful parenting associated with adolescents' well-being in early and middle/late adolescence? The mediating role of adolescents' attachmen representations, self-compassion and mindfulness. Journal of Youth and Adolescence. 47, 1771-1788. doi: 10.1007/s10964-018- 0808-7

Moreira, H.,\& Canavarro, M. (2018). Does the association between mindful parenting and adolescents' dispositional mindfulness depend on the levels of anxiety and depression symptomatology in mothers? Journal of Adolescence 68, 22-31. Retrieved from https://doi.org/10.1016/j.adolescence.2018.07.003

Parent, J., Laura G., Jennifer N.\& Forehand, R.(2016). The Association of Parent Mindfulness with Parenting and Youth Psychopathology Across Three Developmental Stages. Journal Abnormal Child Psychology, 44, 191-202. DOI 10.1007/s10802-015-9978-X

Perez-Blasco, J., Viguer, P.,\& Rodrigo, M. (2013). Effects of a mindfulness-based intervention on psychological distress, well-being, and maternal self-efficacy in breast-feeding mothers: results of a pilot study. Arch. Womens Ment. Health, 16, 227-236. doi: 10.1007/s00737-013-0337-z

Piechowski, M. \& Calangelo, N. (1984). Developmental potential of the gifted. Gifted Child Quarterly, 28, 80-88. Retrieved from file:///C:/Users/ENGAHMED/Downloads/PiechowskiColangelo1984.pdf

Piechowski, M.\& Chucker, J. (2011). Overexcitabilities. Encyclopedia of Creativity, 2, 202-208. Retrieved from https://doi.org/10.1016/ B978-0-12-375038-9.001655

Piechowski, M., \& Miller N. B. (1995). Assessing developmental potential in gifted children: A comparison of Methods. Roeper Review, 17, 176-180. Retrieved from http://dx.doi.org/10.1080/02783199509553654

Rayan, A.\& Ahmad, M. (2018). Mindfulness and parenting distress among parents of children with disabilities: A literature review, Perspective Psychiatry Care, 54 
(2), 324-330. Retrieved from https-www-clinicalkeycom.mplbci.ekb.eg/\#!/content/2-s2.0-28247409

Sand, I. (2016). Highly sensitive people in an insensitive world: How to create a happy life (E. Svanholmer, Trans.). Philadelphia, PA: Jessica Kingsley Publishers.

Shavinina, L.V. (1999). The psychological essence of the child prodigy phenomenon: Sensitive periods and cognitive experience. Gifted Child Quarterly, 43(1), 2538.

Siegel, D. J. (2001). Toward an Interpersonal Neurobiology of the Developing Mind: Attachment Relationships, "Mindsight," and Neural Integration. Infant Mental Health Journal, 22, 67-94. http://dx.doi.org/10.1002/10970355(200101/04)22:1<67::AI IMHJ3>3.0.CO;2-G

Siegel, D. J., \& Hartzell, M. (2004). Parenting from the Inside Out. New York: Penguin.

Silverman, L. (1993). Understanding giftedness. In L.K. Silverman (Ed.), Counseling the gifted and talented (pp. 3-28). Denver: Love Publications

Silverman, L. (1994). The moral sensitivity of gifted children and the evolution of society. Roeper Review. 17(21), 110-116.

Singh, N., Lancioni, G., Winton, A., Fisher, B. C., Curtis, W., Wahler, R.,...Sabaawi, M. (2006). Mindful parenting decreases aggression, noncompliance, and selfinjury in children with autism. Journal of Emotional and Behavioral Disorders, 14(3), 169-177. doi: 10.1177/10634266060140030401

Siu, F . (2010). Comparing overexcitabilities of gifted and non-gifted school children in Hong Kong: Dose culture make a difference? Asia Pacific Journal of Education, 30(1),71-83.

Soons, I., Brouwers, A., \& Tomic, W. (2010). An experimental study of the psychological impact of a mindfulness-based stress reduction program on highly sensitive persons. Europe's Journal of Psychology, 6(4), 148-169. doi:10.1037/e676292011-011

Tak, Y., Van Zundert, R., Kleinjan, M., \& Engels, R. (2015). Mindful Parenting and Adolescent Depressive Symptoms: The Few Associations Are Moderated by Adolescent Gender and Parental Depressive Symptoms. Mindfulness, 6, 812823.

Tieso, C. L. (2007). Patterns of overexcitabilities in identified gifted students and their parents: A hierarchical model. Gifted Child Quarterly, 51(1), 11-22. doi: 10.1177/0016986206296657

Vieten, C., \& Astin, J. (2008). Effects of a mindfulness-based intervention during pregnancy on prenatal stress and mood: results of a pilot study. Arch. Womens Ment. Health 11, 67-74. doi: 10.1007/s00737-008-0214-3

Wang, Y., Liang, Y., Fan, L., Lin, K., Xie, X., Pan, J. \& Zhou, H. (2018) The Indirect Path From Mindful Parenting to Emotional Problems in Adolescents: The Role of Maternal Warmth and Adolescents' Mindfulness.: Front. Psychol. 9, [546]. doi: 10.3389/fpsyg.2018.00546 
Waters, L. (2016). The Relationship between Child Stress, Child Mindfulness and Parent Mindfulness, Psychology, 7, 40-51. Retrieved from http://dx.doi.org/10.4236/psych.2016.71006

Whitney, C. S., \& Hirsch, G. (2007). A love for learning: Motivation and the gifted child. USA: Great Potential Press.

Williams, K. L., \& Wahler, R. G. (2010). Are mindful parents more authoritative and less authoritarian? An analysis of clinic-referred mothers. Journal of Child and Family Studies, 19(2), 230-235. doi: 10.1007/s10826-009-9309-3

Wong, K., Hicks, L. M., Seuntjens, T. G., Trentacosta, C. J., Hendriksen, T. H. G., Zeelenberg, M., \& van den Heuvel, M. (2019). The role of mindful parenting in individual and social decision-making in children. Frontiers in Psychology, 10, [550]. doi.org/10.3389/fpsyg.2019.00550

Yakmaci-Guzel, B. \& Akarsu, F., (2006). Comparing over excitabilities of gifted and nongifted 10th grade students in turkey. High Ability Studies, 17(1), 43-56. doi: 10.1080/13598130600947002

Zeff, T. (2004). The highly sensitive person's survival guide: Essential skills for living well in an over stimulating world. Oakland, CA: New Harbinger Publications, Inc. 